
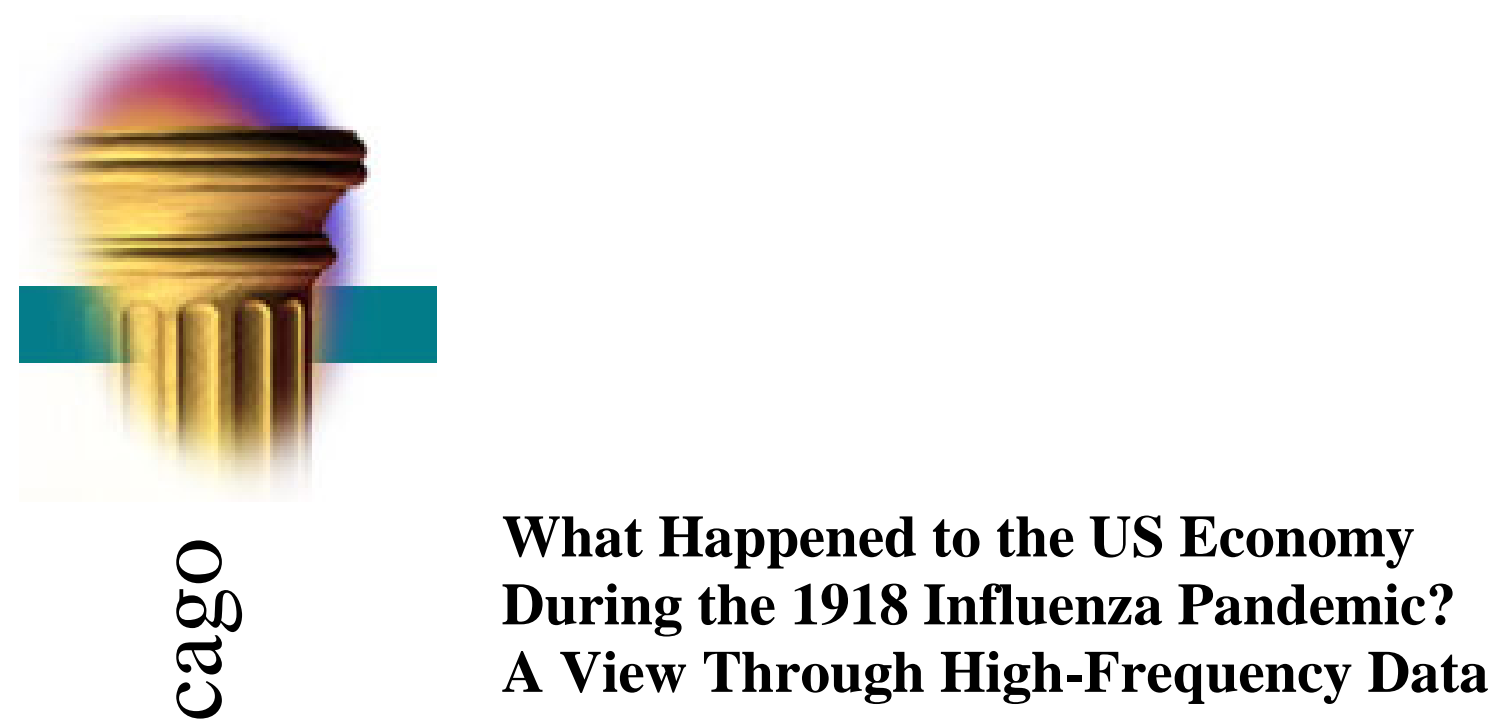

François R. Velde

\author{
REVISED \\ July 7, 2020
}

WP 2020-11

https://doi.org/10.21033/wp-2020-11

${ }^{*}$ Working papers are not edited, and all opinions and errors are the responsibility of the author(s). The views expressed do not necessarily reflect the views of the Federal Reserve Bank of Chicago or the Federal Reserve System. 


\title{
What Happened to the US Economy During the 1918 Influenza Pandemic? A View Through High-Frequency Data
}

\author{
François R. Velde* \\ Federal Reserve Bank of Chicago
}

July 7, 2020

\begin{abstract}
Burns and Mitchell $(1946,109)$ found a recession of "exceptional brevity and moderate amplitude." I confirm their judgment by examining a variety of high-frequency, aggregate and cross-sectional data. Industrial output fell sharply but rebounded within months. Retail seemed little affected and there is no evidence of increased business failures or stressed financial system. Cross-sectional data on manufacturing employment indicates that most of the recession, brief as it was, was due to the Armistice rather than the epidemic. Data from the nationwide coal industry documents the sharp but shortlived impact of the epidemic on labor supply and the lack of spill-overs on demand. City-level economic indicators show that the (brief) interventions to hinder the contagion reduced mortality at little economic cost because reduced infections mitigated the impact on the labor force.
\end{abstract}

Keywords: 1918 influenza epidemic, US economy, business cycles, recession, non-pharmaceutical interventions (JEL E32, H12, I18, I19).

${ }^{*}$ The views presented here do not necessarily reflect those of the Federal Reserve of Chicago or the Federal Reserve System. I thank without implicating Gadi Barlevy, Jeff Campbell, Nicolas Crouzet, and François Gourio for very helpful discussions; participants at the European Macro History Online Seminar and the HeLP seminar for their comments; Chris de Mena for gallant service beyond the call of duty; Matthew Song and Richard deThorpe for outstanding research assistance. 


\section{Revisions}

v1.0 9 Apr 2020

v1.1 17 Apr 2020: minor typos, improved presentation of local projections

v1.2 1 Jul 2020: new section on manufacturing in New York and Massachusetts; new section on measures of mobility and contemporary perceptions of tradeoffs; analysis of the structural estimation rewritten; lagged inflation added to regression of inflation; 3D plot of Figure 3 replaced by a contour map; minor edits and rewrites 


\section{Introduction}

As we grapple with events that are unprecedented in many ways and not quite unprecedented in others, we search for historical events that can shed light in our current darkness. The most recent pandemic of scale comparable to the Covid-19 pandemic took place in 1918. ${ }^{1}$ This paper studies the impact of that pandemic on the US economy. In contrast to Correia, Luck, and Verner (2020), I focus on the short-term impact of the epidemic, up to a year rather than one to five years out, and my perspective is anchored in time series, so I rely on high-frequency times series (weekly, monthly, and bi-monthly).

I begin by briefly reviewing the facts of the epidemic. I then use a collection of monthly time series to document that a sharp but very short-lived recession began at the time of the epidemic. The effect is most visible in manufacturing, while retail is affected only modestly and briefly. Contemporary commentary confirms the fast rebound and suggests that the recession was prolonged by the end of World War I, just as the epidemic waned, and the resulting uncertainties over the return to a peacetime economy.

I then use high-frequency cross-sectional data to confirm the visible but brief impact of the epidemic and of the intervention measures (closings of certain businesses) that were adopted at the time. Banking data shows a financial sector functioning as it should, increasing loans. Conspicuously, there is no evidence of stressed balance sheets in the nonfinancial sector: business failures were on an uninterrupted downward trend, and cross-sectional data fails to find any effect of mortality. Manufacturing employment in New York state and Massachusetts rebounds quickly from the epidemic and that the ensuing recession is mostly a result of the Armistice. Fine-grained data from the coal industry allows me to trace the labor supply shock from the epidemic but I find no connection with the fall in demand for coal after the Armistice. To examine the impact of closings on the epidemic and economic activity, I construct an index of local business conditions from weekly qualitative reports and use it, along with measures of payments volumes, to examine if the speed with which economically costly interventions were put in place made a difference in economic outcomes. I find clear evidence that interventions changed the dynamics of the epidemic and helped economic activity by reducing the number of infected, who were to a large extent of working age, while the direct impact on economic activity is harder to detect.

There are of course differences between 1918 and 2020: monetary and fiscal policy was hyperactive before the epidemic began and financial markets sailed through the episode with nonchalance. I also document through mobility measures that the closings were very mild compared to those of 2020. Contemporaries only tried to "flatten the curve" and perceived a tradeoff in closings: more restrictive measures were deemed unacceptable. I discuss the related literature in the conclusion.

This obviously makes easy comparisons between then and now difficult, but there is still value in documenting properly at least one episode of pandemic, if only to provide a

\footnotetext{
${ }^{1}$ There were three influenza pandemics in the 20th century: 1918, 1957, and 1968 (Kilbourne 2006), but the other two had no visible economic impact (Congressional Budget Office 2006).
} 
sanity check for future theorems about economics of pandemics.

\section{The 1918 Pandemic in the US}

The general features of the 1918 pandemic are well known and I will therefore be brief. From origins, both biological and geographic, that remain unclear ${ }^{2}$ it swept the world in waves. The first wave, in spring 1918, propagated from the US to Europe, probably through troop movements (Patterson and Pyle 1991). Its virulence was noticed in May 1918 as it spread through Europe. ${ }^{3}$ It may have mutated sometime in August, as a much more lethal second wave spread through Europe and simultaneously arrived in New England in late August. Deaths peaked in the US after several weeks and the epidemic was waning by November 1918, although some areas were affected by a third wave in the winter or early spring 1919.

\section{Mortality}

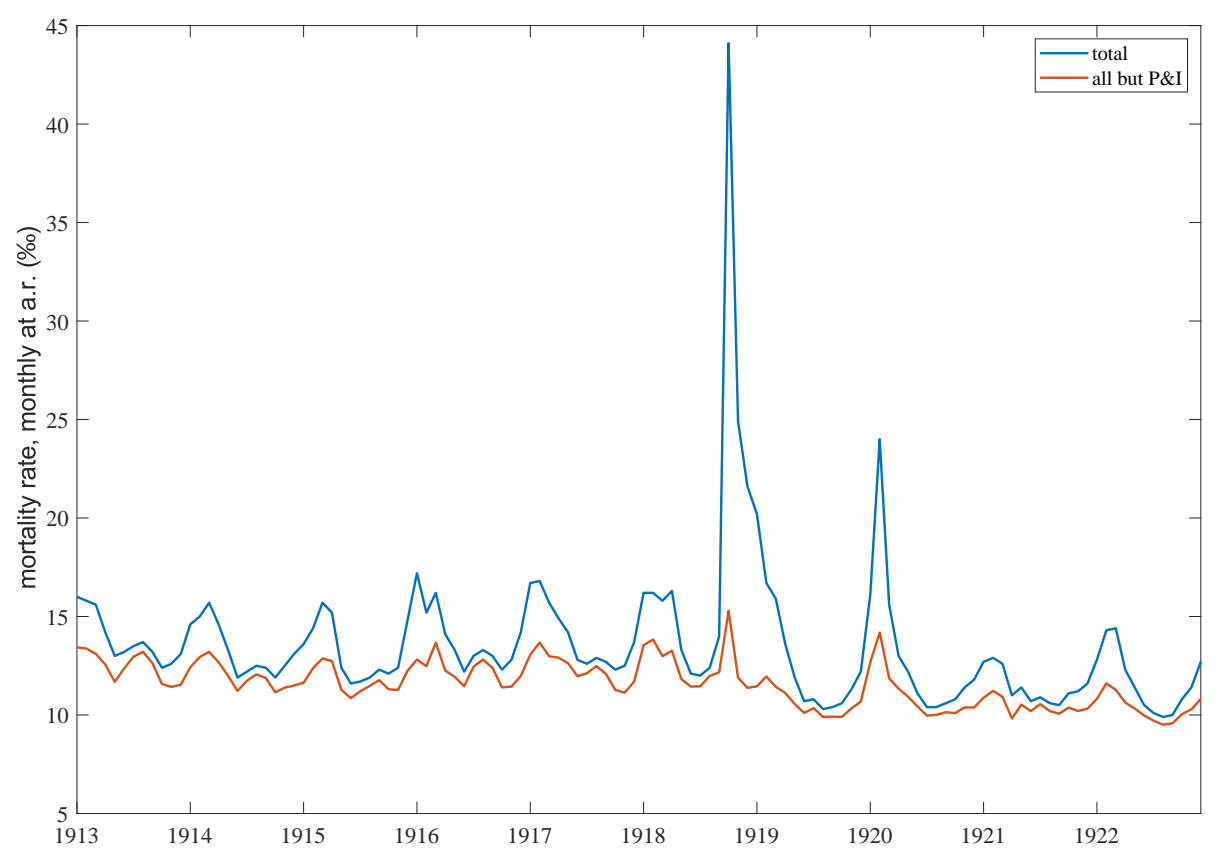

Figure 1: US mortality rate for all causes, and for all except influenza and all forms of pneumonia (P\&I), monthly 1913-23. Source: Census Bureau, Mortality Statistics (191321).

While "most patients experienced symptoms of typical influenza with a 3- to 5-day fever followed by complete recovery" (Kilbourne 2006), the lethality of the virus was unusual. Figure 1 compares the US monthly mortality rate from all causes and from all but

\footnotetext{
${ }^{2}$ The earliest recorded outbreak in the U.S. was early March 1918 in a US Army camp in Kansas (Vaughn 1921, 70), but Olson et al. (2005) show the distinctive W-shaped pattern of mortality by age in New York City in February-April 1918.

${ }^{3}$ It probably started on the west coast of France. Belligerents having little incentive to inform their adversary of their weakened condition, the illness was reported at first only in neutral countries such as Spain, hence its name of Spanish influenza. As the Irish Times of May 31, 1918 noted without visible irony: "It is remarkable that the countries suffering from these epidemics [Sweden and Spain] should both be neutral countries."
} 
pneumonia and influenza (P\&I). ${ }^{4}$ In all years influenza represented a substantial and seasonal component of deaths, peaking between January and March of each year. The year 1918 obviously stands out. A late, but relatively small peak in April 1918 may correspond to the first spring wave, and was followed by the outsize peak of October 1918 and another smaller peak in February 1920.

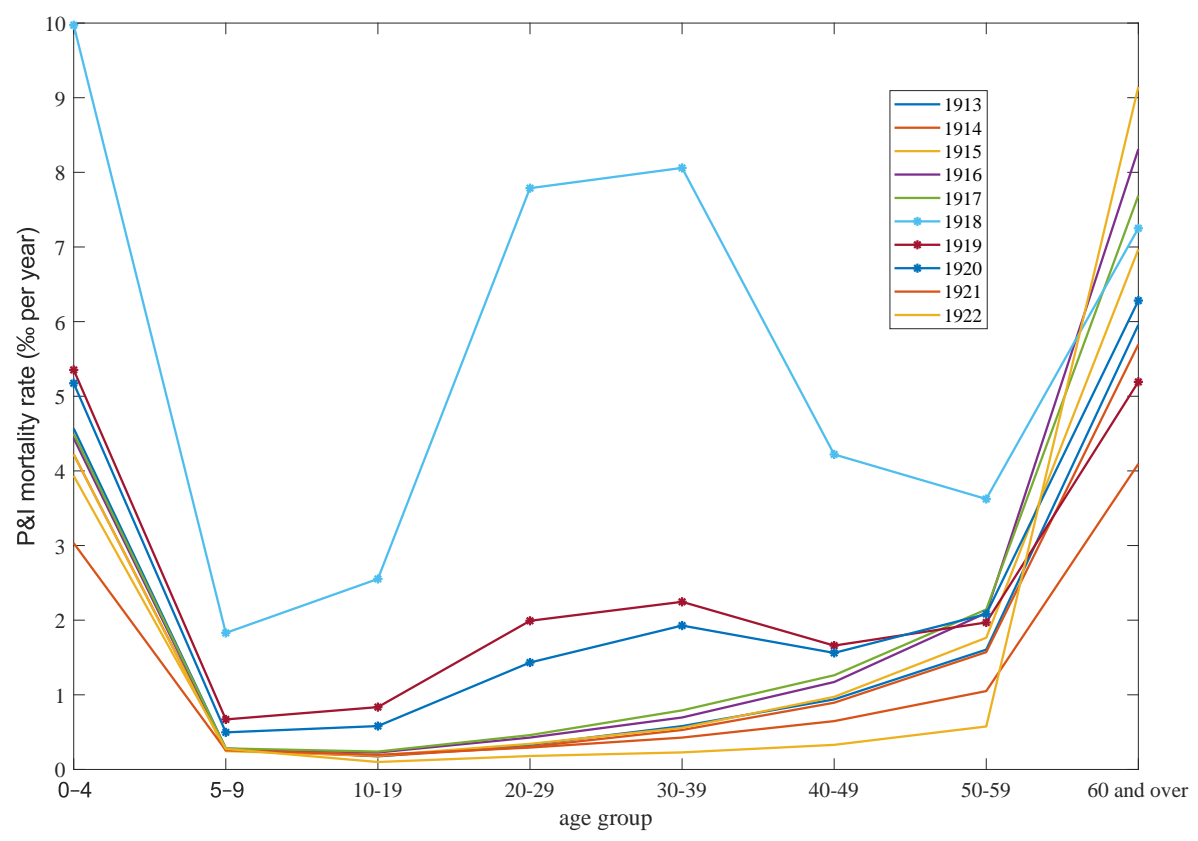

Figure 2: P\&I mortality in the US (registration states) by age group, 1913-22. Source: Census Bureau, Mortality Statistics (1913-21).

\begin{tabular}{lrrrrrrr}
\hline & \multicolumn{5}{c}{ excess mortality } \\
\cline { 2 - 3 } \cline { 5 - 7 } & \multicolumn{2}{c}{ all ages } & & \multicolumn{3}{c}{ ages 20-60 } \\
\cline { 2 - 3 } \cline { 5 - 7 } & Jul 1918- & Jul 1919- & & 1918 & 1919 & 1920 \\
& Jun 1919 & Jun 1920 & & & \\
\hline in thousands & 516 & 72 & & 300 & 65 & 52 \\
as \% of population (103m) & 0.50 & 0.07 & & & \\
as \% of 20-60 age group & & & & 0.56 & 0.12 & 0.10 \\
as \% of labor force (39m) & & & 0.77 & 0.17 & 0.13 \\
\hline
\end{tabular}

Table 1: Estimated excess influenza and pneumonia (all forms) mortality in the U.S., relative to $1913-17$.

The influenza waves of 1918-20 are related in another way, namely the pattern of mor-

\footnotetext{
${ }^{4}$ A few technical details. First, I will rely entirely on mortality data because there is no data on cases. Second, the mortality data are available for the "registration states" which registered deaths completely (in principle at least 90\%). Registration did not cover the whole nation until 1933. From 1913 to 1921 the number of states in the registration area went from 24 to 34, representing 62 to $80 \%$ of the estimated US population. Finally, causes of death were reported but deaths by influenza and all forms of pneumonia (bronchopneumonia, lobar pneumonia, and other pneumonia) need to be taken together to study the incidence of the epidemic because of variation in reporting (in 1918, the ratio of reported influenza deaths to pneumonia deaths varies from 0.4 in North Carolina to 2.0 in Montana). I take the data on mortality from Bureau of the Census (1913-1922, Table 10), which lists deaths by month, area, and cause of death, for the years 1913-22. I collected the number of deaths from influenza, pneumonia, and bronchopneumonia, collectively known as influenza and pneumonia (all forms) of P\&I (see the discussion in Bureau of the Census 1913-1922, 1918, 27-34). Then, for each state and month I compute the median mortality for the years 1913-17 and 1921-22 and subtract it from the mortality in years 1918-20. The result, divided by the estimated population at July 1 of each year from Linder and Grove $(1947,824-71)$, is the excess P\&I mortality rate for each state.
} 
tality by age. Figure 2 shows the mortality rate by age group for successive years. ${ }^{5}$ The years 1913-17 display an identical "U-shaped" pattern of mortality high for the young and old and negligible for ages 5 to 60. The years 1918-20 display a "W-shaped" pattern, particularly pronounced in 1918 but present in the next two years. The overall mortality (applying the death rate of the registration states to the whole population) is shown in Table 1 . This unusual age pattern means that the labor force was much more affected by the lethality, and presumably by the symptoms, than in any other influenza season; more even than World War I, in which US casualties (battle deaths and other deaths) were 116,000. Note, however, that the draft itself had withdrawn nearly $4.2 \mathrm{~m}$ men from civilian life by November 1918 (Sydenstricker 1920, 5).

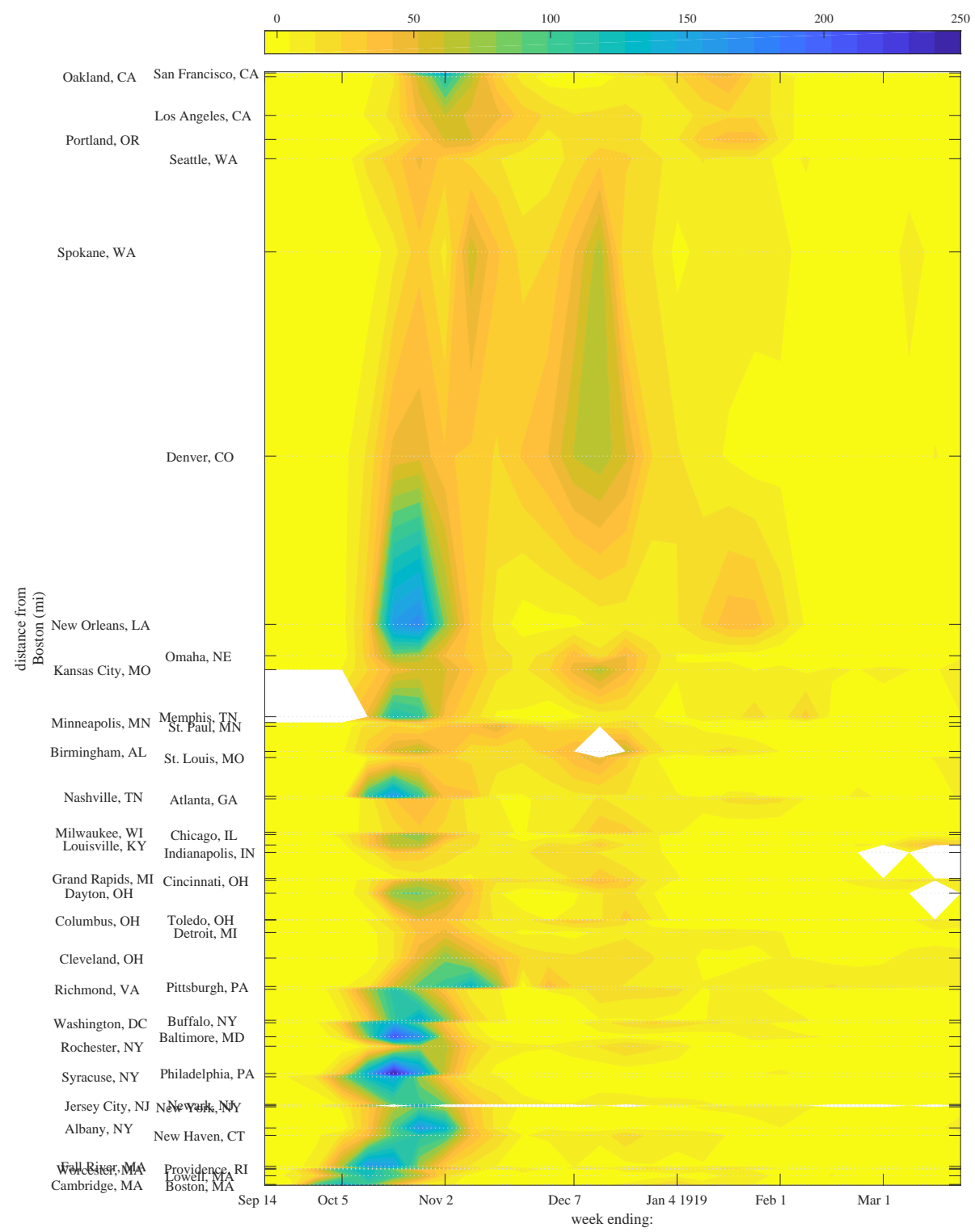

Figure 3: Contour map of excess P\&I mortality rates (deaths per 100,000 per week) of 47 US cities plotted against time (in weeks) and distance from Boston. Source: Collins et al. (1930).

\footnotetext{
${ }^{5}$ More technicalities: the Mortality Statistics report annual (but not monthly) numbers of deaths by age group and cause of death. I use the US age distribution reported in Historical Statistics of the United States for the population as a whole, scaled by the relative share of the registration states, to obtain death rates by age groups.
} 
Figure 3 shows the spatial and temporal pattern of the 1918 epidemic in the US, by plotting excess P\&I mortality for 47 cities at a weekly frequency (Collins et al. 1930). ${ }^{6}$ The spatial dimension is reduced to one by using distance from Boston, the starting point of the epidemic. The figure shows that the epidemic propagated rapidly, peak mortality varied widely across cities, and mortality rates fell back within weeks except for the third wave in some places.

\section{Non-pharmaceutical interventions}

Several papers (Bootsma and Ferguson 2007; Hatchett, Mecher, and Lipsitch 2007; Markel et al. 2007) examine the effectiveness of non-pharmaceutical interventions (NPIs) on mortality outcomes, using the same weekly mortality data for various US cities (43 and 17 respectively) from Collins et al. (1930). As described in those papers, NPIs, imposed mostly by cities but sometimes at the state level, took a wide variety of forms ranging from shutting down public gatherings and crowded places to staggering business hours, closing schools, imposing quarantines for infected people, requiring masks, etc. No intervention went as far as closing non-essential businesses, as have the lockdowns of the 2020 pandemic.

More recently Correia, Luck, and Verner (2020) have used the same mortality data and the measures of NPI defined in Markel et al. (2007) to study how mortality and interventions affected medium and long-run economic activity. My focus will be instead short-term outcomes, with a slightly different measure of NPI.

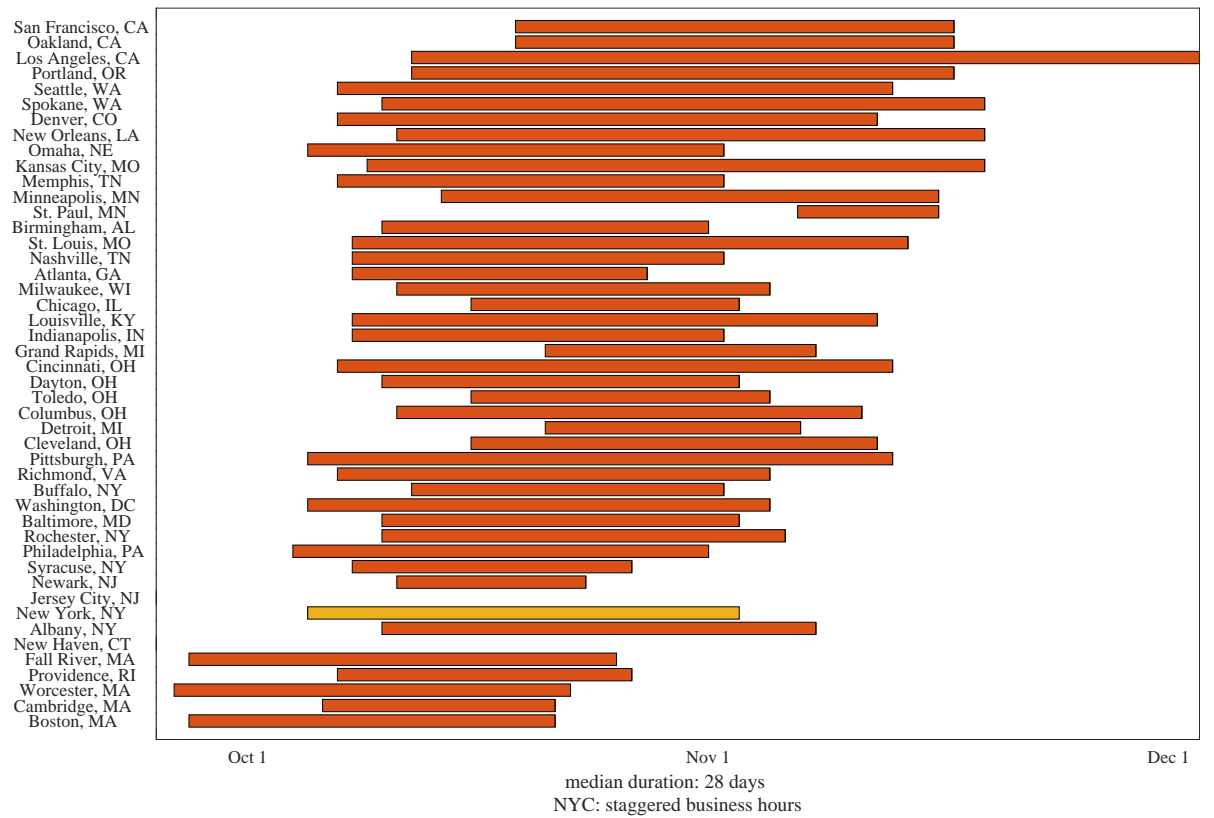

Figure 4: Timing and duration of closings in 43 US cities. Source: Hatchett, Mecher, and Lipsitch (2007), http:influenzaarchive.org, and various newspapers.

\footnotetext{
${ }^{6}$ This is the data set used in Hatchett, Mecher, and Lipsitch (2007) and Markel et al. (2007). Excess mortality is defined relative to $1921-27$ mortality rates.
} 
Markel et al. (2007) measure the NPIs by sorting them into three categories and counting the number of days during which measures of each category are applied: thus, a day on which schools and bars are closed and sick people are quarantined counts as 3. But all measures would not have similar economic effects, quarantines and self-isolation would presumably be much less impactful on the economy than closing bars and theaters, since they concerned individuals already less active (the flu symptoms were debilitating). In addition this one-time measure of intensity of NPI is not practical for time-series purposes. For these reasons I concentrate on the timing and duration of closings of businesses.

Figure 4 shows the duration of closings across US cities. New Haven and Jersey City had no closings. ${ }^{7}$ New York City did not either, but instituted staggered business hours. ${ }^{8}$ The median duration of closings was 28 days, the earliest closing started on September 25 and the latest on October 14. Hence, the cross-sectional variation in timing and duration of closings is quite limited.

\section{Looking for the recession: in the time series}

The epidemic and the interventions were very concentrated in time, compared to the frequency at which economic phenomena are normally measured. If we want to detect and measure the immediate impact of the epidemic (and, possibly, that of interventions) on the economy we will need high-frequency data, at a minimum monthly or bi-monthly. The second challenge is the absence of many modern constructs that we typically use, because "data" are always constructed to some degree, particularly aggregate data. Finally, although much data was published by public and private actors, ${ }^{9}$ systematic collection by government agencies was only beginning. ${ }^{10}$ As a result, many modern series begin, annoyingly for us, in January 1919.

\section{GNP}

If we start at the top of the aggregation chain, we immediately run into difficulties. In 1918, national income accounting had not been invented, let alone implemented. Only in 1932 did the Federal government commission Simon Kuznets and the NBER to construct NIPA (national income and product accounts), which he did starting for the year 1929. He later he extended the annual series to 1919 and even earlier, but felt that it was unsuitable for business cycle purposes such as ours (as opposed to the study of trends). Nevertheless,

\footnotetext{
${ }^{7}$ New Haven barred "promiscuous gatherings indoors of a public character" on October 15 but closed neither theaters nor restaurants or bars (Hartford Courant, Oct 16, 1918, p. 5). New Jersey state authorities instituted bans but the mayors of Jersey City and Newark protested and did not enforce them (Journal of the Medical Society of New Jersey, Nov 1918, 15:390). Dates of closings are from Hatchett, Mecher, and Lipsitch (2007) and the website influenzaarchive.org. Dates for Memphis come from the Knoxville Journal and Tribune, Oct 7, 1918 p. 10 and Oct. 30, 1918 p. 5; for Milwaukee from the Oshkosh Daily Northwestern, Oct. 11, 1918 p. 1 and Nov. 2, 1918 p. 1. I was unable to find any information on Lowell, MA.

${ }^{8}$ New York's cumulative excess P\&I mortality was $0.51 \%$, below the median of $0.55 \%$.

${ }^{9}$ E.g., the weeklies Commercial and Financial Chronicle and Bradstreet's. In academia, the Review of Economic Statistics (which became R.E.Stat.) began in 1919, edited by Warren M. Persons and publishing exactly what its title announced.

${ }^{10}$ The BLS's Monthly Labor Review and the Fed's Bulletin began in 1915, the BEA's Survey of Current Business began in 1921. The NBER was founded in 1920.
} 
his work and that of his students led to the so-called "standard" annual series, recently challenged and revised by Balke and Gordon (1989) and Romer (1989) who provided their own annual estimates.

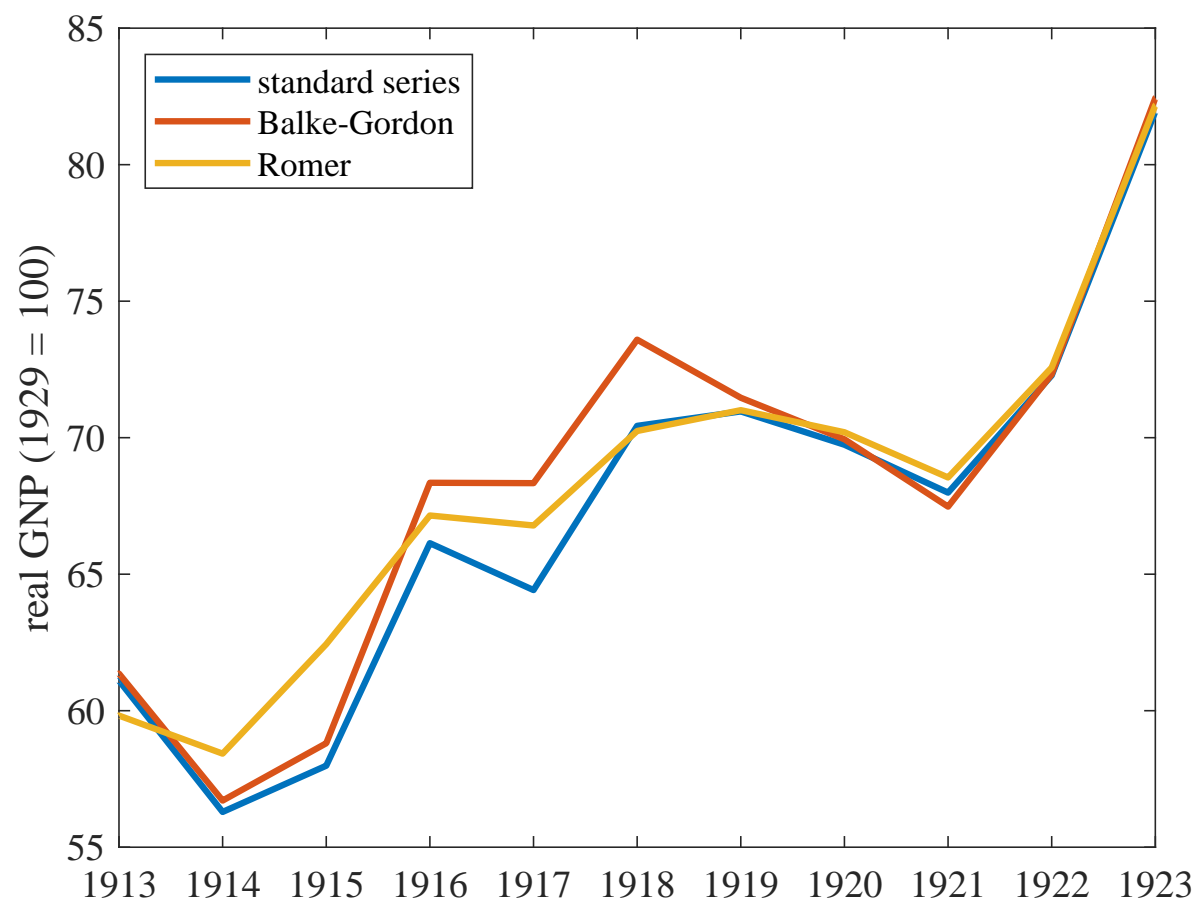

Figure 5: Modern estimates of GNP. Sources: Balke and Gordon (1989) and Romer (1989), HSUS Table Ca211.

The three series are annual and are plotted for our time period in Figure 5. Although they show very close agreement after 1919 when data becomes more abundant, they disagree on our period of interest. The standard series and the Romer series peak in 1919 and drop only by $3.5 \%$ over the ensuing two years 1920 and 1921, while the Balke-Gordon series peaks in 1918 and drops by $8 \%$ over three years.

Interestingly, Romer (1988) extensively discusses US output during and after World War I and does not mention the influenza epidemic at all, let alone link it to the recession that is visible in the annual data, that of 1920-21.

\section{The recession of 1918-19}

In fact, business cycle historians do find a cyclical downturn at the time of the epidemic, but it is not the recession of 1920-21. In their classic work, Burns and Mitchell (1946, 78,109) find a business cycle peak in August 1918 and a subsequent trough in April 1919, but note the "exceptional brevity and moderate amplitude" of the recession. ${ }^{11}$ The data they used was a vast array of economic time series at the monthly frequency. ${ }^{12}$ The rest of this section essentially follows in the footsteps of Burns and Mitchell, examining some of the same monthly time-series to ascertain the timing and extent of the 1918 recession.

\footnotetext{
${ }^{11}$ The modern, "official" dating (www.nber.org/cycles.html) is August 1918 to March 1919 (Moore and Zarnowitz 1986), while Romer (1994) moves the peak back a month to July 1918.

${ }^{12}$ Romer (1994) discusses in detail the data and methods used at the early NBER to date business cycles.
} 
In the absence of aggregate constructs I will resort to a wide array of series, in the hope of picking up signs of the recession in different sectors of the economy. For this purpose we can be less picky than modern historians: how far back the series extend, what long-term trends drive them, are less important than their sensitivity to the cycle of interest. In the next section I will use more modern methods and rely on the cross section as well.

\section{Industrial production}

We begin with a classic measure of economic activity, industrial production. The series we use is that of Miron and Romer (1990), plotted in Figure 6. The standard NBER recessions are indicated by the usual yellow stripes. The series peaks in July 1918 and bottoms out $20 \%$ lower in January 1919 , but rebounds almost immediately to the prior level and oscillates thereafter in the same range until the next peak of March 1920. The ensuing contraction, by contrast, is much more severe and prolonged: the trough is reached fourteen months later and the contraction is by half.

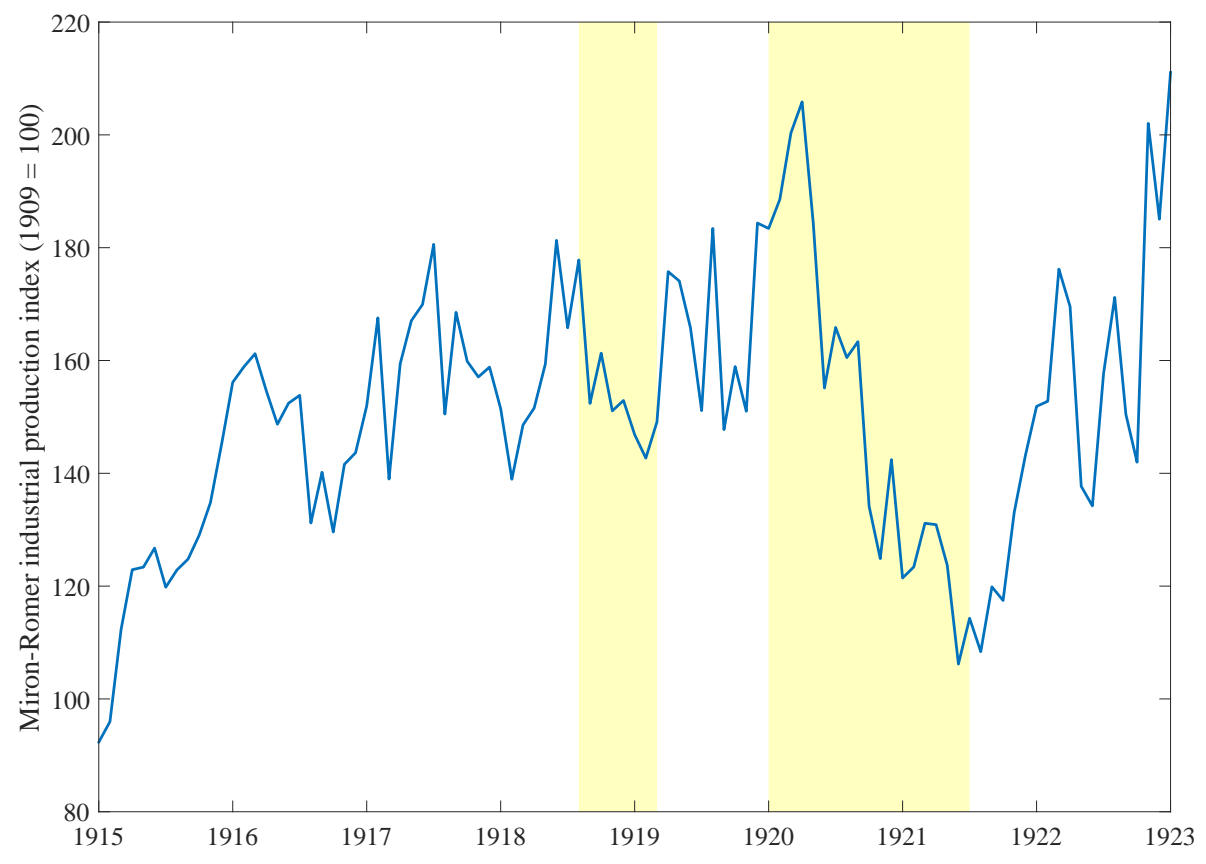

Figure 6: Industrial production. Source: Miron and Romer (1990).

This feature of the series (short and mild recession in 1918-19, long and deep recession in 1920-21) is what Burns and Mitchell observed, and will reappear over and over again in the next graphs.

\section{Consumer Durables}

The automobile industry was, of course, a very recent one in 1918, although at that date there were already over six million vehicles registered in the country. During the war the production of vehicles for civilian use was not considered essential but it continued nevertheless. Figure 7 is a measure of factory shipments on a monthly basis. A slowdown 


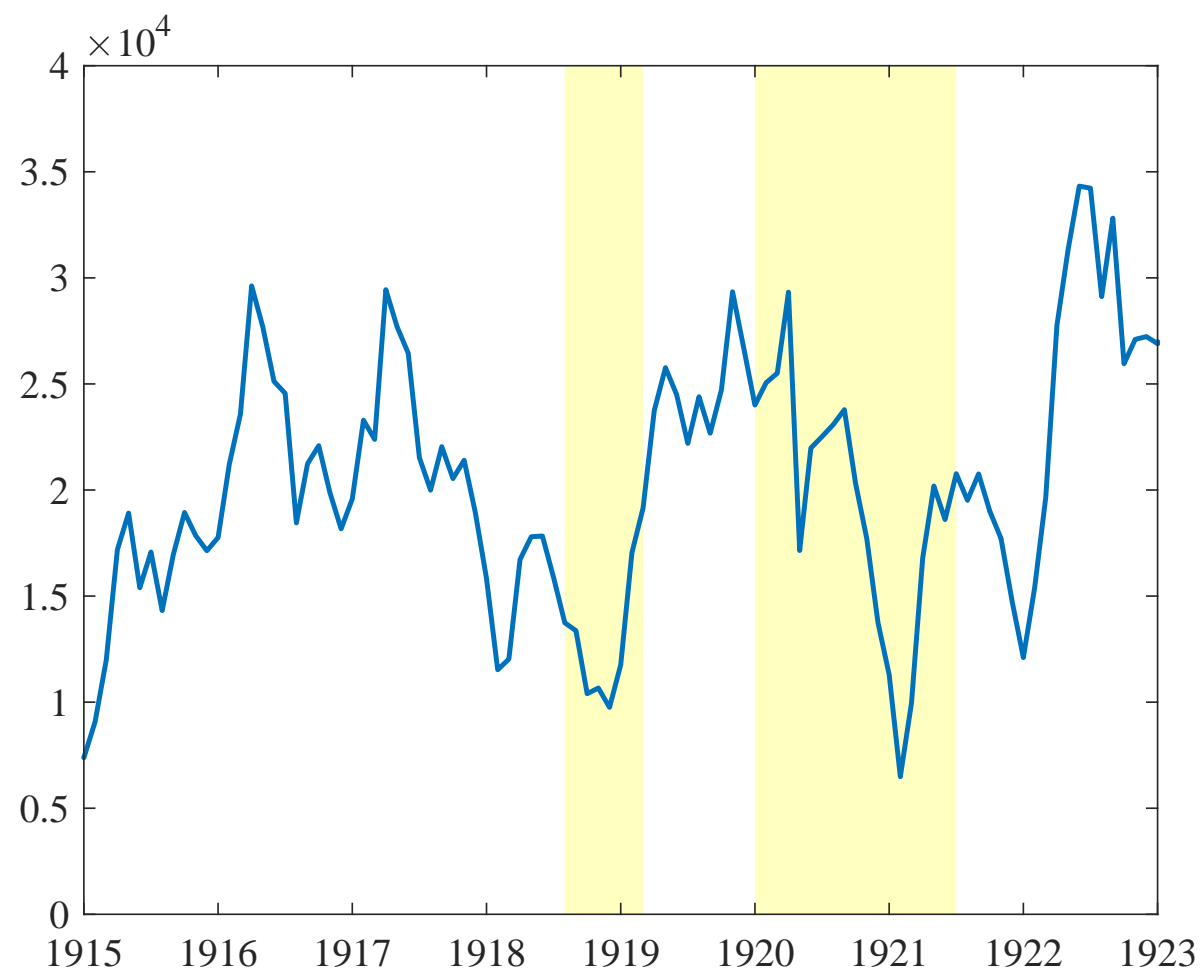

Figure 7: Railroad freight car load shipments from automobile factories. Source: Moody's Transportation 1924, p. xxxviii.

seems to start slightly before the epidemic itself, but otherwise the recession is quite visible, with a fast rebound from January 1919. The scale of the downturn in 1920-21 is much larger.

\section{Retail}

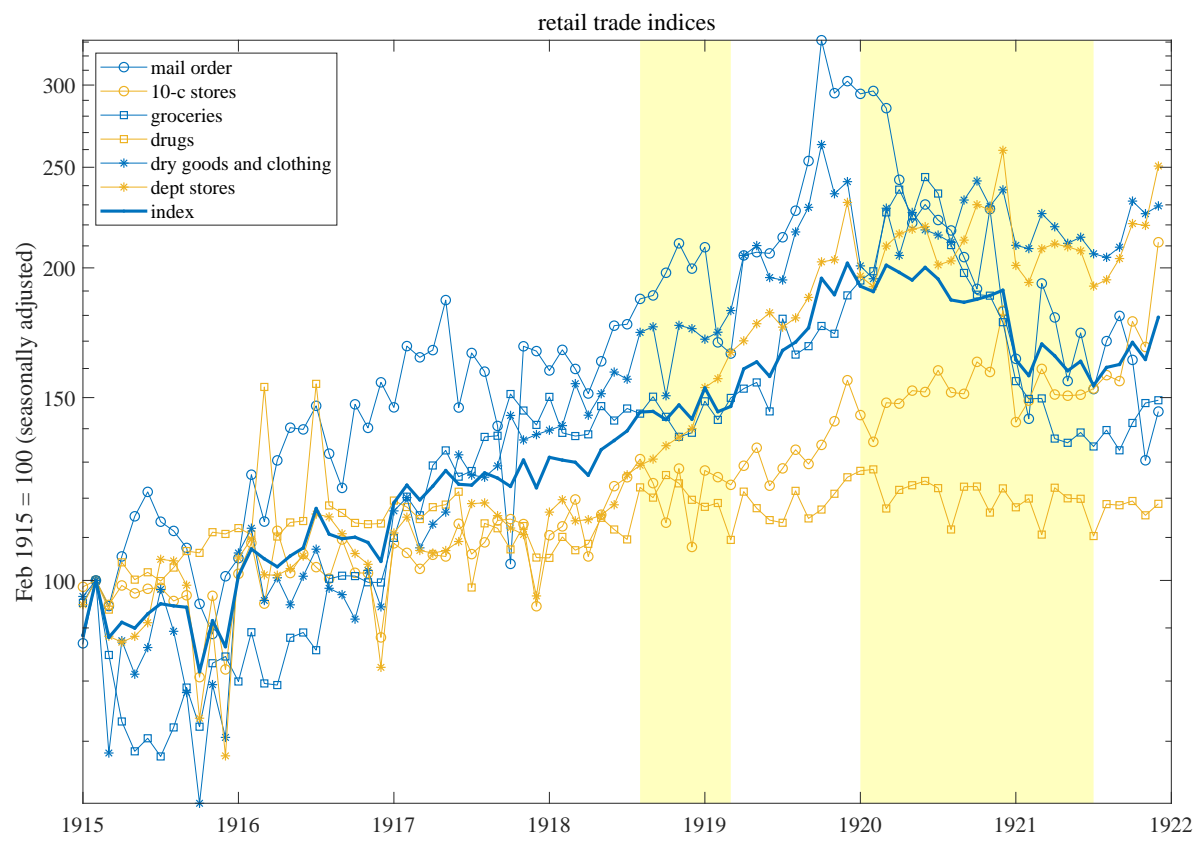

Figure 8: Indices of retail sales by type of store, monthly (s.a.). Source: Copeland (1929). 
Copeland (1929) provides data on the volume of retail trade. The data comes from two mail-order stores (Sears-Roebuck and Montgomery-Ward), two five-and-ten-cent store chains (Woolworth and Kresge), one grocery chain in the New York Fed's district, one drug chain (Liggett and Co), one dry-goods and clothing chain (JC Penney and Co), and five department stores all near New York City. ${ }^{13}$ He concedes the "scarcity and peculiar nature" of the data prior to 1919 and that it represents probably less than 3\% of total retail sales. It is particularly limited in geographic scope, and as it happens New York City was the one major city to eschew the use of business closings, relying instead on quarantines, isolation, tracking of infections, and an education campaign (Aimone 2010). This, however, only affects the grocery and department store index.

\begin{tabular}{lrrrrrr}
\hline & $\begin{array}{c}\text { mail } \\
\text { order }\end{array}$ & ten-cent & grocery & drugs & $\begin{array}{c}\text { dry goods, } \\
\text { clothing }\end{array}$ & $\begin{array}{c}\text { dept } \\
\text { store }\end{array}$ \\
\hline Sep 1918 & 0.8 & -5.2 & 3.8 & -2.2 & 1.2 & 1.4 \\
Oct & 6.0 & -13.2 & -0.7 & 2.8 & -13.1 & 4.4 \\
Nov & 13.1 & -2.1 & -5.0 & 0.9 & 1.6 & 6.4 \\
Dec & 6.9 & -17.7 & -4.2 & -2.7 & 0.8 & 8.4 \\
Jan 1919 & 12.1 & -2.5 & 2.8 & -4.2 & -1.5 & 18.8 \\
Feb & -9.2 & -3.9 & -1.4 & -3.4 & 0.0 & 21.2 \\
Mar & -11.4 & -5.5 & 3.5 & -11.0 & 5.0 & 28.5 \\
\hline
\end{tabular}

Table 2: Percent change in retail indices relative to August 1918.

Table 2 shows the movements in the seasonally adjusted volume indices relative to August 1918. Perhaps not surprisingly the drugstore did well in October and November, as did the mail-order chains, an early version of the "Amazon effect"; and both suffered in early 1919 as the epidemic waned. Dry goods and 10-cent stores and groceries suffered during the epidemic, again as one might expect, but bounced back more or less quickly. It is again worth noting that the retail indices respond quite significantly in the 1920-21 recession.

The picture meshes with reports from the Federal Reserve Bank of Philadelphia that in October "the number of customers visiting the stores decreased about one-third and the volume of sales from 30 to 50 percent" but in November "retail trade improved wonderfully and merchants expressed the belief that the buying during the balance of the year would more than make up the loss caused by the epidemic" and by December "retail trade was exceptionally good, retailers of men's wearing apparel reporting business 25 per cent ahead of December, 1917. With the war over, the public believed there was no further need for stringent economy and felt free to purchase liberally all kinds of goods." Likewise, the New York Fed reported that "the influenza epidemic caused a very excessive slackening in business during October. Following the signing of the armistice, retail sales increased decidedly in nearly all lines, due partly to the decrease of influenza, but principally to the relaxation of the rigid economies practiced during the war. The result was a holiday trade of record proportions" (Federal Reserve Board 1919b, 375,423-24).

\footnotetext{
${ }^{13}$ The proportion of familiar names is probably correlated with the reader's age.
} 


\section{Employment}

Data on employment is relatively sparse, particularly at the monthly frequency (Monthly Labor Review 1926). The national census of manufacturing was quinquennial from 1899 to 1919 and became biennial in 1921: it thus skipped over the year of the pandemic. A few states do have data. The monthly collection of employment data began at the state level in New York in 1914, while Wisconsin began bimonthly collection in 1915. The BLS also began data collection at about the same time, but the scope enlarged only in the 1920s. Massachusetts carried out annually a census of manufacturing that collected monthly data for the past year: the survey was retrospective for the past year but covered all establishments, while the other three monthly reports covered only a fixed set of establishments. Ohio's census was similarly comprehensive, as it covered all employers of five or more persons and recorded employment on the 15th of each month. In addition, Ohio's data covers all industries, while the other series measure employment in manufacturing only.

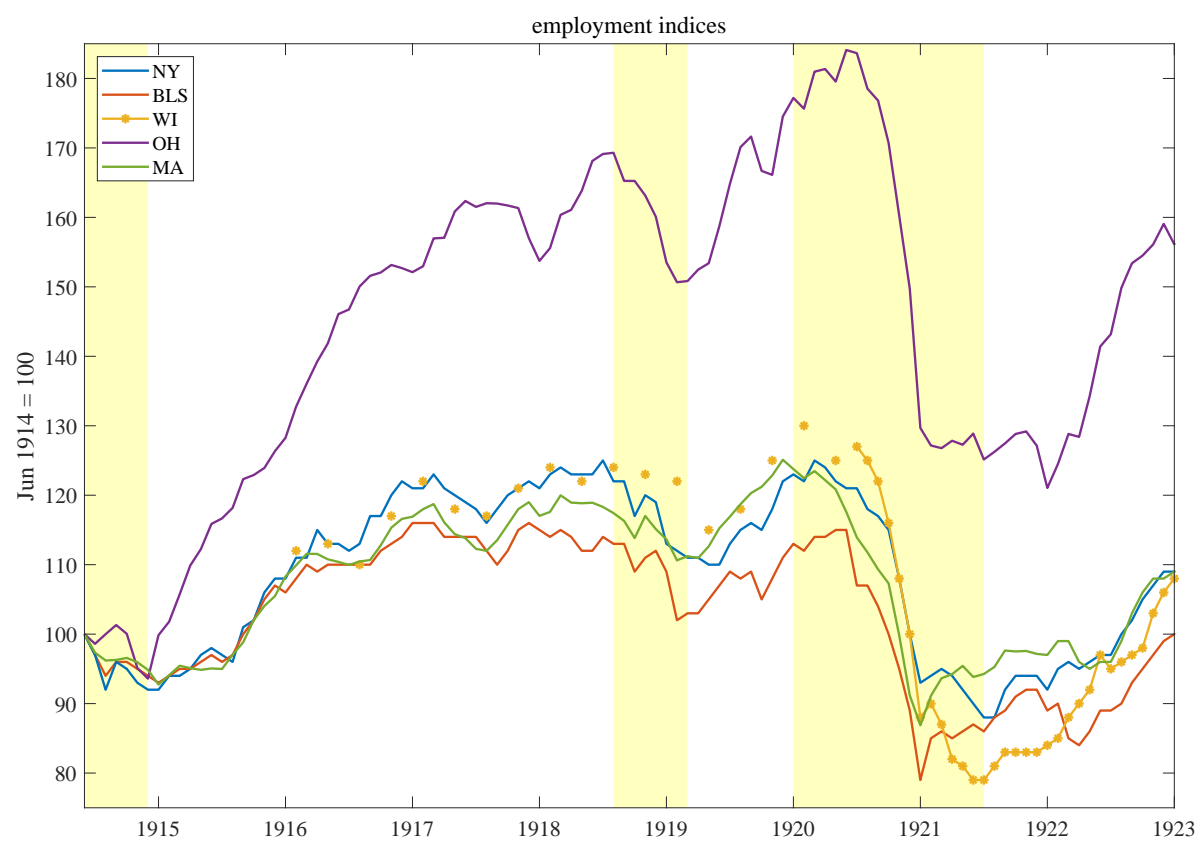

Figure 9: Employment indices for the nation (BLS), New York, Massachusetts, Wisconsin, and Ohio. Source: Monthly Labor Review (1926), Bureau of Labor Statistics (1932), and Commonwealth of Massachusetts (1913-1922).

The five series are represented in Figure 9 and present broadly similar behavior. From the peak in summer 1918 New York's index falls by $15 \%$, the BLS by $12 \%$, Ohio by $11 \%$, Massachusetts and Wisconsin by 7\%. All indices then recover over the course of twelve months and regain their previous levels by December 1919 at the latest; Massachusetts and Ohio by August 1919. The fall in 1920-21 is substantially worse (30 to 40\%), levels remain depressed for longer, and the ensuing recovery only begins in early 1922 although once it starts it is extremely rapid. 


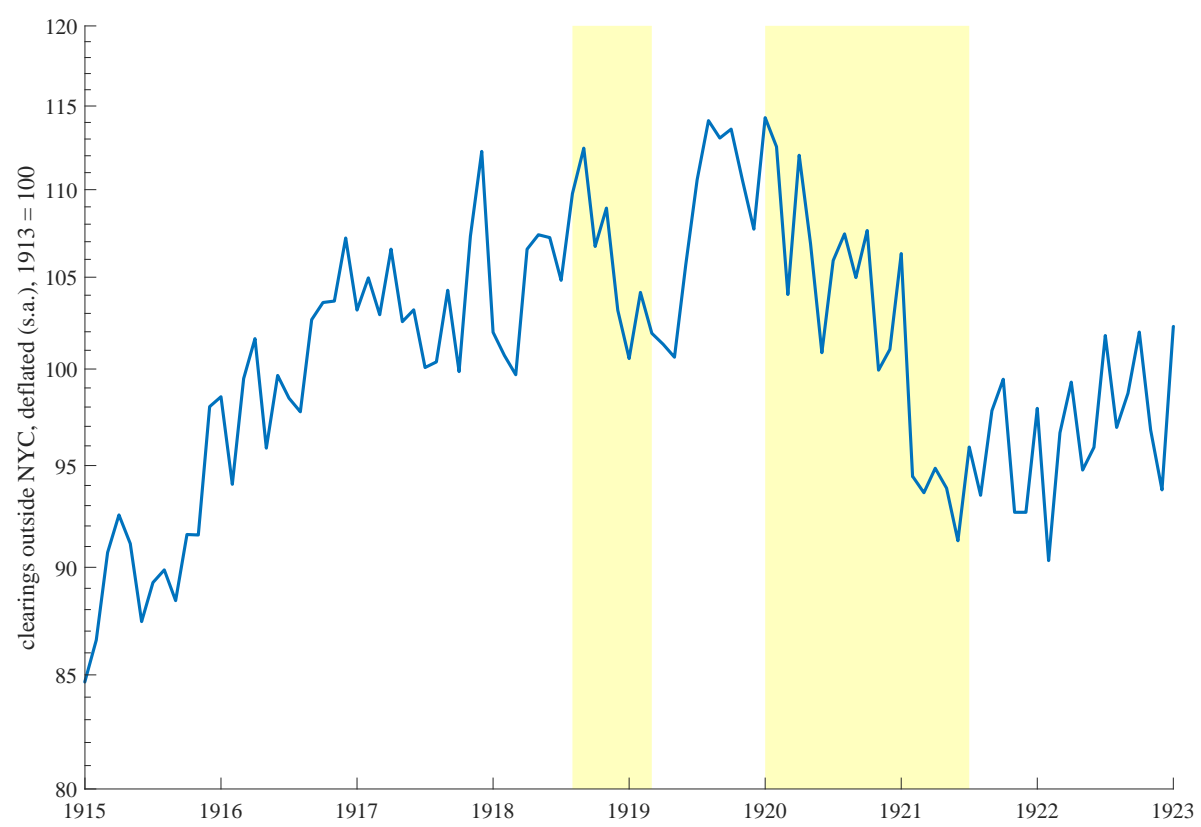

Figure 10: Deflated bank clearings outside New York City (s.a.). Source: NBER macrohistory database, series m12018ba, from Macaulay (1938, A255-A270).

\section{Payment volumes}

A favorite series of early statisticians trying to measure the business cycle ${ }^{14}$ was the volume of bank clearings reported by various cities' clearing houses. This seems like a good reason to glance at it - but we will revisit it in the cross-section as well. Typically New York's clearings, which reflected settlements of stock market transactions, were excluded for business cycle purposes. Admittedly the variable is not a clean gauge of economic activity. Miron and Romer (1990) do not use them to measure production because they are neither pure quantity nor pure price. They are not necessarily monotonically related to economic activity. Inasmuch as they measure interbank activity, a rise in volume could well reflect increased lending to distressed households and businesses, and increased withdrawals by banks from their correspondents. ${ }^{15}$

Clearings in fact increase during the epidemic proper, but register a sharp fall in early 1919 , quickly reversed. It should be noted that February 1919 brought the end of wartime price controls: the wholesale price index registered an abrupt $8 \%$ fall in that month, and retail prices fell by $5.5 \%$ on average from January to March 1919 (see Figure 27). Hence clearings are also shown as deflated: the size of the fall during the recession is about the same magnitude $(10 \%)$ but the timing is a little different. Note again that the contraction during the 1920-21 recession is about twice as large. 


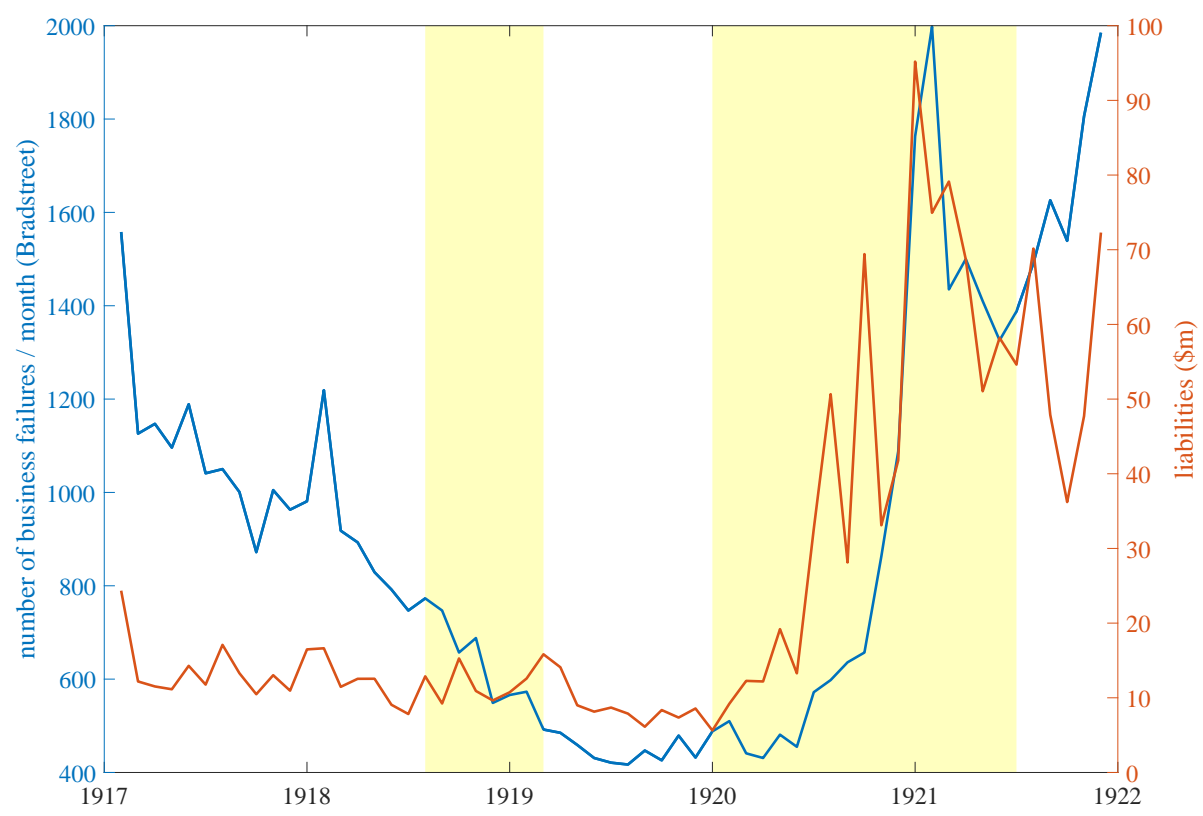

Figure 11: Business failures (number and liabilities). Source: Bradstreet, NBER macrohistory database.

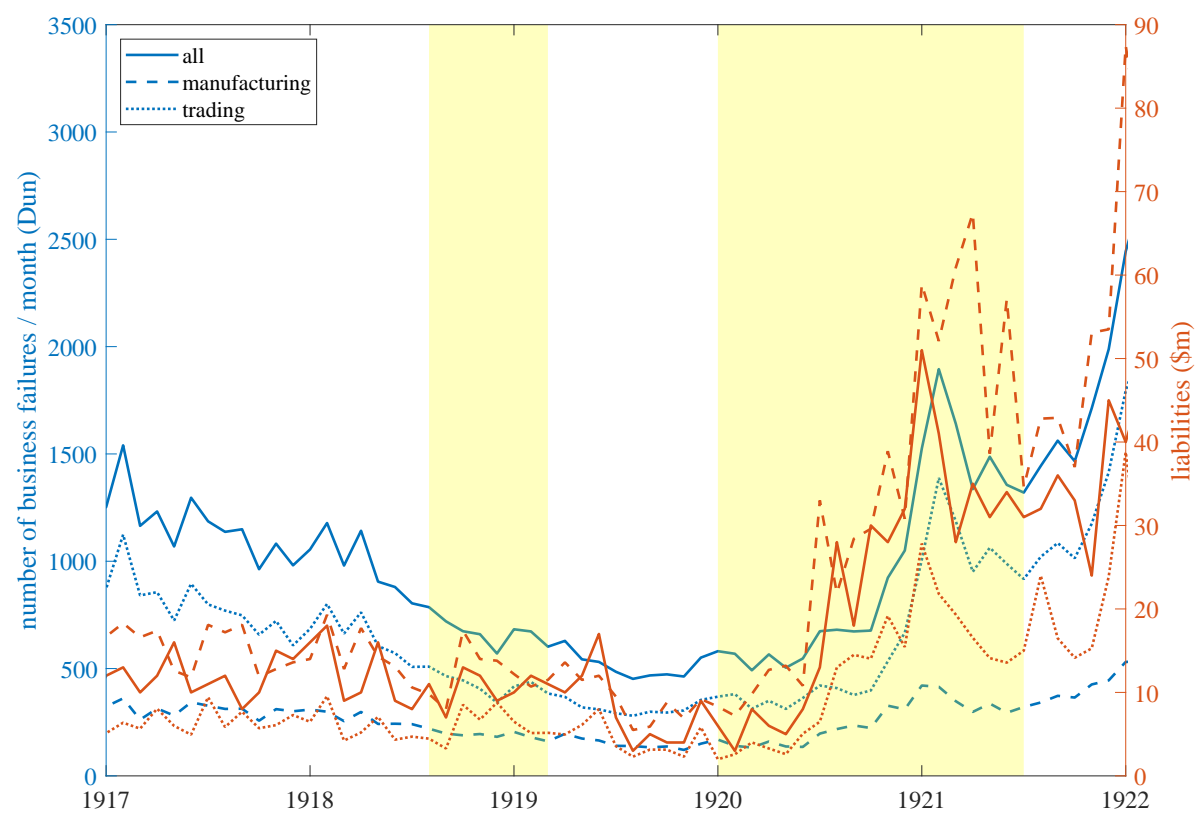

Figure 12: Business failures (number and liabilities) for all commercial, manufacturing, and trading. Source: Dun, NBER macrohistory database. 


\section{Business failures}

Two credit rating agencies, Dun and Bradstreet (the firms merged in 1933) systematically collected data on business failures, for which Bradstreet required that it involve "some loss to creditors of individuals, firms or corporations engaged in ordinary commercial operations," (Persons 1919, 44, who judges it "comprehensive"). Although this excluded professionals, it did not necessarily bias the sample toward large firms: in 1918-19, the average size of assets was around $\$ 10,000$ in the Bradstreet sample. The data from these two firms is shown in Figures 11 and 12. The most striking aspect of the series is the almost complete absence of a surge in failures during the 1918 recession (note that the data are not seasonally adjusted). In fact, the number of failures goes down steadily. In contrast, the number of failures rises by a factor of four or five during the 1920-21 recession.

Bradstreet's analysis of the year 1918 (Feb. 1, 1919, p. 77) is worth quoting at length because it documents where contemporaries placed the epidemic within the context of all the events affecting the economy:

Failure returns for 1918 reflected unprecedented prosperity of a vast proportion of the country's inhabitants, due mainly to the stimulus of a highly successful war conducted at a distance, so that few unfavorable effects were to be seen or felt. The results were total business casualties below any thing witnessed for a third of a century, liabilities that compared favorably with any but the best of years, an unprecedentedly small number of banking casualties, and a smaller proportion of failures to those engaged in business than ever before recorded since Bradstreet's records of Business Mortality were first made up. ... There were some unfavorable features met with in the year, notably extremes of cold and heat in winter and summer, a severe drought causing partial failures of corn and cotton, an unprecedentedly fatal epidemic, government interdiction ending in partial paralysis of a number of important industries, notably building, brewing, distilling and automobile manufacturing, and accompanying restriction of all but most essential operations in other lines. On the other hand, there was first and foremost a hothouse stimulation of all lines aiding in war operations, immense demand from government sources for all kinds of materials and products that could be used in war, active employment at high wages for all who could work with their hands, and a vastly enlarged purchasing power of the mass of the people... It is an additionally interesting feature that, notwithstanding the slowing down in business that followed fast upon the signing of the armistice and the interruption to trade at many centers by the influenza, so great was the momentum in business and so profitable had been the previous months' trade, that the lowest monthly totals of casualties ever recorded were reached in the closing quarter of the year.

\footnotetext{
${ }^{14}$ See Persons (1919), the first editor of the Review of Economic Statistics, and Rorty (1923), co-founder of the NBER.

${ }^{15}$ I thank Kris Mitchener for this observation.
} 
The epidemic was just one of many "headwinds" in an eventful year, like extreme weather, drought, and wartime restrictions on production (the "government interdiction"), which a booming economy in the first half-year, stimulated by government demand, enabled firms to face. Even the slowdown caused by the Armistice did not dent the "momentum in business."

\section{Contemporary testimony}

The sharp but brief downturn in production and the transient impact on retail are well attested from the reports of the Federal Reserve Banks on the conditions in their districts.

It is legitimate to wonder if the reports were not biased by patriotic ardor, especially on the part of quasi-public institutions such as the Federal Reserve Banks, whom it behooved to describe the war effort in the most positive and encouraging way. That does not seem to be the case in the description of the epidemic's first effects. In fact, the tone of the October reports is forthright and vivid (Federal Reserve Board 1918, 1126-40).

In Boston, "The epidemic of influenza which has prevailed during the past month has seriously interfered with business. Production of all kinds has been restricted. Retailers in large centers have had a material falling off in business, while those serving small local trade have to a considerable extent reaped benefits... Cotton mills have been seriously retarded by shortage of labor due, to a considerable extent, to the illness of employees ... Retail business has been adversely affected by restrictions on shopping and by the weather." In New York, "influenza has greatly hampered production in certain centers, although the situation is not yet as serious as reported in some of the other districts." In Philadelphia "a heavy loss in production was occasioned by the influenza epidemic... The influenza epidemic had greatly affected the coal output. Conservative estimates show that it has caused, a decline in the production of anthracite coal of from 250,000 to 300,000 tons per week, some of the collieries being compelled to close." Although Cleveland reported that "so far the epidemic of influenza has not contributed to any great extent in the labor shortage," Atlanta stated that "Alabama coal output showed a considerable decrease in September, and the spread of the influenza, coupled with labor shortage, caused the October reduction, leaving the outlook far from bright." In St. Louis "the influenza epidemic, and the measures taken to combat it, have had a disturbing effect on certain branches of business in this district. Theaters, schools, churches, and other meeting places have been closed entirely, and some of the large stores have been compelled to open later and close earlier than usual. This has especially handicapped retail trade, though other lines have also been affected. Some activities have suffered considerably on account of the depletion of their working forces through contraction of the disease." In Dallas "unseasonably warm weather, accompanied by the influenza epidemic, has had a very serious effect on business in nearly all parts of the district during the past 30 days, and trade is generally inactive as a result." In Kansas City "added to the labor shortage October and the first half of November saw serious complications resulting from a general epidemic of Spanish influenza among all classes of workers throughout the district. No branch of industry 
escaped. The mines were especially disorganized, many men being incapacitated from one to two weeks. In many cases it was difficult to maintain operations. Factories and large industrial plants were affected in the same way and in the same proportion. Men, on returning to their work proved unequal to their former tasks."

The rapid reversal after the epidemic is likewise attested by the monthly reports of November 1918 (Federal Reserve Board 1918, 1220-36), by which time the Armistice made self-censorship unnecessary. In Boston "conditions are rapidly returning to normal." In New York, the epidemic was "fairly well checked by November, and business was proceeding at top speed" and retail trade "showed a decided gain toward the end of November"; "sales by retailers, which were somewhat restricted at the beginning of the period under report because of the influenza epidemic and the spirit of war economy, showed a decided gain toward the end of November." In Philadelphia "a more normal situation has resulted from the waning of the influenza epidemic." In December Richmond said that "the subsidence of the prevalent influenza permitted the reopening of churches, schools, and other places of gathering... trade has been spotted and below normal during the influenza period, but on the whole prosperous and on a sound basis... the effects of the influenza are passing." In Atlanta "the mercantile business, while reported fair, is not very good, owing to the influenza epidemic, which prevented many traders from visiting stores, and resulted in a considerable curtailment of sales. Business, however, is increasing, and a large holiday trade is anticipated." In St. Louis "the influenza epidemic is on the decline in this district, and the bans placed on business to combat it, in most instances, have been lifted. Department stores, theaters, etc., are now operating as usual, and schools, churches, lodges, etc., are again open. This has materially helped the retail trade. It is also being stimulated by Christmas shopping, which is being done early this year in response to the requests of merchants." In Kansas City "the high tide of business ... shows a continued upward sweep, in spite of slight and temporary checks which may be attributed to special factors, such as the influenza epidemic, elections, the financing of the fourth Liberty loan, and the cessation of hostilities. As a whole, the situation is viewed with optimism and upon the broad assumption that America's task of equipping and provisioning a large part of the world has only begun." In Dallas there was "general dullness in business" but "it is expected that this slump in trade will be only temporary; in fact, reports now indicate that the situation is somewhat improved, and we believe the worst of the danger is over."

By the January 1919 issue of the Federal Reserve Bulletin, covering December 1918, the epidemic ceased to be mentioned.

The uncertainty associated with the Armistice is also apparent in many reports: New York reported that after the Armistice "followed a period of uncertainty and hesitation with regard to the steps necessary to readjust business to a peace basis. Gradually Government restrictions, such as priority rules, were removed, and many lines were able promptly to return to approximately their prewar bases. Many other industries, however, felt obliged to pursue a waiting policy pending announcement of the Government's program for cancellations and the disposal of Government-owned stocks of raw materi- 
als." In Philadelphia "there was a strongly defined tendency to mark time, with a view to determining the probable extent of readjustment after the war, the consensus of opinion was that the period of readjustment would be relatively short, to be followed by an era of industrial activity" (Federal Reserve Board 1919b, 373,424). "Practically throughout the country the month of January [1919] has been characterized by the uncertainty incident to a period of transition in business." The hesitation revolved around prices of commodities and raw materials: "Uncertainty, not only among consumers, but also among those who would ordinarily be in the market for raw materials with which to manufacture goods, concerning the possibility or probability of a further drop in values, tends in the same direction" (Federal Reserve Board 1919a, 104,109).

\section{Summing up}

Visual inspection of the series leads to a consistent conclusion: the 1918 recession was mild and quickly reversed, and stands in very sharp contrast to the 1920-21 recession. Our series do not fail to detect recessions: indeed, that is why students of business cycles used them at the time. The 1918 recession, often overlooked in business cycle histories, was simply not that remarkable, particularly compared to the one that followed.

Did it have anything to do with the influenza epidemic? Its onset certainly coincided with it, and contemporary economic commentary did not fail to note the impact of the epidemic both on labor supply and, through business closings, on trade. The cross-section will allow us further to probe the link between the epidemic and the recession.

\section{Looking for the recession: using the cross section}

In this section I investigate the relationship between the epidemic and economic activity. The goal is to understand the mechanism linking the two and how interventions to slow the epidemic affected it, the tool is the cross section, the constraint is data availability.

There are two levels of cross section that can be used: city and state. As described above, Linder and Grove (1947) provide monthly mortality data at the state level for thirty states, while Collins et al. (1930) provide excess P\&I data for 47 cities. In addition, at the city level we have measures of NPIs, namely closings and reopenings of business: mostly places of entertainment and socializing (theaters and movie theaters, dance halls, bowling alleys, "saloons," restaurants, etc). The dates of closings are in Appendix 1.

\section{Manufacturing in New York State}

As mentioned above, the state of New York conducted an annual census of manufacturing, albeit based on a fixed sample of establishments. This nevertheless provides us with regional employment data for seven industrial regions at the monthly frequency, shown in Figure 13.

The visual evidence is striking. All series show a dip in October 1918, with some variation across industrial regions in the size of the dip from $1.5 \%$ in Syracuse to $9.4 \%$ in New 


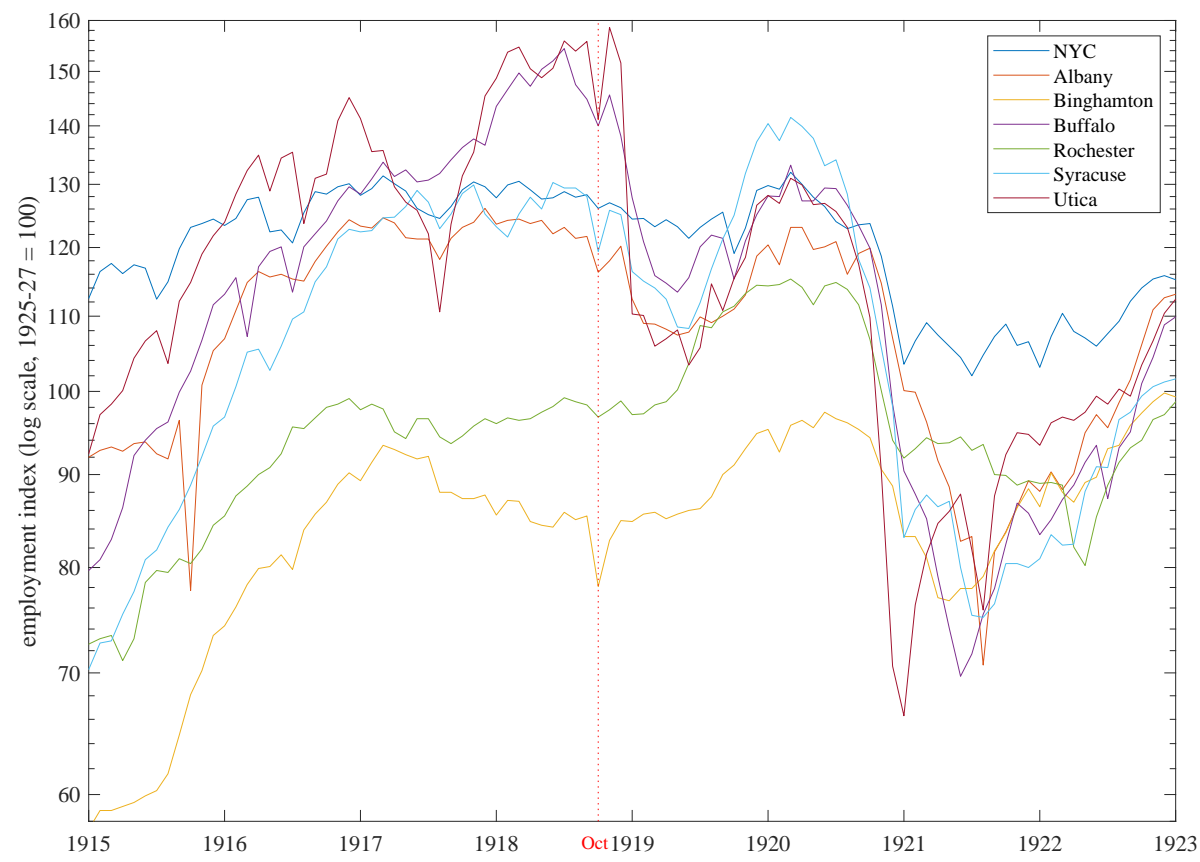

Figure 13: Employment relative to 1925-27 in seven regions of New York state, monthly, Jan 1915 - December 1923 (log scale). Source: New York State Department of Labor (1940, 176-82).

York City (the aggregate index for New York State, shown in Figure 9, falls by $4 \%$ ). All regions show a bounce-back in the following month of November. What happens next varies slightly by region. Employment turns down in December in New York, Buffalo, and Syracuse; in January in Albany, and Utica. The downturn is severe in Buffalo (-20\% to June 1919) and Utica (-35\%) but the trough is reached by mid-1919. Employment in Binghamton and Rochester actually grows by a few percentage points throughout the 1919 recession. In the aggregate the fall from December 1918 to June 1919 is 8\%. In contrast, the fall during the 1920-21 recession is $30 \%$.

\begin{tabular}{|c|c|c|c|c|c|c|}
\hline \multirow[b]{2}{*}{ correlation with: } & \multicolumn{3}{|c|}{ P\&I mortality in: } & \multicolumn{2}{|c|}{ days closed in: } & \multirow{2}{*}{$\begin{array}{l}\text { growth from Apr } \\
1917 \text { to Sep } 1918\end{array}$} \\
\hline & Sep & Oct & total & Oct & total & \\
\hline emp. growth from Sep to Oct 1918 & -0.19 & -0.55 & -0.49 & -0.47 & -0.30 & -0.22 \\
\hline emp. growth from Dec 1918 to Jun 1919 & -0.06 & -0.75 & -0.71 & -0.20 & -0.21 & -0.86 \\
\hline emp. growth from Apr 1917 to Sep 1918 & -0.13 & 0.37 & 0.34 & 0.26 & 0.26 & 1.00 \\
\hline total P\&I mortality rate & 0.46 & 0.99 & 1.00 & 0.42 & 0.46 & 0.34 \\
\hline
\end{tabular}

Table 3: Correlations between employment growth rates, P\&I mortality, closings. Sources: as in Fig. 13 for employment; Collins et al. (1930) for mortality in New York City, Eichel (1923) for mortality outside of New York City, and New York State Department of Health (1920, 3:44) for estimated population in 1918.

It seems that employment fell in the month of the epidemic, rebounded, and fell after the Armistice. Could there be a relation between the epidemic's impact and the postArmistice fall? Although the number of regions small, a simple correlation (shown in Table 3) might suggest so. The first row shows a clear negative correlation between mortality and the coincident drop in employment. The second row would suggest that the fall in employment after the armistice is strongly correlated with mortality (although not 
with closings), but it also indicates that it is even more correlated with the growth in employment from the start of the war in April 1917 to September 1918.
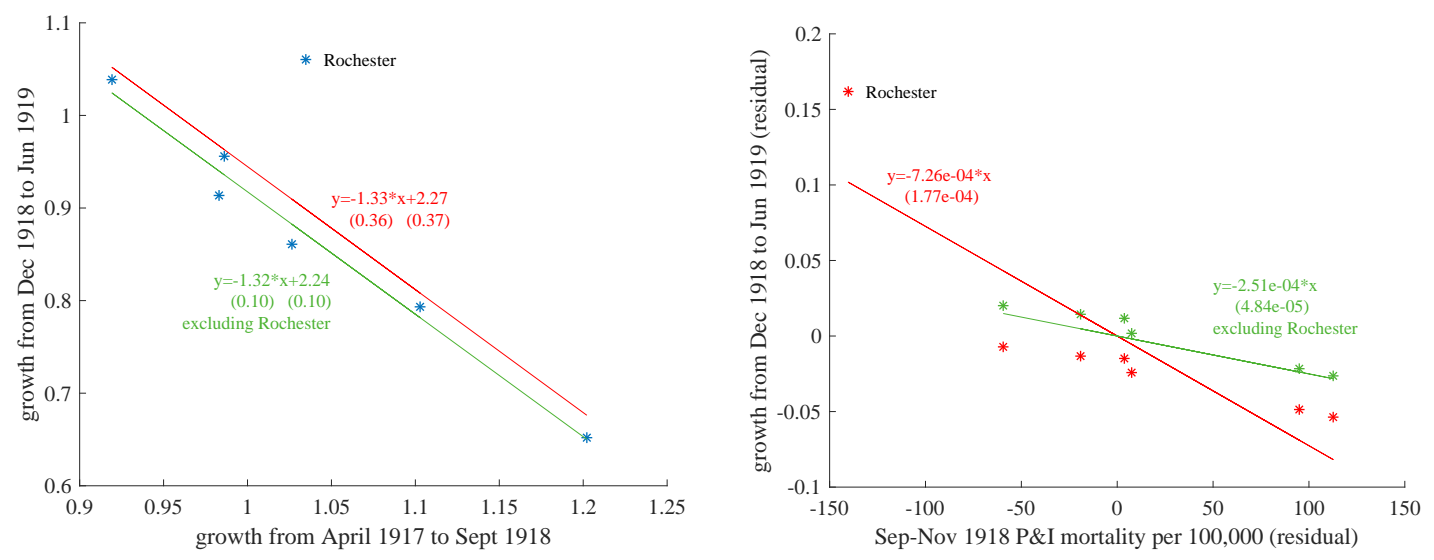

Figure 14: Regression of growth from Dec 1918 to Jun 1919 on growth from Apr 1917 to Sep 1918, and residual regression on P\&I mortality rates, New York state, by industrial region. The green regression lines exclude Rochester.

Figure 14 shows partial regression plots. First (in the left panel) I regress employment growth after the armistice with employment growth from the start of the war to the epidemic. The relation is very tight, except for Rochester: employment drops after the armistice more than one-for-one. I then regress the residuals on the residual of mortality regressed on 1917-1918 employment growth. There remains a significant negative effect of mortality on subsequent employment, but the epidemic only explains a very small fraction of the 1918-19 recession (excluding Rochester, mortality explains 1\% of the variation).

\section{Manufacturing in Massachusetts}

I attempt a similar exercise with data from Massachusetts, albeit with less data. The state of Massachusetts also conducted a census of manufacturing; unfortunately, the publication gives monthly numbers by industry, and annual number by city, but not monthly numbers by city. I use city-level mortality statistics by cause for the year 1918 and estimated population in 1915 (Commonwealth of Massachusetts, Office of the Secretary 1920, 190-214) to construct a vector of annual city-level P\&I death rates $X$ of length $N$. From the statistics of manufacturing (Commonwealth of Massachusetts, Bureau of Statistics 19171920, 1917, 12-44, Tables IB, IE) I find the share of total Massachusetts employment in industry $i$ located in city $j$, which gives me a matrix $\left(a_{i j}\right)$ (the rows don't add to 1 because the information provided is incomplete). I interpret the product $Y=A X$ as a vector of industry-level exposure to the epidemic. I collect monthly employment data on various industries in Massachusetts (Commonwealth of Massachusetts, Bureau of Statistics 1917-1920, Table III) and aggregate to fourteen industries using the classification of the US Census of Manufactures for 1914 (Department of Commerce, Bureau of the Census 1917, 29).

As in Figure 14, I show partial regression plots in Figure 15. Remarkably, the slope in the left panel is almost identical in Massachusetts. There is again a significant negative 

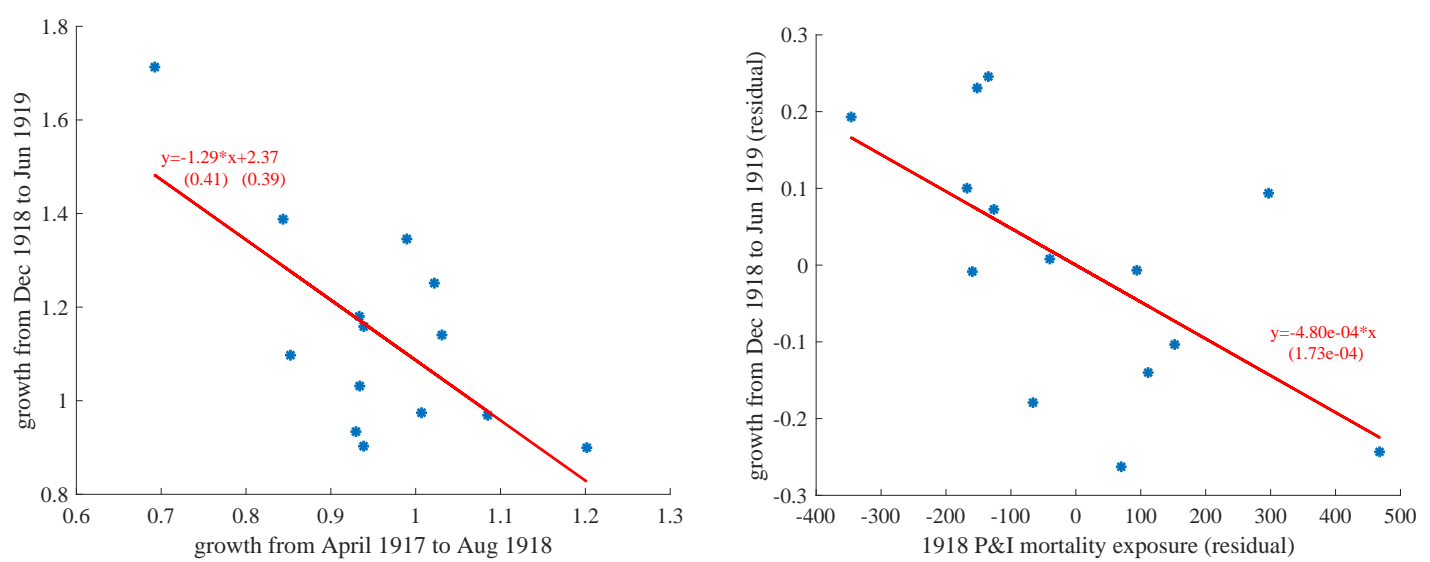

Figure 15: Regression of growth from Dec 1918 to Jun 1919 on growth from Apr 1917 to Sep 1918, and residual regression on industry exposure to P\&I mortality, Massachusetts, by industry.

effect of mortality on employment growth after the armistice: the magnitude is larger but the estimate is less precise. Adding exposure to the epidemic increases the $R^{2}$ from $46 \%$ to $66 \%$.

\section{The coal industry}

In this section I focus focus on one particular industry, located throughout the nation. Coal mining at the time employs around $1 \mathrm{~m}$ people or $2.5 \%$ of the labor force. The second-most important component of the Miron-Romer IP index is shipments of anthracite, a form of coal mostly used for domestic heating and principally mined in Pennsylvania. The other major form of coal was bituminous or soft coal, used for industrial purposes and mined throughout the United States. Figure 16 shows weekly production estimates for both types of coal. Production of anthracite peaks in the last week of August and bottoms out in the in the first week of March 1919 56\% lower. Bituminous coal peaks in the last week of September and bottoms out in the first week of April 1919 46\% lower. Both outputs regain their peak levels in early October 1919 just before the onset of strikes and labor disputes.

It is possible to learn more about the causes of the fall in output, from statistics generated by the US Fuel Administration, created when the US entered World War I to manage the production and distribution of national energy sources. Every week the administration collected and published reports by mine operators on their production relative to capacity, and explanations for the shortfall classified as car shortage (transportation), mine disability, labor shortage, strikes, and "no market," i.e., low demand. The reports came from mines representing between 65 and $90 \%$ of total national output across the country, and they are published by producing regions, which I aggregate into states.

Figure 17 plots the weekly decomposition of capacity utilization based on these reports, for the country as a whole. Aside from punctual events ${ }^{16}$ the figures shows how labor shortages grew sharply in October and peaked mid-November, and fell back by mid-

\footnotetext{
${ }^{16}$ Onetime sharp surges in labor shortages (weeks ending Apr. 5 1918, Jun. 1 1918, and Dec. 281918 reflect holidays. On Sep. 121918 registration day (for military service) also affected labor supply.
} 


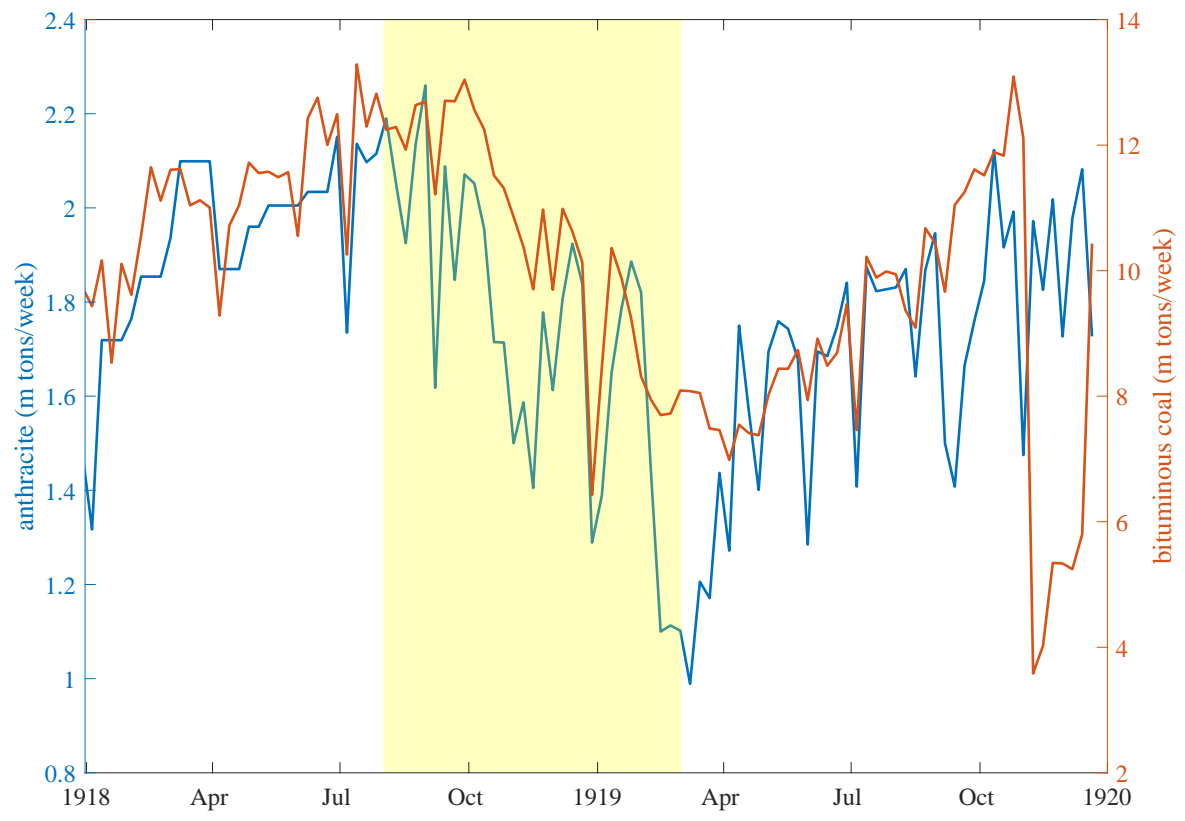

Figure 16: Weekly production of anthracite and bituminous coal in the United States. Source: United States Fuel Administration (1919) and the Coal Trade Journal, various issues.

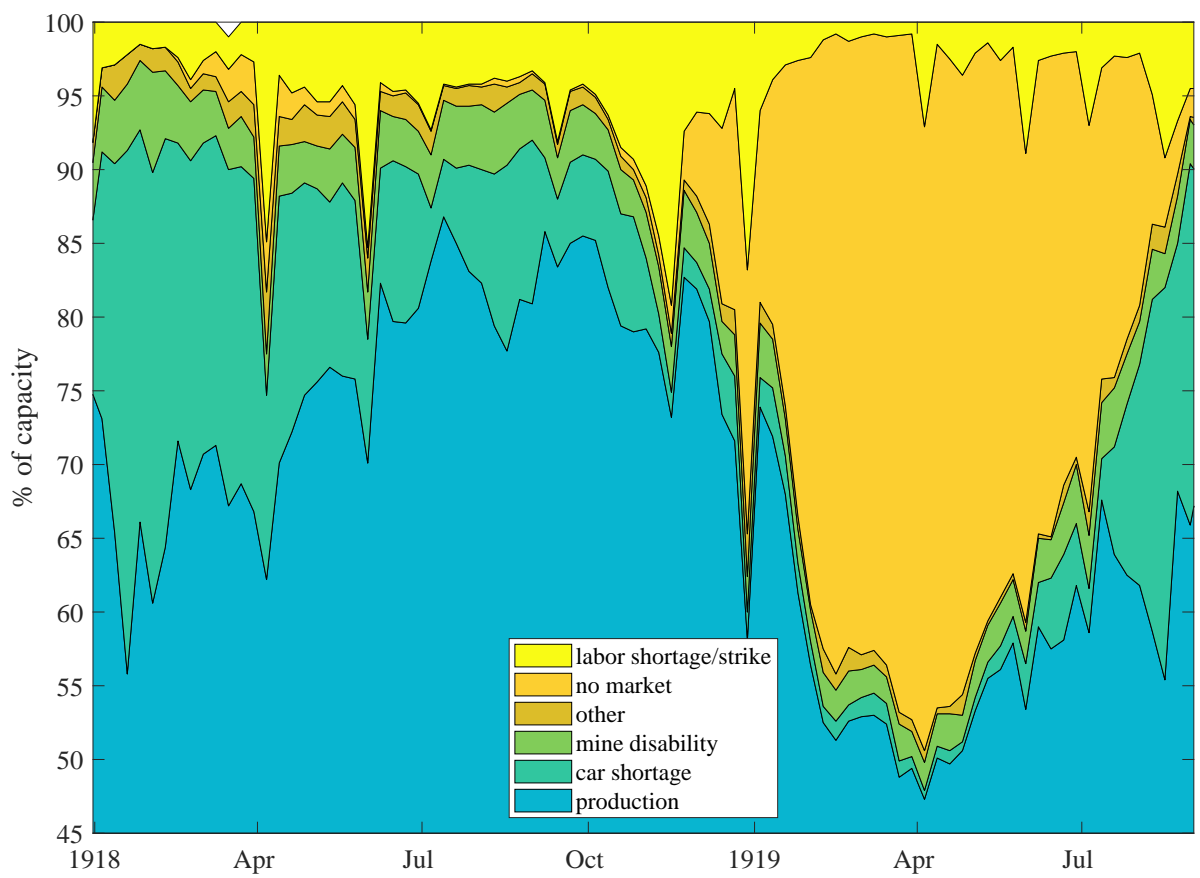

Figure 17: Capacity utilization as reported by mines, weekly. Source: United States Fuel Administration (1919) and the Coal Trade Journal, various issues. 
January to the August level. The continued diminution in mine output was then driven by another factor, "no market," which grew from November 1918 to April 1919 and then subsided. Contemporary observers saw several factors at play. An analysis in the Coal Trade Journal (March 5, 1919) saw the "primary causes" as "the sudden cessation of hostilities abroad and the unusually mild winter at home," while the "chief secondary causes" were "the unpreparedness of the country for peace and the delays incident to the settlement of war contracts and the clarification of the government's future attitude toward business enterprises of all kinds". The comment alludes to the fact that the Federal government relinquished control over the coal industry in late January 1919, withdrawing price controls and regional restrictions (the US had been divided into regions and coal could not be shipped across regions).

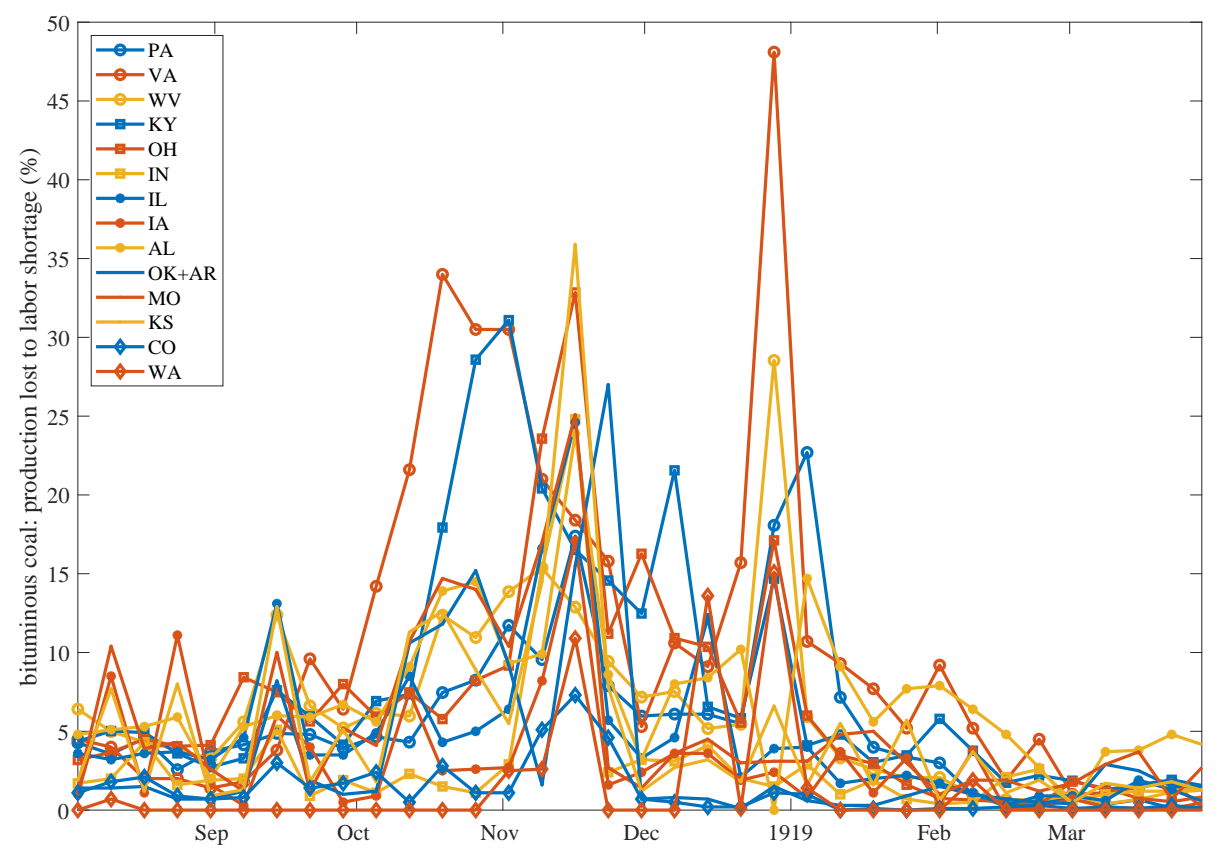

Figure 18: Capacity unused because of labor shortage, weekly, by state. Source: United States Fuel Administration (1919) and the Coal Trade Journal, various issues.

It is tempting to think of the epidemic as a supply shock giving rise (through "labor shortage") to a subsequent fall in demand ("lack of market"): in terms of Figure 17, the yellow area begetting the orange area. The cross section data shows that the story is not so simple. We can confirm that the epidemic reduced labor supply, but there is no linkage to lack of market.

First, the evolution of labor supply state by state is shown in Figure 18. Aside from two special weeks (September 12, registration for military service, and Christmas), a pattern of waves is discernible reminiscent of the epidemic's waves. Virginia is the first hit, closely follow by Kentucky; the rest of the states (both Midwest and West coast) peak in midNovember. The west of the country seems less affected and second wave is apparent in some states (Kentucky, Alabama, Ohio).

Figure 19 confirms the relation between mortality and the labor supply shock by state. The x-axis plots the cumulative excess P\&I mortality rate starting in August 1918. Each 


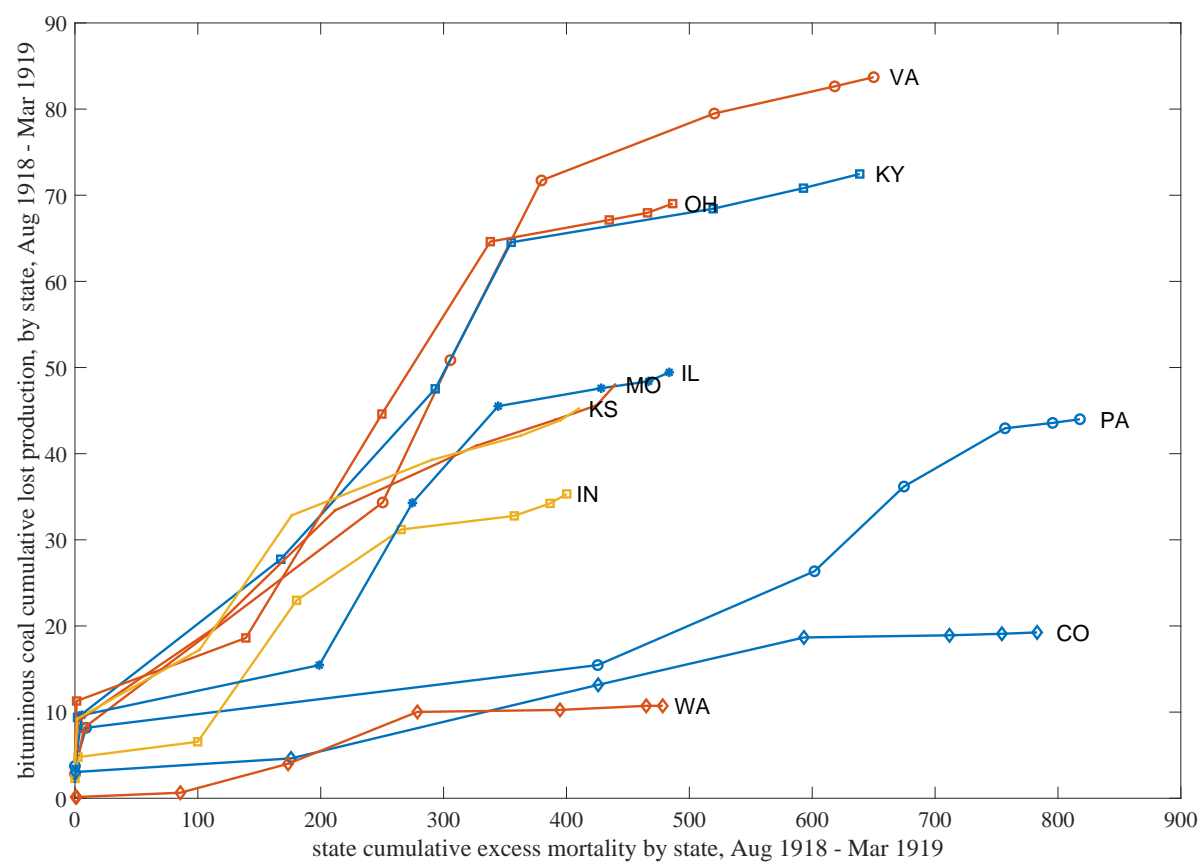

Figure 19: Cumulative excess mortality by state and cumulative lost production, Aug 1918-March 1919.

line is a state, and each marker on the line is a month; because excess mortality is nearly always positive in this period, time runs from left to right. The vertical axis shows the cumulated output loss due to labor shortages for each state. The relation between the two is clear except for the two western states (Washington and Colorado), but the slopes differ markedly across states. The first-hit states (Virginia and Kentucky) also experiences the steepest relation between mortality and labor shortage.

Finally, Figure 20 addresses the possibility of a link from labor supply shock to aggregate demand. It shows the relation, or rather the lack thereof, between mortality and the labor shortage it induced on one hand, the ensuing shortfall in production due to lack of demand on the other hand. The two regression lines are not consistent with each other and the slope coefficients are not significant ( $p$-values of 0.37 and 0.47 ).

\section{Banking data}

The complexity of US banking regulation means that the data are dispersed in various sources. There are two major ways to divide banks, by charter and by membership of the Federal Reserve System.

According to the first distinction national banks, chartered under the National Bank Act, are regulated by the Comptroller of the Currency whose annual reports provide some balance-sheet data on call dates, six times a year. Non-national banks are chartered by state, and data are available if the state banking regulator published it, which is the case for some of the states for which we have vital statistics, albeit at varying call dates. ${ }^{17}$ Members

\footnotetext{
${ }^{17}$ National banks represented between 40 and $43 \%$ of all bank assets between 1896 and 1922. I plan to collect the state-level data and extend the present analysis.
} 

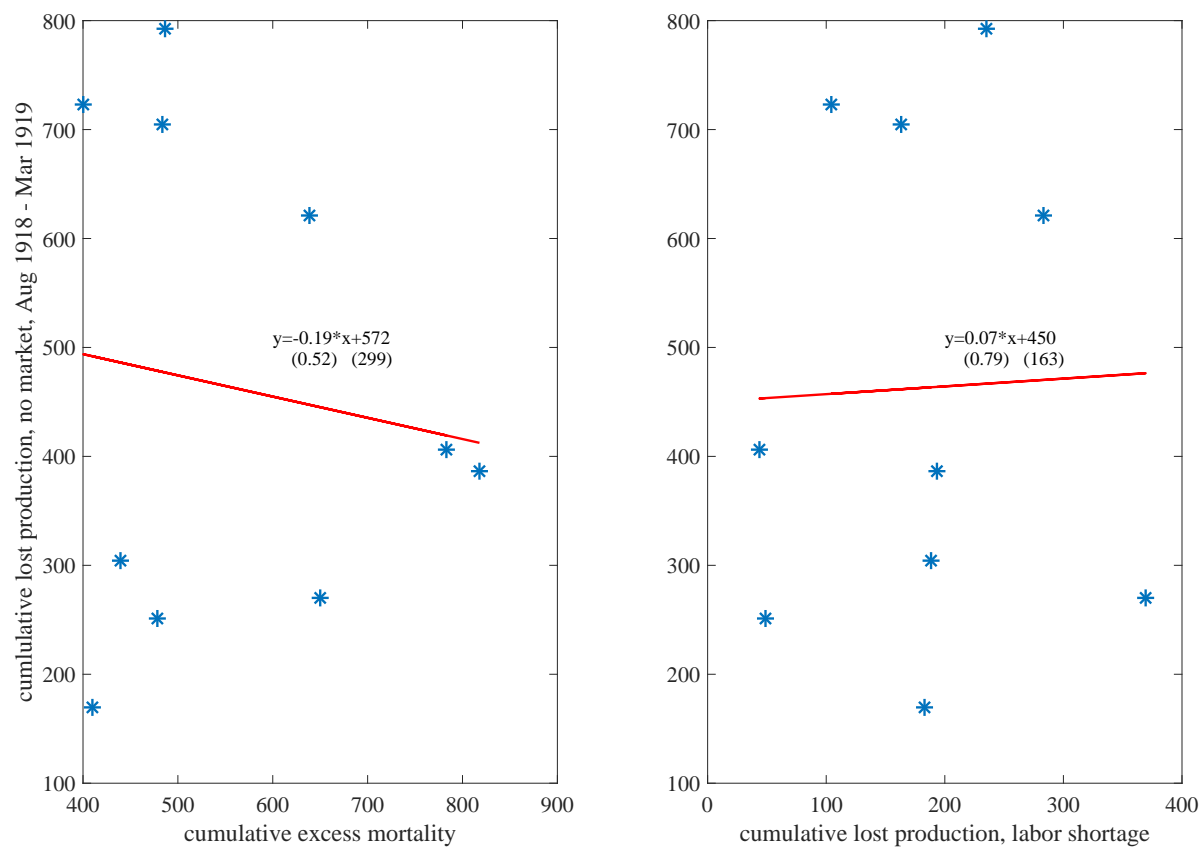

Figure 20: Relation between cumulative excess mortality, resp. cumulative lost production due to labor shortage, and cumulative lost production due to lack of market, Aug 1918 Mar 1919. Red lines are regression lines.

of the Federal Reserve System could be national or state banks; the Fed published some data for its members' balance sheets, but mostly broken down by Federal Reserve district, which does not neatly overlap with the state-level mortality statistics. We do, however, have data for member banks located in the twelve district cities on call dates.

From the Comptroller's annual reports we have the national banks' total assets and their loans and discounts on call dates by state and for reserve cities. I use the thirty states and the thirty-seven reserve cities for which we have excess P\&I mortality data, and the mortality data is summed into bimonthly series. The sample runs from December 1916 to November 1921 (thirty call dates). I use local projections of assets and loans (in logs) on bimonthly mortality, of the following form, with $i$ denoting either region or city:

$$
\begin{array}{ll}
\Delta \log \left(\operatorname{assets}_{i, t+h}\right)=\beta_{h} m_{i, t}+\sum_{k=1}^{4} \gamma_{k} \Delta \log \left(\operatorname{assets}_{i, t-k}\right)+a_{i}+b_{t}, & h=0, \ldots 6 \\
\Delta \log \left(\operatorname{loans}_{i, t+h}\right)=\beta_{h} m_{i, t}+\sum_{k=1}^{4} \gamma_{k} \Delta \log \left(\text { loans }_{i, t-k}\right)+a_{i}+b_{t}, & h=0, \ldots 6
\end{array}
$$

The response of these variables to mortality is shown in Figure 21, scaled by the median city's shock size. The city-level evidence is somewhat stronger, although these cities are the most important financial centers. They show a rise in loans and total assets after two months, partly reversed after one year.

Figure 22 separates cities that moved early (starting date of closings before the median) from those that moved late. It suggests that the rise in bank balance sheets is sharper in the cities moving late, followed by a quicker reversal. The error bands are wide and the differences are not statistically significant so not much weight can be placed on them. 

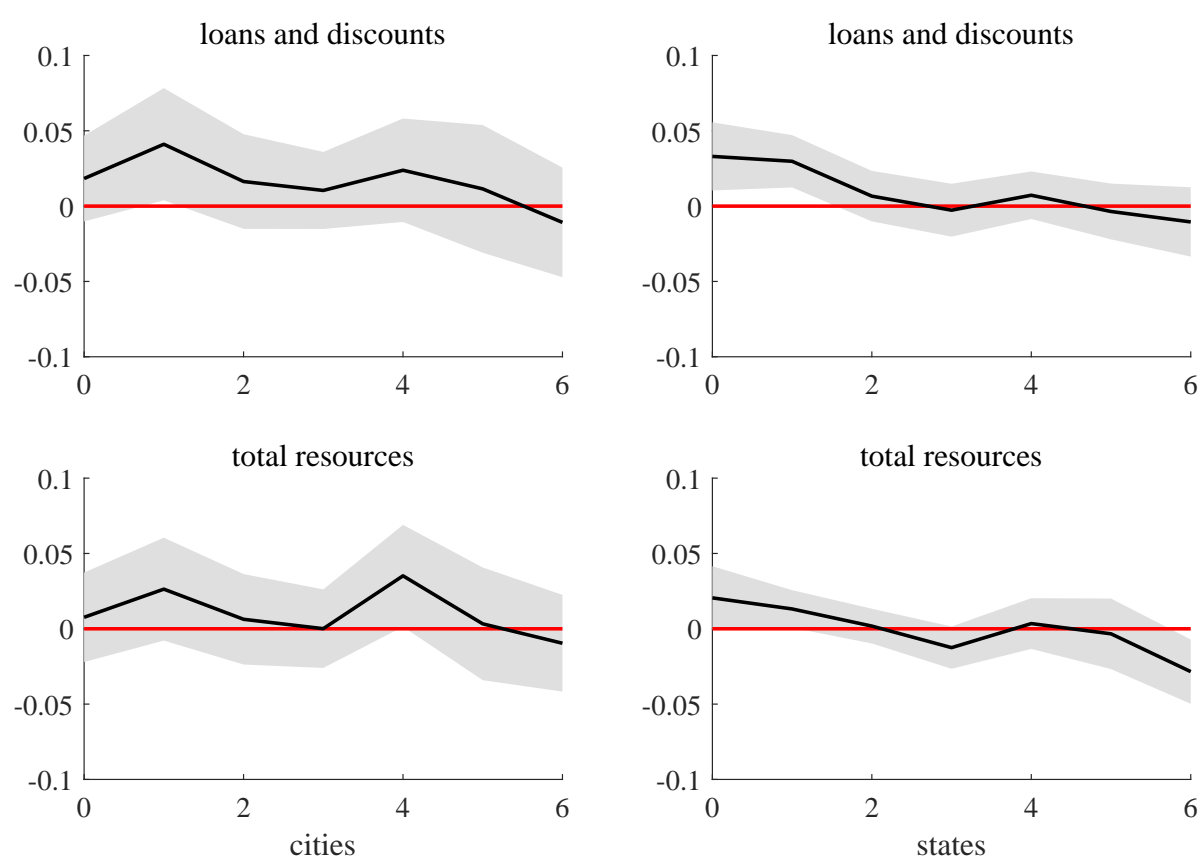

Figure 21: Impulse response functions from local projections of national banks' loans and discount and total resources (in logs) on city (resp. state) mortality. The units of the xaxis are periods of two month (between call dates). The response is to a shock of $0.1 \%$ mortality (100 deaths per 100,000) in one month.
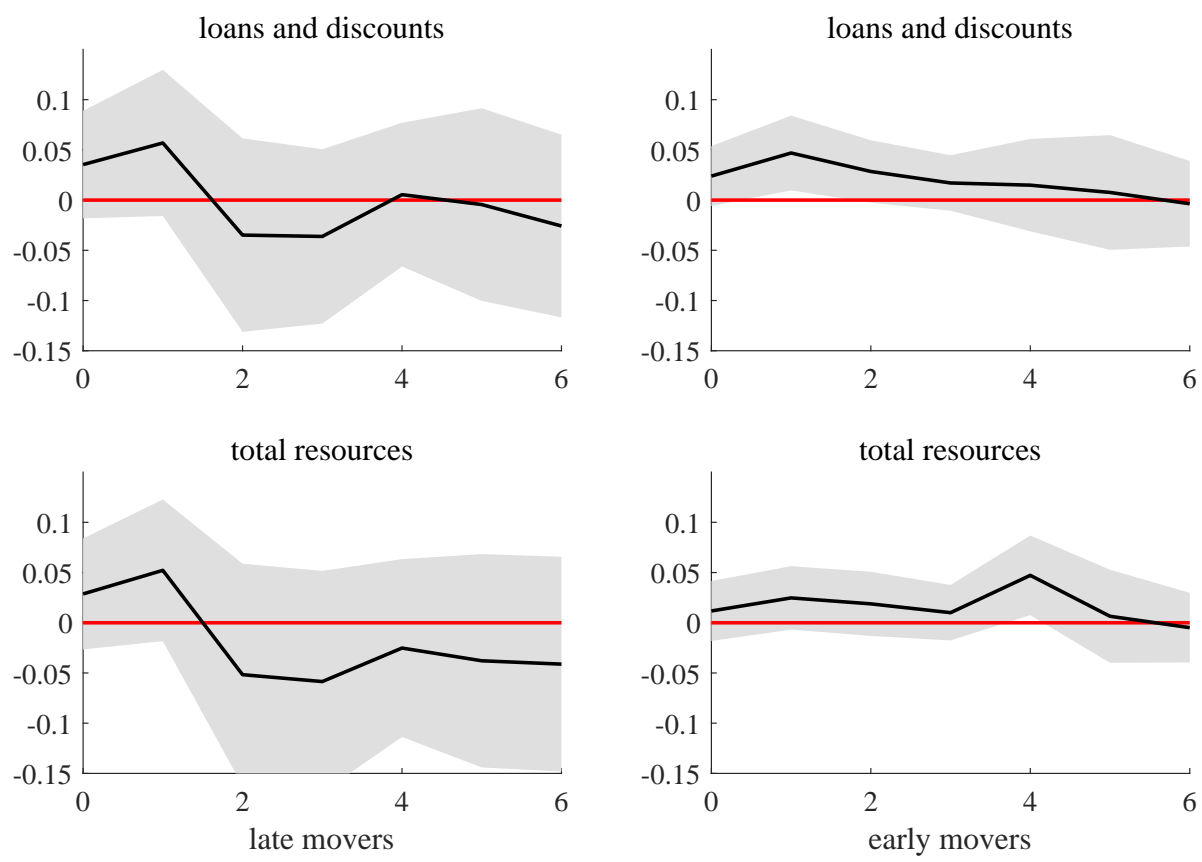

Figure 22: Same IRFs as Figure 21, separating cities who imposed closings early (before the median date) and late. 


\section{High-frequency city-level evidence}

The evidence presented here comes from Bradstreet's, A Journal of Trade, Finance, and Public Economy. Every issue, published on Saturday, abounded with information of all kinds. The section "Measures of movements" included some of the information used above, such as the data on coal mines and business failures. The section "Financial, money and exchange" reported bank clearings, that is, the volumes of net clearings through the local clearing houses on a weekly basis.

\section{Business failures}

Bradstreet reported every week the number of business failures at the regional level (six regions of the US). I aggregate the weekly city-level data into the corresponding regions to try and detect any impact of mortality. ${ }^{18}$ Then I compute a local projection of the weekly change in business failures in each region on the region's mortality as follows:

$$
\Delta \text { fail }_{i, t+h}=\beta_{h} m_{i, t}+\sum_{k=1}^{8} \gamma_{k} \Delta \text { fail }_{i, t-k}+\sum_{k=1}^{3} \delta_{k} m_{i, t-k}+a_{i}+b_{t}, \quad h=0, \ldots 16
$$

Figure 23 shows some impact from mortality, although never quite significant and equally positive or negative. The magnitudes, in any event, are very small: the impact of one death per million is on the order of $1 \mathrm{e}-3$ failures per million, or 0.1 failures for the US population (100 million). The peak weekly mortality at the national level was on the order of 600 per million: hence $1 \mathrm{e}-3$ on the vertical scale of Figure 23 means 60 failures nationally.

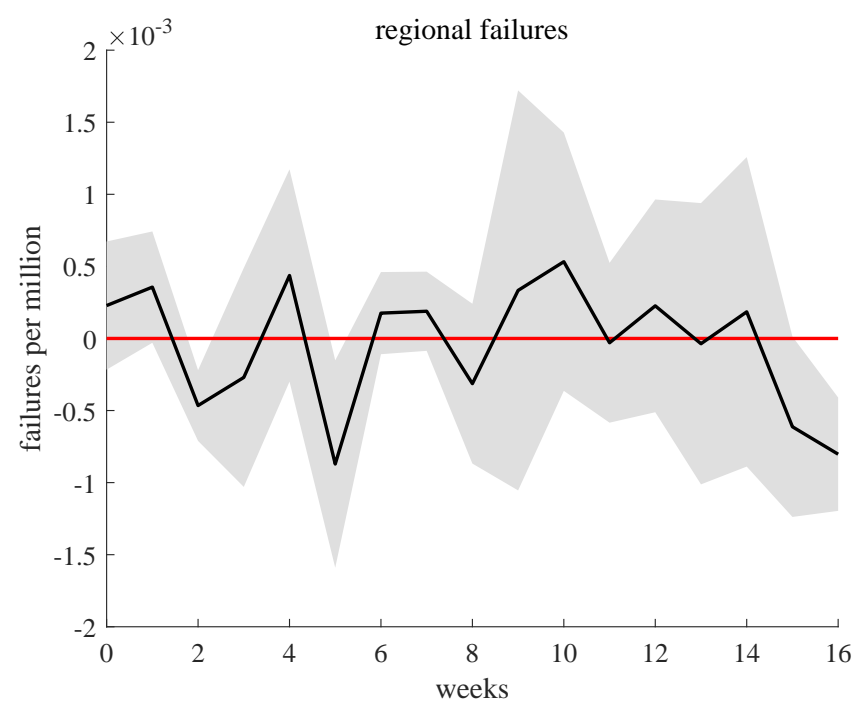

Figure 23: Response of the number of failures reported by Bradstreet to city excess P\&I mortality aggregated at the regional level.

\footnotetext{
${ }^{18}$ The mortality proxy for each region is the population-weighted average of per 100,000 mortality rates of cities in that region. The regions are defined in terms of states, but we have state-level mortality at the monthly frequency only.
} 


\section{Mortality, closings, and business conditions}

Another feature of Bradstreet's was the "trade at a glance" box at top right of the front page, which reported on various cities' business conditions in "wholesale and jobbing trade," retail, manufacturing and industry, and collections on commercial debt. ${ }^{19}$ Condition in each city and activity was described by a single adjective, with additional remarks for the city as a whole. The most common adjectives are shown in Table 4, as I have classified them into five groups. This sorting is of course discretionary, but in each class one adjective is overwhelmingly common: in effect, the hierarchy between "good," "fair," "quiet," "slow," and "restricted" is the backbone of my classification. Each class is assigned a score from 5 to 1, and an average across the four activity categories yields an indicator of business condition for each week in each city (the list of cities is in the Appendix). The number of occurrences reported in Table 4 suggest that, between July 1918 and June 1919, business conditions were rarely worse than "quiet." This is consistent with the results of the previous section about aggregates, although on its own it might not be fully convincing. In a war, and even in the absence of outright censorship, patriotic ardor could have biased reporters and editors toward more cheerful adjectives.

\begin{tabular}{lrrrr}
\hline & wholesale & retail & manufacturing & collections \\
\hline good $(72 \%)$, active & 1059 & 968 & 1170 & 1042 \\
\hline fair $(98 \%)$, better, & 503 & 569 & 243 & 548 \\
\hline $\begin{array}{l}\text { quiet }(57 \%), \text { steady, quieter, } \\
\text { improving, increasing }\end{array}$ & 158 & 170 & 152 & 15 \\
\hline $\begin{array}{l}\text { slow (55\%), dull, slower, } \\
\text { irregular, uncertain }\end{array}$ & 35 & 47 & 69 & 104 \\
\hline $\begin{array}{l}\text { restricted (33\%), reduced, curtailed, } \\
\text { backward, poor, unsettled }\end{array}$ & 5 & 5 & 72 & 7 \\
\hline
\end{tabular}

Table 4: Classification of adjectives describing business conditions in Bradstreet with number of occurrences, July 1918 - June 1919. The most common adjectives in each group is in bold and followed by its share in parentheses.

To analyze the impact of the epidemic and of interventions on the economy, I use the following variables. The first, taken from Markel et al. (2007) is an indicator of the week in which the city's P\&I mortality first reached a threshold level defined as twice the baseline level for that week of the year. The second is an indicator of the week in which theater and other closings were imposed in that city (see Appendix 1). I carry out local projections of mortality, log of bank clearings excluding New York deflated by the retail cost of food $(C l)$, and business conditions $(B C)$ on these two shocks. Specifically:

$$
\begin{aligned}
& \operatorname{mort}_{i, t+h}=\beta_{h} S_{i, t}^{j}+a_{i}+b_{t}, \quad h=0, \ldots 16, \quad j=1,2 \\
& B C_{i, t+h}=\beta_{h} S_{i, t}^{j}+\sum_{k=1}^{8} \gamma_{k} B C_{i, t-k}+a_{i}+b_{t}, \quad h=0, \ldots 16, \quad j=1,2 \\
& \log \left(C l_{i, t+h}\right)=\beta_{h} S_{i, t}^{j}+\sum_{k=1}^{8} \gamma_{k} \log \left(C l_{i, t-k}\right)+a_{i}+b_{t}, \quad h=0, \ldots 16, \quad j=1,2, \quad i \neq \mathrm{NYC}
\end{aligned}
$$

\footnotetext{
${ }^{19}$ Correia, Luck, and Verner (2020, June version) use the same data.
} 
where $\left\{S_{i, t}^{j}\right\}_{j=1,2}$ is a dummy variable that is zero in all weeks except the one in which (1) the mortality threshold was reached, or (2) closings were imposed.
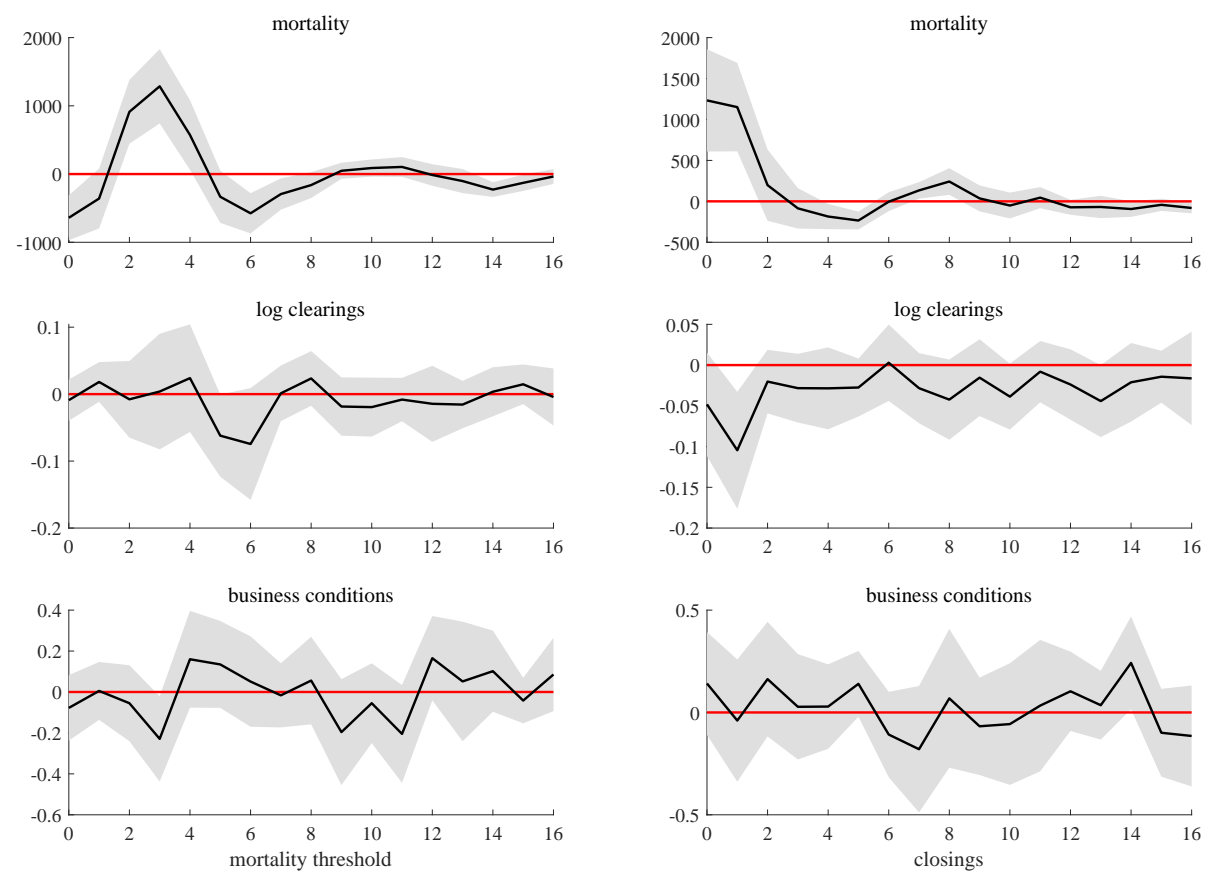

Figure 24: Impulse response functions from local projections on onetime shocks (mortality threshold and closings).

Figure 24 shows the impulse responses from the two shocks. Mortality rises after the epidemic threshold is reached, then falls back. It rises in the week in which closings begin, but falls within two weeks: this is of course not a sign that closings cause a contemporaneous increase in mortality, but rather that closings probably respond to such an increase. The volume of transactions is affected about five weeks after the epidemic shock, and a week after closings by about $10 \%$, but not any further. Business conditions show a weakening three weeks after the epidemic hits and a week after closings. In short, however imperfect our measures, they do pick up some impact of the epidemic and the closings on economic activity.

To evaluate the impact of the speed of intervention on economic outcomes, I split the sample of cities depending on the (possibly negative) time elapsed between reaching the threshold of epidemic and the date of closing. Early movers are those for whom that elapsed time is below the median. Figures 25 and 26 compare early movers and late movers). The response of mortality is very similar in shape but quite different in scale: it is much larger for the early movers, strongly suggesting that moving early or late was endogenous to the epidemic. Clearings do not seem to respond either to the epidemic shock or to the closing shock for early movers. By contrast, late movers have a sizeable contraction in payments five weeks after the epidemic shock and after the closing shock: the response that we noticed for the cities as a whole comes entirely from the later movers. For business conditions, the cities that would turn out to move late end up slightly more affected by the mortality shock three weeks later. The response of business conditions to closings seems slightly worse for early movers. The size of the standard error bands, of 

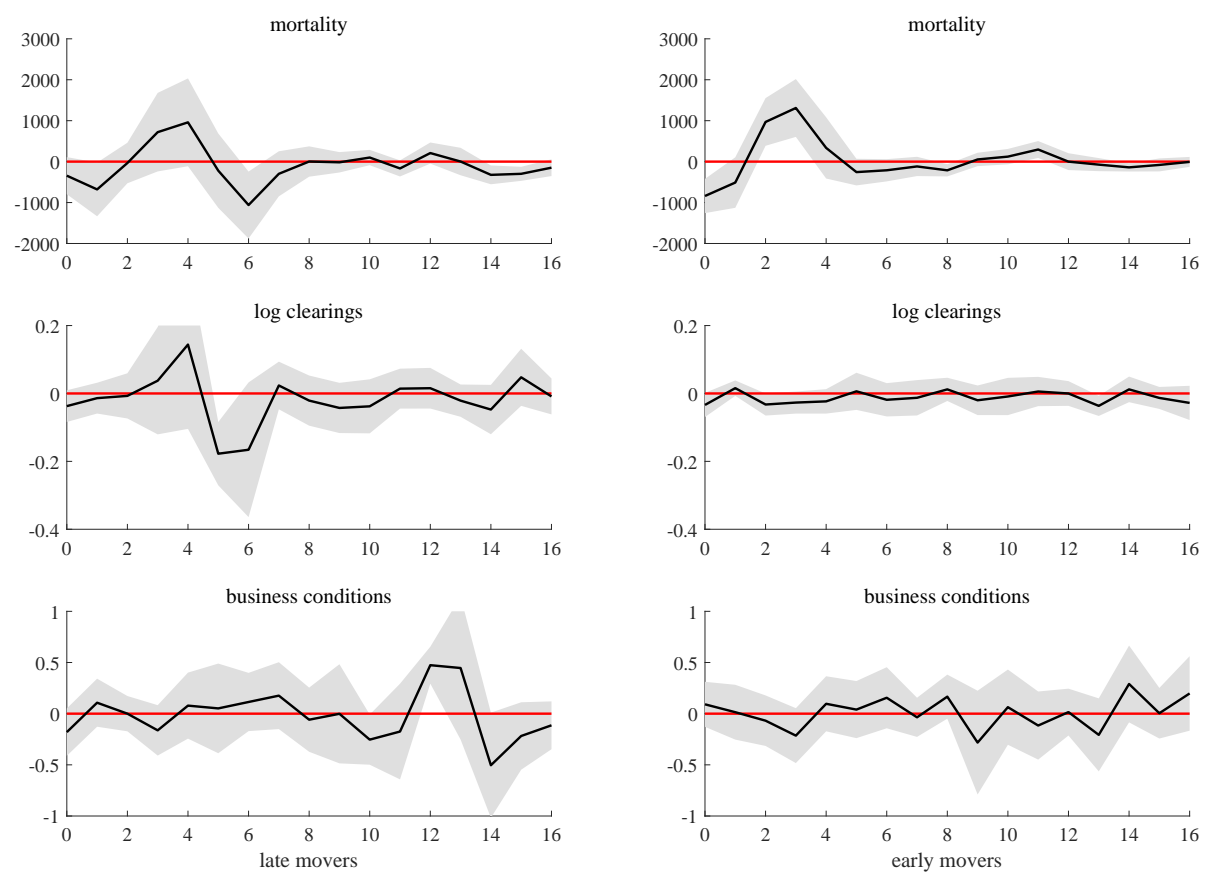

Figure 25: IRFs from local projections, response to the mortality threshold.
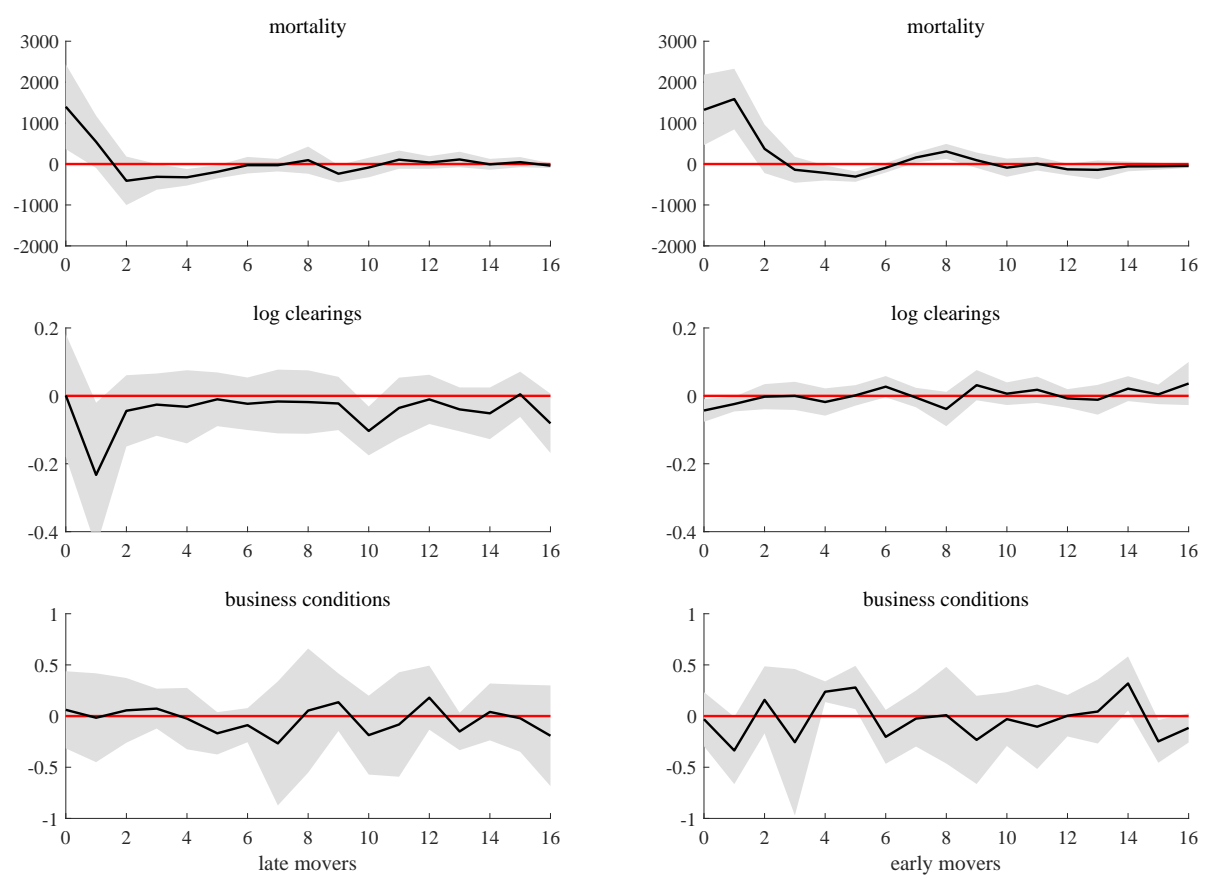

Figure 26: IRFs from local projections, response to closings. 
course, make such nuances subject to caution, and in any event the impacts are transient.

\section{A lightly structural estimation}

The endogeneity of the closings to the epidemic is intuitively obvious, easily documented in contemporary sources and strongly suggested by the results of the previous section. Dependence of the closings on other pre-determined variables that could be correlated with economic outcomes is also plausible. This creates identification problems when trying to measure the impact of closings on the epidemic and on economic activity (Barro 2020).

$\mathrm{We}^{20}$ do not tackle endogeneity head-on by modeling the decision to close. Instead, the approach in this section is "lightly" structural: we use distinguish the dynamics within each regime and see how closings change them.

To this effect we use the SIR (susceptible-infected-recovered) model of epidemiology as adapted by economists (Atkeson 2020; Alvarez, Argente, and Lippi 2020; Eichenbaum, Rebelo, and Trabandt 2020). Appendix 2 presents a very simple SIR model in which susceptible agents $(S)$ are infected by infected agents $(I)$ at a rate $\beta$, infected agents become "recovered" agents $(R)$ at a rate $\gamma$, of which a fraction $\phi$ are in fact deaths. The cumulated deaths is $D_{t}$, current mortality is the change in $D_{t}$ or $\Delta D_{t}$. In addition, economic activity is a linear function of both the number of susceptible and recovered $(S+R)$ and of the infected $I$, the latter with possibly lower productivity. In the model NPIs (closings) reduce the productivity of both types of agents, but also change the dynamics of the epidemic by reducing the rate at which susceptible agents are infected. Appendix 2 shows how to express mortality and economic activity and as a linear function of future, current, and past mortality, as follows:

$$
\begin{aligned}
\Delta D_{t} & =\left(1+\beta_{t-2}-\gamma\right) \Delta D_{t-1}-\frac{\beta_{t-2}}{\phi \gamma}\left(\Delta D_{t-1}\right)^{2}-\frac{\beta_{t-2}}{\phi} D_{t-2} \Delta D_{t-1} \\
Y_{t} & =w_{t}-w_{t} D_{t}-\frac{w_{t} w_{t}^{i}}{\phi \gamma} \Delta D_{t+1}
\end{aligned}
$$

Equation (1) captures the dynamics of mortality, equation (2) those of economic activity. The effect of NPIs appears in the time subscript on the infection rate $\beta$ and the productivities $w$ and $w^{i}$ of healthy and infected. NPIs affect deaths (which is what we measure, rather than infections) with a 2-period lag. ${ }^{21}$ In the equation for activity the lead of mortality appears as regressor because the current number of infected $I_{t}$, which affects current output, translates into future mortality $\Delta D_{t+1}$. If the NPI affects infections today, it will affect output today and mortality next period.

The regression results are shown in Table 5.

The dynamics of mortality conform well to the SIR model, with coefficients of the right sign and magnitude. Indeed, the values of the SIR model that one can back out are quite reasonable: the case fatality rate is $7-8 \%$, the rate at which infected recover per week $(\gamma)$ is 0.5 , in line with contemporary descriptions of the course of the disease (Brundage and

\footnotetext{
${ }^{20}$ The change in pronoun reflects the contributions of my colleague Gadi Barlevy.

${ }^{21}$ According to Brundage and Shanks $(2008,1194)$, median time from illness onset to death was 7-10 days.
} 


\begin{tabular}{|c|c|c|c|c|c|c|}
\hline \multirow{2}{*}{$\begin{array}{l}\text { dependent variable: } \\
\Delta D_{t-1}\end{array}$} & \multicolumn{2}{|c|}{$\Delta D_{t}$} & \multicolumn{2}{|c|}{ conditions } & \multicolumn{2}{|c|}{ clearings } \\
\hline & $\begin{array}{c}1.781^{* * *} \\
(0.095)\end{array}$ & $\begin{array}{r}2.022^{* * *} \\
(0.168)\end{array}$ & & & & \\
\hline$\left(\Delta D_{t-1}\right)^{2}$ & $\begin{array}{r}-8.83 \mathrm{e}-05^{* * *} \\
(1.28 \mathrm{e}-05)\end{array}$ & $\begin{array}{r}-9.68 \mathrm{e}-05^{* * *} \\
(1.58 \mathrm{e}-05)\end{array}$ & & & & \\
\hline$D_{t-2} \Delta D_{t-1}$ & $\begin{array}{r}-4.40 \mathrm{e}-05^{* * *} \\
(3.97 \mathrm{e}-06)\end{array}$ & $\begin{array}{r}-4.92 \mathrm{e}-05^{* * *} \\
(6.75 \mathrm{e}-06)\end{array}$ & & & & \\
\hline $\mathbf{1}_{t-2} \Delta D_{t-1}$ & $\begin{array}{r}-0.691^{* * *} \\
(0.124)\end{array}$ & $\begin{array}{r}-0.666^{* * *} \\
(0.218)\end{array}$ & & & & \\
\hline $\mathbf{1}_{t-2}\left(\Delta D_{t-1}\right)^{2}$ & $\begin{array}{r}7.19 \mathrm{e}-05^{* * *} \\
(1.34 \mathrm{e}-05)\end{array}$ & $\begin{array}{r}6.64 \mathrm{e}-05^{* * *} \\
(1.69 \mathrm{e}-05)\end{array}$ & & & & \\
\hline $\mathbf{1}_{t-2} D_{t-2} \Delta D_{t-1}$ & $\begin{array}{l}1.37 e-05^{* *} \\
(6.68 \mathrm{e}-06)\end{array}$ & $\begin{array}{r}1.52 \mathrm{e}-05 \\
(1.17 \mathrm{e}-05)\end{array}$ & & & & \\
\hline$\Delta D_{t+1}$ & & & $\begin{array}{r}-2.82 \mathrm{e}-05 \\
(2.75 \mathrm{e}-05)\end{array}$ & $\begin{array}{r}-5.30 \mathrm{e}-05^{* * *} \\
(2.23 \mathrm{e}-05)\end{array}$ & $\begin{array}{r}-1.15 \mathrm{e}-05^{* *} \\
(5.42 \mathrm{e}-06)\end{array}$ & $\begin{array}{r}-1.04 \mathrm{e}-05^{* * *} \\
(3.61 \mathrm{e}-06)\end{array}$ \\
\hline$D_{t}$ & & & $\begin{array}{r}4.34 \mathrm{e}-06 \\
(6.18 \mathrm{e}-06)\end{array}$ & $\begin{array}{r}7.50 \mathrm{e}-07 \\
(4.11 \mathrm{e}-06)\end{array}$ & $\begin{array}{r}7.36 \mathrm{e}-07 \\
(2.65 \mathrm{e}-06)\end{array}$ & $\begin{array}{r}1.34 \mathrm{e}-07 \\
(1.31 \mathrm{e}-06)\end{array}$ \\
\hline $\mathbf{1}_{t} \Delta D_{t+1}$ & & & $\begin{array}{r}-2.72 \mathrm{e}-05 \\
(5.67 \mathrm{e}-05)\end{array}$ & $\begin{array}{r}2.42 \mathrm{e}-06 \\
(5.97 \mathrm{e}-05)\end{array}$ & $\begin{array}{r}5.99 \mathrm{e}-06 \\
(9.83 \mathrm{e}-06)\end{array}$ & $\begin{array}{r}9.99 \mathrm{e}-06 \\
(7.96 \mathrm{e}-06)\end{array}$ \\
\hline $\mathbf{1}_{t} D_{t}$ & & & $\begin{array}{r}-1.98 \mathrm{e}-05 \\
(1.32 \mathrm{e}-05)\end{array}$ & $\begin{array}{r}-2.85 \mathrm{e}-06 \\
(9.37 \mathrm{e}-06)\end{array}$ & $\begin{array}{r}-2.45 \mathrm{e}-06 \\
(4.56 \mathrm{e}-06)\end{array}$ & $\begin{array}{r}2.49 \mathrm{e}-06 \\
(3.09 \mathrm{e}-06)\end{array}$ \\
\hline $\mathbf{1}_{t}$ & & & $\begin{array}{r}0.081 \\
(0.274)\end{array}$ & $\begin{array}{l}-0.096 \\
(0.238)\end{array}$ & $\begin{array}{r}-0.039 \\
(0.110)\end{array}$ & $\begin{array}{r}-0.131 \\
(0.0911)\end{array}$ \\
\hline conditions $(t-1)$ & & $\begin{array}{r}-16.59 \\
(61.33)\end{array}$ & & $\begin{array}{l}0.315^{* * *} \\
(0.0604)\end{array}$ & & \\
\hline conditions $(t-2)$ & & & & $\begin{array}{r}0.109^{*} \\
(0.0625)\end{array}$ & & \\
\hline conditions $(t-3)$ & & & & $\begin{array}{r}-0.0226 \\
(0.0348)\end{array}$ & & \\
\hline conditions $(t-4)$ & & & & $\begin{array}{r}0.0844 \\
(0.0545)\end{array}$ & & \\
\hline $\log$ real clearings $(t-1)$ & & $\begin{array}{r}0.813 \\
(181.6)\end{array}$ & & & & $\begin{array}{l}0.394^{* * *} \\
(0.0482)\end{array}$ \\
\hline $\log$ real clearings $(t-2)$ & & & & & & $\begin{array}{r}0.0783 \\
(0.0614)\end{array}$ \\
\hline $\log$ real clearings $(t-3)$ & & & & & & $\begin{array}{l}-0.00817 \\
(0.0432)\end{array}$ \\
\hline $\log$ real clearings $(t-4)$ & & & & & & $\begin{array}{l}0.161^{* * *} \\
(0.0331)\end{array}$ \\
\hline constant & $\begin{array}{r}538.1^{* * *} \\
(185.7)\end{array}$ & $\begin{array}{r}89.92 \\
(1,008)\end{array}$ & $\begin{array}{r}4.994^{* * *} \\
(0.127)\end{array}$ & $\begin{array}{r}2.679^{* * *} \\
(0.321)\end{array}$ & $\begin{array}{l}5.584^{* * *} \\
(0.0469)\end{array}$ & $\begin{array}{r}2.141^{* * *} \\
(0.484)\end{array}$ \\
\hline observations & 1,499 & 676 & 809 & 583 & 900 & 900 \\
\hline number of cities & 43 & 24 & 29 & 25 & 25 & 25 \\
\hline
\end{tabular}

Table 5: Panel regressions of mortality $\Delta D$, business conditions index, and log deflated bank clearings on leads and lags of mortality and cumulative mortality $(D)$ and a dummy $\mathbf{1}_{c t}=1$ if businesses were closed during week $t$. Time and city fixed effects included; robust standard errors in parentheses. ${ }^{* * *} p<0.01,{ }^{* *} p<0.05,{ }^{*} p<0.1$.

Shanks 2008), the rate of infection ( $\beta$ ) is about 1.3 to 1.5 , yielding a value of $R=\beta / \gamma \simeq$ $2.6-3.0$, consistent with the findings of the modern epidemiological literature. ${ }^{22}$. Closings affect mortality as predicted by reducing $\beta$ to $0.6-0.8$, which brings down the effective $R$ to $1.2-1.7$, approximately a half: a substantial impact but not enough to stop the epidemic.

The regressions of economic outcomes are shown with and without lags. ${ }^{23}$ Future mortality (as proxy of current infections) clearly affects current output negatively, which, in the model, means that the productivity of the infected is lower than the susceptible,

\footnotetext{
${ }^{22}$ Mills, Robins, and Lipsitch (2004) find $R$ to be "approximately $2-3$ " when estimating a SEIR model, without NPIs, on the same data.

${ }^{23}$ For business conditions, requiring lags reduces the number of observations because Bradstreet did not report continuously for all cities. For clearings, the significance of the fourth (weekly) lag is robust and likely due to monthly seasonality in payments.
} 
because they either work less or not at all, as we saw in the coal mining data. From this coefficient, the constant, and the coefficients of the mortality equation one can back out a loss of productivity of the infected of $60 \%$ (using the business conditions equation), which seems plausible given the evidence on the labor supply effect of the epidemic. NPIs attenuate that channel, i.e., reduce the coefficient on $\Delta D_{t+1}$ but the effect is not well estimated: for business conditions, the point estimate of the effect is about $5 \%$. Likewise the direct effect of NPIs on economic activity, which should be picked up by the closings dummy, is small and insignificant, but both clearings and business conditions would suggest an intensity of lockdown of about $5 \% .{ }^{24}$ The coefficients on the current cumulative mortality are not significant and of the wrong sign, suggesting that the (permanent) loss of workers is not the main channel through which activity is affected.

In sum, the short-run dynamics of the epidemic allow us to measure the impact of the closings on the epidemic, which they slow but do not stop. The direct impact of the closings on economic activity is small if it exists, while the indirect impact through a reduction in incapacitated (infected) workers is significant. If we take the point estimates at face value, NPIs were not very costly and were compensated by the mitigation of the negative labor shock. This mitigation, of course, is peculiar to the influenza which affected prime-age workers disproportionately, and might not be expected in other epidemics.

\section{Prices}

A final word on the behavior of prices: as mentioned above, the US was under partial price controls during the War, and the controls were removed on Feb. 1, 1919. Prices actually fell, as government stopped buying large quantities of raw materials at guaranteed prices. The effect is shown in Figure 27.

Interestingly, there is a hint of cross-sectional impact of the epidemic on food prices. I first regress each city's 12-month inflation from September 1918 (to set the comparison frame on the onset of the epidemic) to August 1919 on inflation from September 1918 to August 1919. Figure 28 plots the residual of that regression on mortality. There is a mild negative relationship: a city experiencing half as much again as the median cumulative mortality would see a fall in food inflation of about $3 \%$.

\section{8 and 2020}

A century elapsed between the two pandemics. The world has changed and circumstances are different. Before concluding, I recall some of these differences, not because they make the 1918 experience irrelevant, but because they may help us understand why the pandemic had limited short-run effects.

The US economy has changed. In 1914, the population was roughly evenly split between rural and urban, whereas the ratio is 5 to 1 now. Agriculture accounted for $33 \%$ of employment, and manufacturing another $28 \%$; the shares today at $2 \%$ and $8 \%$. Home

\footnotetext{
${ }^{24}$ Although the assumption of quadratic matching technology delivers a "double benefit" of lockdown (Acemoğlu et al. 2020, fn 6) ( $\beta$ is reduced to $\beta \theta^{2}$ ), this estimate is too low to match the reduction in half of $\beta$.
} 


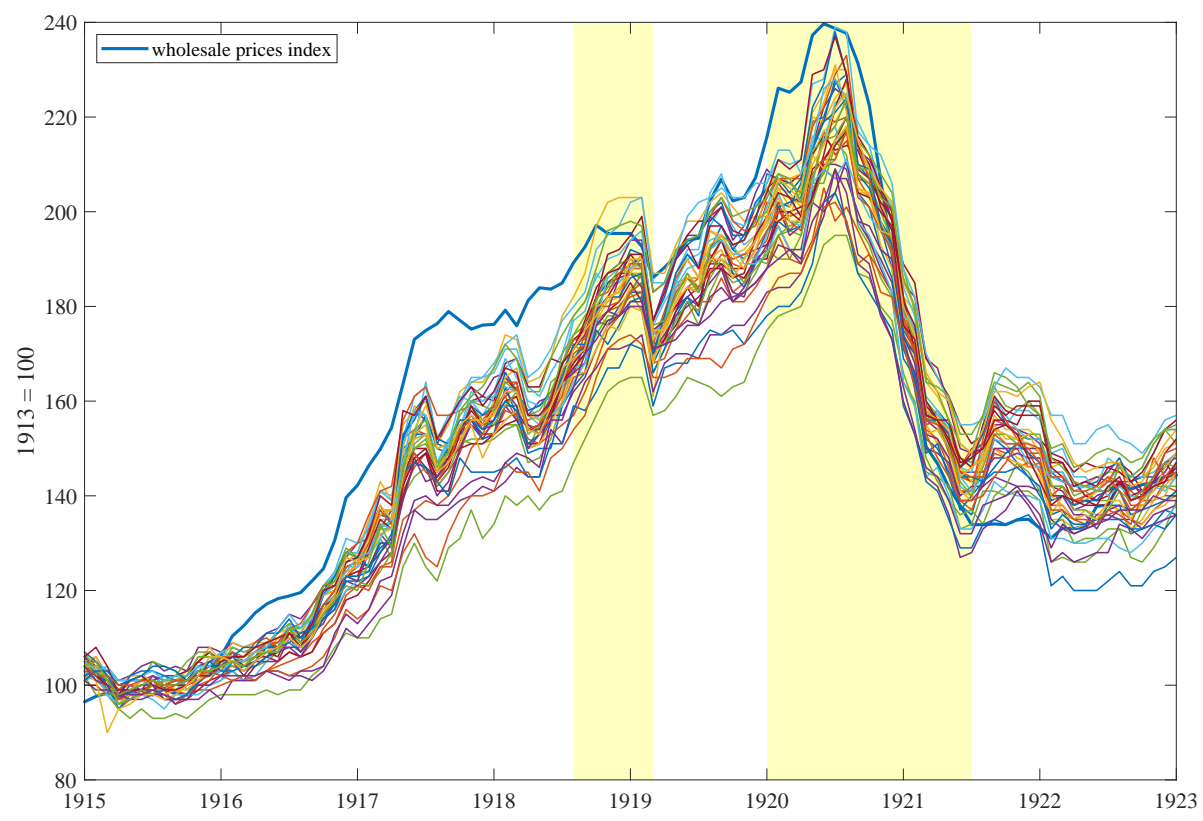

Figure 27: US wholesale price index and retail cost of food in 41 US cities. Source: Bureau of Labor Statistics $(1929,38-41)$ and Bureau of Labor Statistics $(1923,36-43)$.

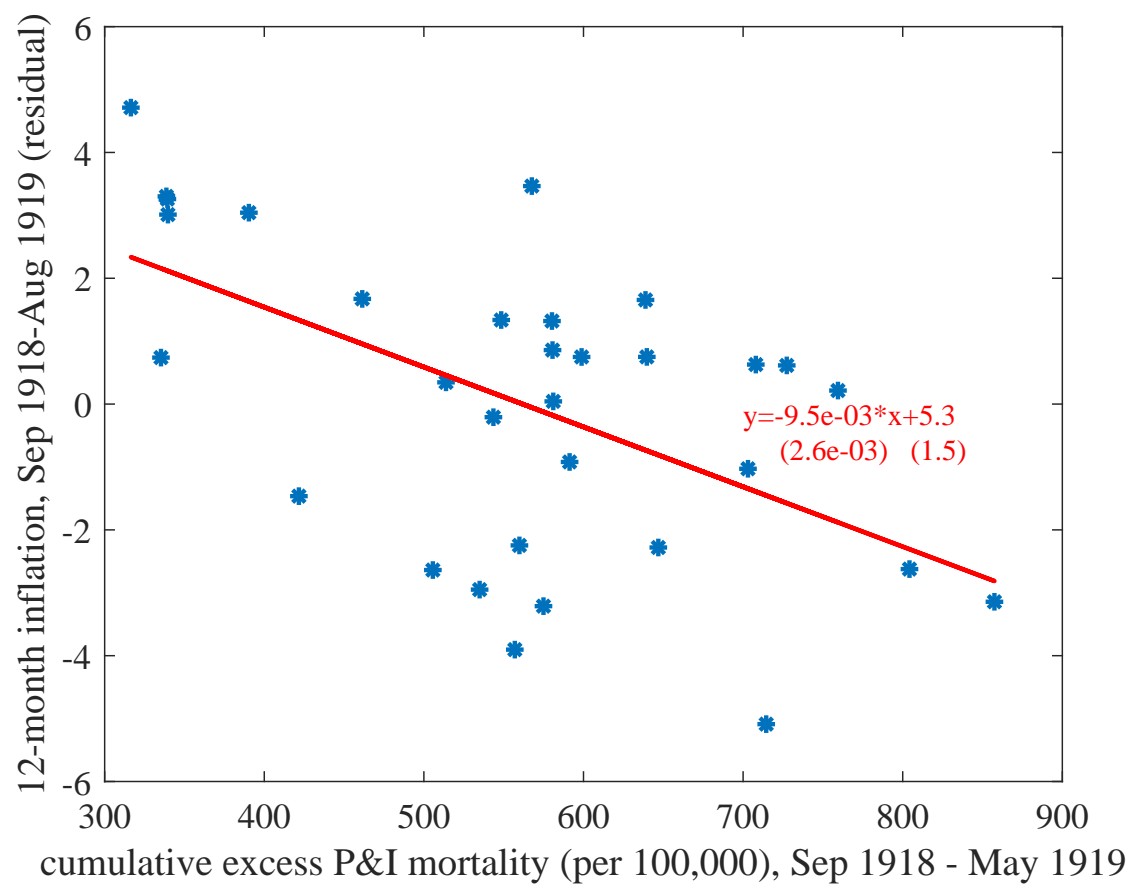

Figure 28: Cumulative excess P\&I mortality and change in inflation in 32 US cities. 


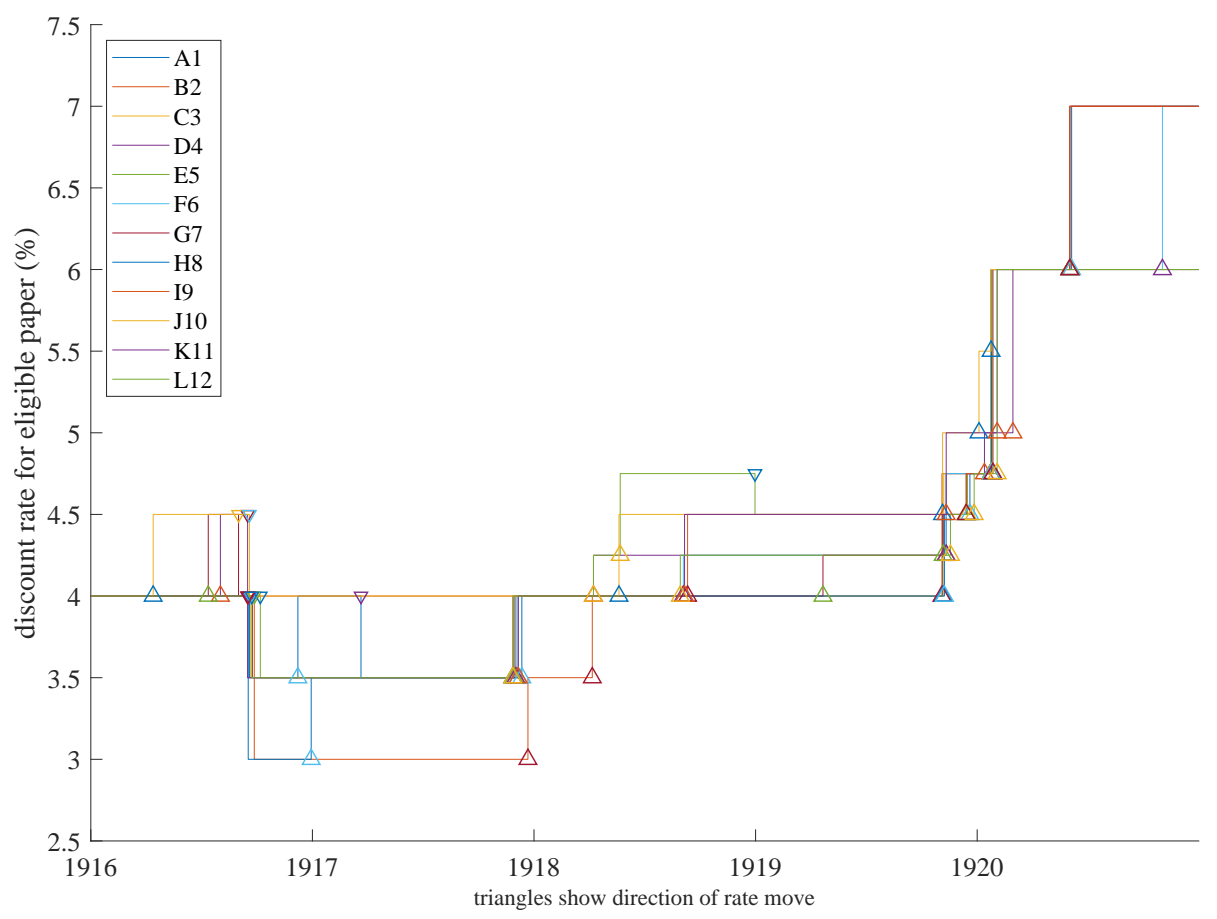

Figure 29: Federal Reserve Banks' discount rates on eligible paper, Jan 1916 - Dec 1920. Source: Federal Reserve Board (1943).

production probably accounted for a much larger share of output than today. The size of the Federal government was about $1 \%$ of GDP, the Federal Reserve System had barely begun to function.

By the time of the pandemic, of course, the United States had entered World War I (in April 1917) and the Federal Government was running a deficit of $20 \%$ of GDP and increasing the debt from virtually nothing to $36 \%$ of GDP. Two and a half million men (five times the casualties of the pandemic) were in the armed forces: in camps in the US, on ships, or in trenches in France. The US economy, which had already been producing for the Allies, had moved to war production, and government contracts and regulations determined quantities and prices in many sectors, leaving little scope for animal spirits.

The Federal Reserve System's policy was to support the Treasury borrowing: "the Federal Reserve became to all intents and purposes the bond-selling window of the Treasury, using its monetary powers almost exclusively to that end" and this "subservience to the Treasury" lasted until mid-1919.(Friedman and Schwartz 1963, 216,225).

Practically, this meant that the Fed lent at banks at below market rates to support the purchases of government debt (Liberty Loans or short-term Treasury certificates) by them or their customers (Meltzer 2010, 1:84-90). This gave Fed leaders the appearance of not directly monetizing the debt (poor form under gold standard orthodoxy) but achieving the same purpose.

Four Liberty Loans and one Victory Loan were issued from 1917 to 1919 at rates set by Congress, rising from $3.5 \%$ to $4.75 \%$. The Third Liberty Loan, at $4.5 \%$, had concluded in May 1918, and the Fourth was floated at $4.25 \%$ in the midst of the epidemic, in September 1918. The Reserve Banks saw to it that the bonds remained close to par and lent at 


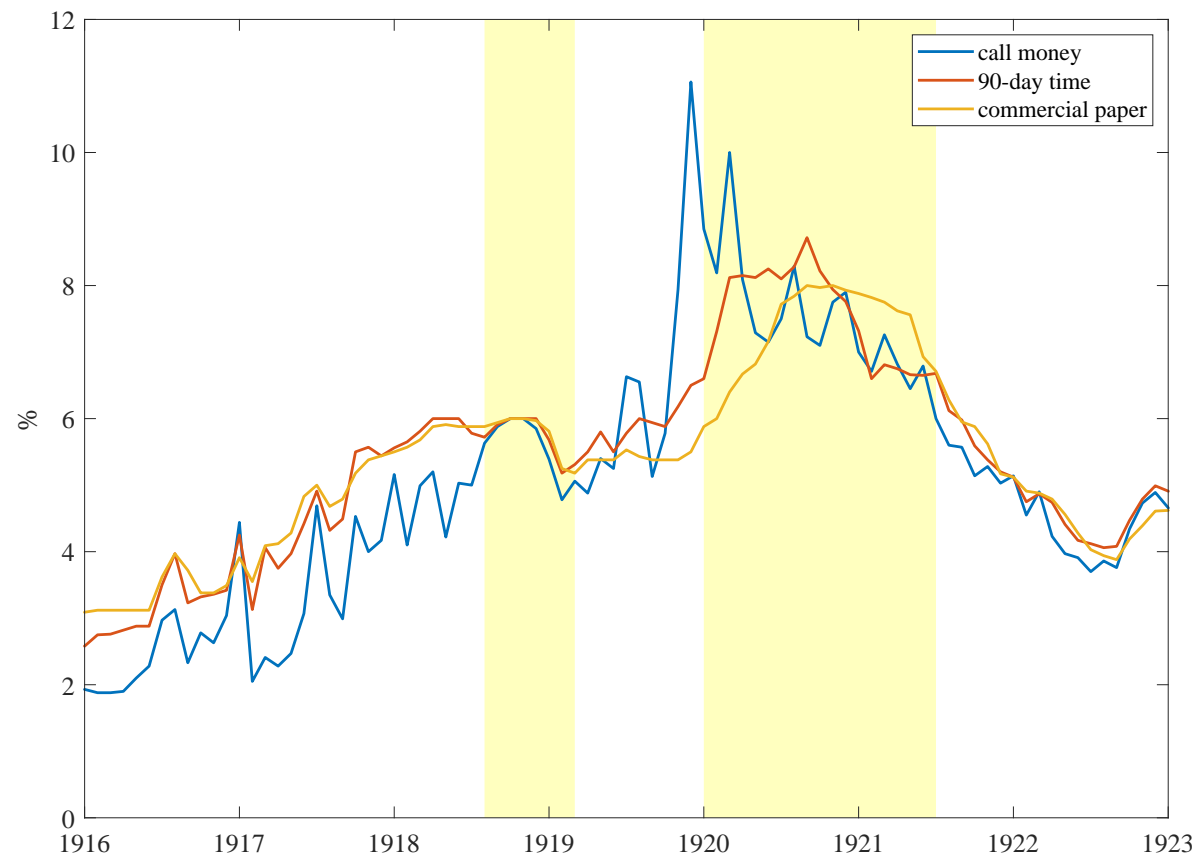

Figure 30: Commercial short-term interest rates in New York, monthly, Jan 1916 - Dec 1922. Source: Macaulay (1938, A142-61).

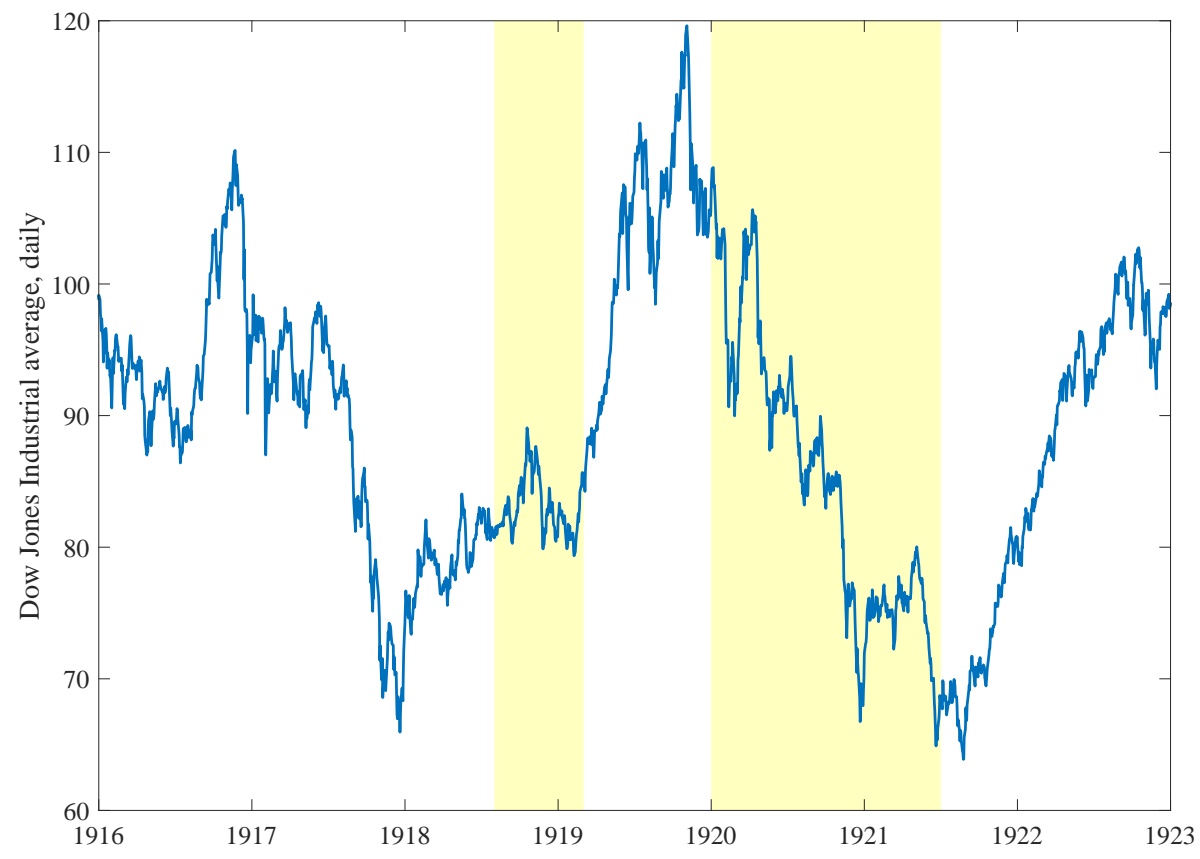

Figure 31: Dow-Jones industrial stocks index, daily, Jan 1916 - Dec 1921. Source: Bloomberg.

preferential discount rates of 4 to $4.5 \%$.

The interest rates ${ }^{25}$ set by the Fed are shown in Figure 29. Before the pandemic rates ranged from 4 to $4.75 \%$. Over the following twelve months six banks changed their rates, all but one upward. ${ }^{26}$ Only Richmond cut its rate on Dec. 30, 1918, and modestly at that:

\footnotetext{
${ }^{25}$ The plural is requisite because each of the twelve Banks set its own rate.

${ }^{26}$ San Francisco raised from $4 \%$ to $4.25 \%$ on Aug. 29 ; Atlanta from $4 \%$ to $4.25 \%$ on Sep. 3; Dallas from $3.5 \%$ to $4 \%$ on Sep. 5; Minneapolis from $4 \%$ to $4.5 \%$ on Sep. 10; Chicago from $4 \%$ to $4.25 \%$ on Apr. 21, 1919.
} 
from $4.75 \%$ to $4.5 \%$. It is moreover apparent from the Fed's Annual Report that the main concern arising from the pandemic was its deleterious effect on floating the 4th Liberty Loan: the large rallies held to encourage patriotic saving could not be held, and banks didn't have the clerks to handle the paperwork.

Against this background of a serendipitously massive monetary and fiscal policy, financial markets displayed great equanimity during the pandemic. Figures 31 reminds us that the US stock market did quite well during the epidemic. From August 14, 1918, when the influenza's arrival in the US is first mentioned in newspapers, to October 18, when nationwide deaths peaked at 20,000 per week, the Dow Jones Industrial rose 9\%. Only in the second half of November, after the armistice, did it fall back to its summer level where it remained until it started climbing again in late February 1919, to gain 50\% in nine months. The 1920-21 recession cut the DJIA's value in half.

Figure 30 plots short-term commercial rates in New York. Call money rates are rates on short-term loans to finance stock holdings, the time money rates are 90-day, and the commercial paper is "choice 60-90 day two-name paper." All rates remain steady from July to October 1918 and begin to fall in November 1918, the month of the Armistice.

As in many previous graphs, the contrast with the recession of 1920-21 is striking, here with a very large spike in short-term interest rates caused by the Fed's sharp tightening in the face of mounting inflation. This, and the general wartime context, suggests that the stance of monetary and fiscal policy can matter even in the face of a pandemic.

\section{The severity of closings measured through reduced mobility}

Besides the accommodative monetary and fiscal environment, an important factor in 1918 was the severity of the measures taken to slow the progress of the epidemic.

The restrictions likely to impact economic activity directly were essentially closings of places of gatherings mandated by local authorities. The list varied somewhat, but almost always included theaters, movie theaters, bowling alleys, dance halls, and places of amusement in general. Saloons were not always included, and restaurants are rarely mentioned. Retail stores were not closed, although some cities like New York instituted staggered business hours to lessen crowding in public transportation. Outside of entertainment and saloons, businesses were not closed, nor were any restrictions placed on the movement of people or the sizes of gatherings.

The intensity of 1918 closings can be quantified with the same methods as those of today. Using the scoring method of Hale et al. (2020), no city's stringency rates higher than 45; by contrast, throughout April 2020 only four countries out of 177 rated below 45 .

One way to measure, or at least place an upper bound, on the intensity of closings is to measure their impact on mobility in urban areas. ${ }^{27}$ We have nothing like the big data used today (e.g., Gao et al. 2020) but we can use gross earnings of electric railway companies to measure variations in the use of public transportation. These companies ran both streetcars or trolleys (the equivalent of buses in our cities), and rapid transit which

\footnotetext{
${ }^{27}$ This is an upper bound because monthly data does not allow us to distinguish between the effect of closings per se from the endogenous response of agents avoiding contacts of their own volition.
} 
included elevated and subway lines. Monthly earnings reports are available for a number of companies in daily newspapers as well as services like the Standard corporation's Daily Revised or Poor's equivalent publication. Some companies combined the production and distribution of electricity with transportation activities, so I restrict attention to those that were only in the transportation business, as described in the Commercial and Financial Chronicle's Electric Railways triennial supplements. Inspection of the annual reports confirms that the gross earnings consist almost entirely from passenger revenues.

Figure 32 plots the monthly gross earnings for several such companies. All display a drop in revenues in October 1918, followed by an immediate rebound. For all the companies in the figure the fares are constant at least from August to November $1918 .^{28}$

Figure 33 relates the size of the dip visible in Figure 32 to each city's excess mortality. On the horizontal axis is mortality in each month of the epidemic (September through November 1918) in each city. On the vertical axis is the change in that month's earnings for each company. The figure shows the clear negative relation between mortality and earnings, which I interpret as a fall in ridership. The slope of the relationship, however, is not quite identical across cities, and it is not explained by differences in the duration of closings (represented by the diameter of the circles). For example, Philadelphia's closing lasted almost all October, but the decline of ten percent in that month is less pronounced than the one in San Francisco, which was closed only part of the month.

Whatever the variations across cities, the most severe downturn in ridership is in San Francisco, and it reaches 20 percent in November. Even if we attribute all of this effect to closings (as opposed to precautionary behavior of individuals), the closings of 1918 were thus much less restrictive than the lockdowns of 2020.

\section{Contemporary perceptions of trade-offs}

Why were the closings so limited? To answer this, we need to look at the pandemic from the perspective of contemporaries.

As the epidemic was hitting Chicago, William A. Evans, recent president of the American Public Health Association (see Benjamin, Fee, and Brown 2010) wrote in the Chicago Tribune (Oct. 6, 1918):

Influenza will sweep over the country as it did in 1891 and as it has always done. We cannot escape it, but we can spread the cases over several weeks instead of having them all lump together as they usually come when the epidemic attacks men in barracks. If the epidemic can be spread out to a moderate extent our hospitals' nurses and physicians can handle the situation.

In modern parlance, he advocated flattening the curve to avoid excess burden of the health care system. A similar view was expressed by the Milwaukee Health Commissioner soon after the epidemic:

\footnotetext{
${ }^{28}$ The fares that electric railway companies could charge were constrained by their franchises; typically the fare was 5 cents, dating from before the war. The rise in costs created big difficulties and the companies fought to raise their rates, but few were successful. The Boston Elevated increased its rate from 5 to 7 cents on August 1 , and to 8 cents on December 1.
} 


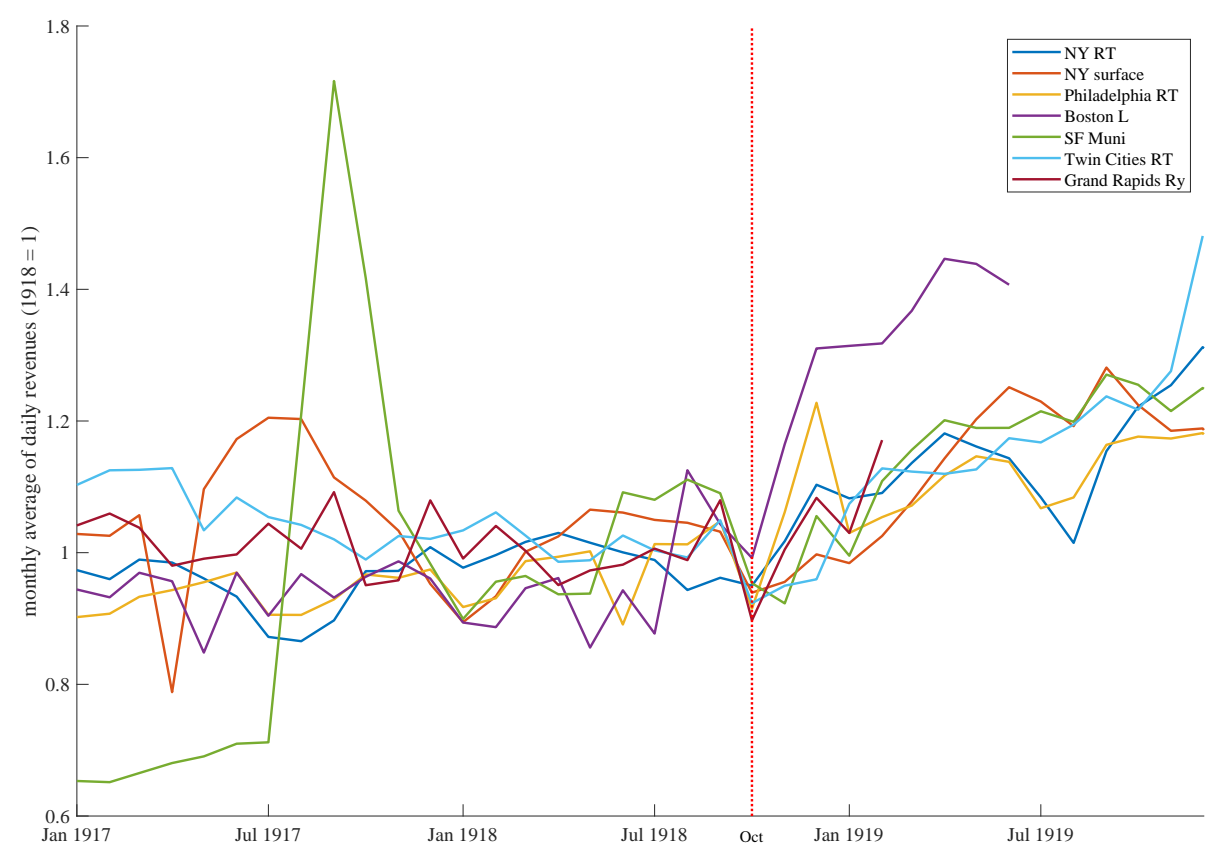

Figure 32: Gross revenues (passenger earnings for New York) for several American cities, monthly, Jan 1917 - Dec 1919. Each series is normalized by the 1918 average and adjusted for the number of days in each month. The vertical line indicates October 1918. Source: earnings reports in various newspapers, annual reports of the Public Service Commission for the First District of the State of New York.

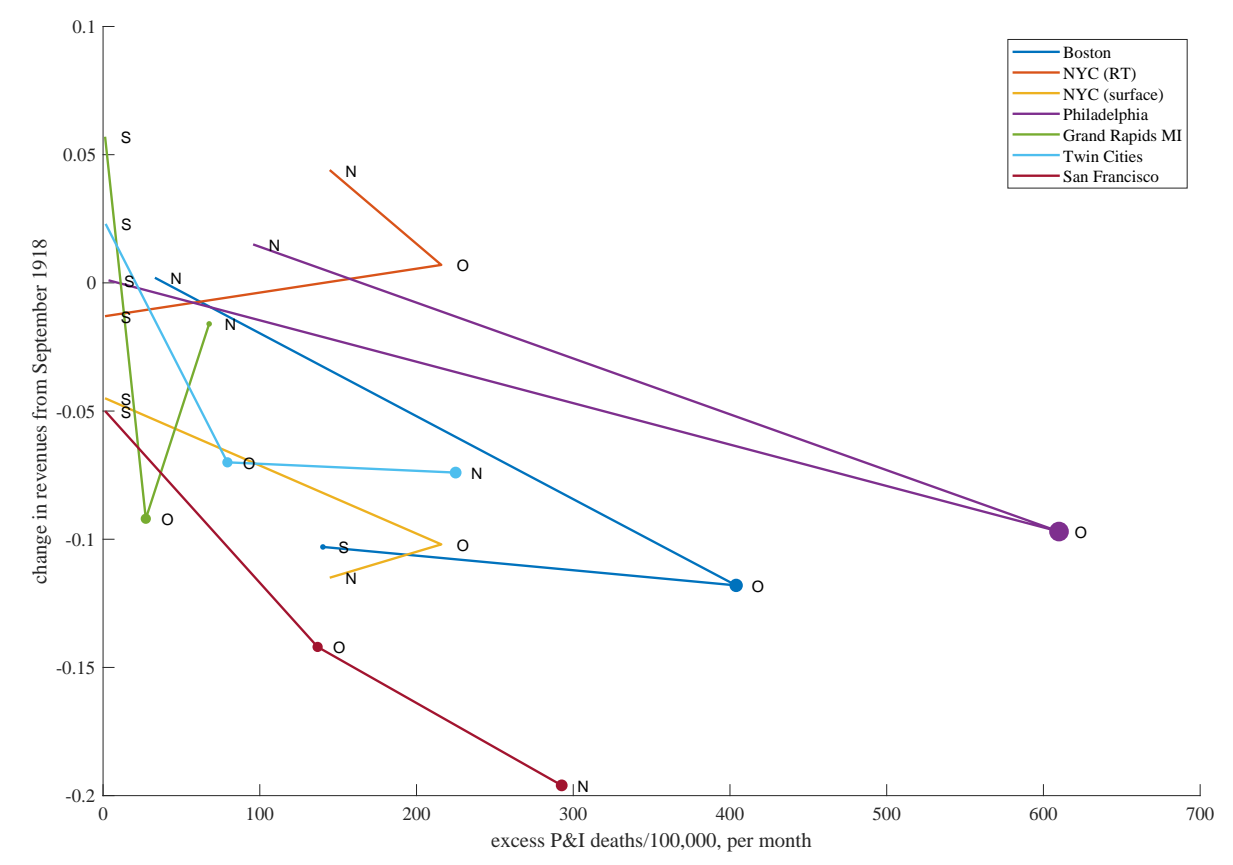

Figure 33: Decrease in electric railways gross revenues from August 1918 as a function of monthly excess P\& I mortality for the months of September, October, and November 1918 (the corresponding points are labeled $\mathrm{S}, \mathrm{O}, \mathrm{N}$ ). The diameter of the circles is proportional to the extent of closings during that month in that city. 
It must be recognized that the closing order could do no more than stagger the peak in the incidence of the infection. By avoiding the simultaneous development of large numbers of cases, for which neither an adequate number of physicians nor hospital facilities were available, the spread of the disease itself undoubtedly was checked as well as the number of deaths lessened (Ruhland 1918)

and in an editorial of the Ohio Public Health Journal in December 1918:

Restrictive measures, students of influenza have come to believe, have their chief value in preventing the development of enough cases at any one time to paralyze a community and in reducing the death rate, rather than in actually preventing the development of a given total of cases in the entire epidemic.

The cumulative incidence was generally expected to reach $40 \%{ }^{29}$

The fatalistic attitude followed from the state of knowledge about the disease. When the epidemic hit in 1918, it was quickly understood to be a form of the familiar influenza whose etiology was not understood and for which there was neither cure nor prevention. The search for a vaccine was intensive, but without even a notion of the influenza virus (discovered later) it was completely empirical and proved vain (Eyler 2010). The State of Massachusetts spent $\$ 19,000$ on vaccine development; Illinois tried eighteen varieties of vaccine but found the physicians' reports useless. The similarities with the 1889-91 pandemic was widely noted, and the experience of the epidemic showed that death followed mostly from (bacterial) pneumonia rather than influenza itself (Brundage and Shanks 2008).

One fact everyone agreed on was that transmission was through "nasal and pharyngeal discharges," and therefore close contact with infected persons, including the asymptomatic. ${ }^{30}$ Reducing contacts would logically help reduce transmission and an absolute reduction would stop the epidemic. Complete quarantines were tried effectively for small communities and institutions (Jordan 1927, 452-58), but not on a large scale. The regression results of the previous section suggest that the closings that were put in place were not very costly. But doing more was viewed as unacceptably costly, as the following quotes from public health officials make clear:

\footnotetext{
${ }^{29}$ The same editorial states: "It is estimated that in the course of an influenza epidemic forty percent of the population, on the average, will have the disease." See also the California State Journal of Medicine 1918, 16(11):479: "previous epidemics have attacked as high as 40 per cent of the population"; New York City Department of Health weekly bulletin 1918, 44:344: "we have found in practically every other community that 25 to 40 per cent of the population has been affected by this disease." The actual incidence is difficult to establish. Frost $(1920,588)$ publishes the results of surveys carried out at the end of 1918 in a few locations. Persons were asked if they had been influenza, pneumonia, or an illness suspected to be influenza. He finds rates from $15 \%$ to $54 \%$ with an average of $28 \%$.

${ }^{30}$ The possibility of asymptomatic transmission was understood: see New York State Department of Health Annual Report 1919, 77: "A very large number of persons suffer with what appear to be ordinary colds with slight fever and general malaise followed by a dry cough. ... Such persons are apparently immune to the more severe attacks but are able to transmit the disease in sever form to others" and New York City Department of Health Weekly Bulletin (1918, 41:321) describing "those who harbor the organisms of a disease, without being ill themselves. These "carriers" give off the germs in their discharges and persons coming into contact with such material and being susceptible succumb to the malady. The percentage of carriers varies from 2 or 3 per cent to about 15 per cent of the community."
} 
Without doubt [quarantine] is the only method that is effective in the control of the more highly contagious diseases such as measles and influenza. The greatness of the problem usually prevents the use of this method except in times of nervous stress or hysteria, and then it is always incomplete, consisting in closing the schools or the churches, saloons, etc. Contact still goes on, however, and even if less free the epidemic goes through its complete course in a little longer time. (Place 1918)

In a great city like Chicago, in which one fortieth of the population of the entire nation resides, and in war time, when it is absolutely essential in time of war to keep the arteries of business open, the plan of closing business and stopping commerce could not be considered for one moment ... While it may be accepted as axiomatic that the temporary suspension of all travel, as well as social and commercial intercourse, would cause any epidemic of a crowd disease to subside or disappear in the course of a few days, it is obvious that this ideal of quarantine is chimerical and impossible of realization in the complicated life of a modern city. (Robertson 1918, 45,74)

It is impracticable to indefinitely keep closed and paralyze the business and industry of a large city, nor will this be necessary if every citizen will see to it that he will carefully carry out the measures in personal hygiene which this department has urged from time to time. (Ruhland 1918)

"As the living necessities of a community out-weigh the more rigid, but more consistent measure of a total closing, the Health Department closed those places of crowding not essential to the life of a town ... Those cities which tried total closing methods did not bear with them except for a very short period. ... A total closing would undoubtedly have ameliorated the trouble. The emergency of a daily livelihood is too great and such a condition could not be accomplished." (Minneapolis Department of Health 1918, 5-6, 11)

This choice may follow from different preferences or from a different (perceived) shape of the tradeoff, compared to today. Note, however, that in a model like Alvarez, Argente, and Lippi (2020), the eventuality of a vaccine has a large quantitative impact on the optimal lockdown policy.

\section{Discussion, Related literature, and Conclusion}

The 1918 recession was mild and brief, particularly when compared to that of 1920-21. This seems surprising given the size of the demographic shock, on the order of $0.5 \%$ of the labor force and the population. The coal industry data confirms that labor supply was indeed an important channel affecting industrial output, but the impact was very brief. If anything, the recession might have been even briefer (or unnoticed) without the uncertainty brought by the Armistice. The need to shift from wartime to peacetime economy became more probable as rumors of peace talks floated in October 1918 and a 
certainty on November 11 . The government had been heavily involved in the economy in various ways, first of all by running a deficit of $20 \%$ of GDP and using it for government purchases. Non-essential economic activities like construction and consumer durables were curtailed. Prices were controlled, in some cases by floors and others by ceilings, All this was presumably coming to an end, but contemporaries were uncertain about the timing. By March 1919 the uncertainty had dissipated, the economy had worked through various internal imbalances, and expansion resumed.

The literature on the economic consequences of the 1918 pandemic (Beach, Clay, and Saavedra 2020, for an early survey) is relatively limited but growing. ${ }^{31}$ The survey by Bell and Lewis (2004) concludes that it had "very limited macroeconomic effects in relative terms." Brainerd and Siegler (2002) look at the growth rate of states in the years after the pandemic and find evidence of higher growth rates in the 1920s for states more affected by the epidemic, which they say might be a sign of return to trend growth. Karlsson, Nilsson, and Pichler (2013) study the impact on income in Sweden, and find a negative impact on capital income and poverty rates (after 1920) but no effect on earnings. More recently, mild and short-lived effects have been documented from household consumption data in the US (Norling 2020), for Denmark (Dahl, Hansen, and Jensen 2020), and for Spain (Domènech Feliu, Roses Vendoiro, and Basco Mascaro 2020) (see also Benmelech and Frydman 2020).

Two recent papers offer a different perspective on the 1918 pandemic. Related to the disasters literature, Barro, Ursúa, and Weng (2020) use annual aggregate data for a crosssection of countries and find evidence for sizeable effects of the mortality caused by the pandemic on GDP (negative), stock prices (negative), and inflation (positive). The approach here is different, since I drill in on one particular country rather than search for worldwide patterns. Barro (2020) examines the effect of the closings on the epidemic and addresses the endogeneity issues but does not consider the economic impact.

Correia, Luck, and Verner (2020, April version) use a different approach, in the line of Brainerd and Siegler (2002), by examining the impact of mortality and of NPIs on outcomes in later years using the cross-section of cities and states (1919 to 1923). They find large negative impact of mortality, and positive impact of interventions, on output, employment, bank balance sheets, and consumer durables five years after the epidemic. ${ }^{32}$

The main conclusion is that the pandemic coincided with the start of a mild recession from which the economy rebounded quickly. Most of the recession is likely due to the end of the war rather than the pandemic itself. Output was contemporaneously affected through a negative labor supply shock but demand reacted very little, and there was little damage done to the balance sheets of the nonfinancial or financial sector. NPIs affected mortality, as is known from the epidemiological literature, but had limited implications for contemporaneous economic outcomes. Given the peculiar nature of the epidemic, affecting the labor force through mortality but mostly through incapacitation, the negative direct impact of NPIs (if any) was compensated by the mitigation of the labor supply

\footnotetext{
${ }^{31}$ The pandemic has been studied by economists for its demographic consequences (Clay, Lewis, and Severnini 2018) or as an instrument to investigate various questions (Hilt and Rahn 2018).

${ }^{32}$ The June version of the same paper nuances the findings somewhat.
} 
shock. Although I limit the horizon of study to one to two years, the quick rebound (in contrast with the massive and long-lasting 1920-21 recession) makes it challenging to understand possible long-run outcomes (Correia, Luck, and Verner 2020) without identifying a state variable through which the disturbance of 1918 could have propagated with increasing force all the way to 1923.

In the relative dearth of comparable episodes, it is natural to reach to the nearest analog and draw conclusions-for this purpose, getting the facts right about the 1918 recession seems important. But the point of this paper is not to predict that the 2020 pandemic will not have economic consequences. Rather, it is to say that pandemics can be economic disasters but they need not be, and that it is important to understand what has changed and what hasn't. 
Appendix 1: City-Level Data

\begin{tabular}{|c|c|c|c|c|c|c|c|}
\hline & \multicolumn{2}{|c|}{ mortality } & \multicolumn{2}{|c|}{ closings } & \multicolumn{3}{|c|}{ data available: } \\
\hline & peak & total & start & end & clearings & conditions & banks \\
\hline Albany, NY & 166 & 646 & Oct 9 & Nov 7 & & & $x$ \\
\hline Atlanta, GA & 50 & 339 & Oct 7 & Oct 26 & $\mathrm{x}$ & $\mathrm{x}$ & $\mathrm{x}$ \\
\hline Baltimore, MD & 216 & 647 & Oct 9 & Nov 2 & $x$ & $x$ & $\mathrm{x}$ \\
\hline Birmingham, $\mathrm{AL}$ & 75 & 581 & Oct 9 & Oct 30 & & & $\mathrm{x}$ \\
\hline Boston, MA & 162 & 727 & Sep 27 & Oct 20 & $x$ & $x$ & $x$ \\
\hline Buffalo, NY & 145 & 458 & Oct 11 & Nov 1 & $x$ & $x$ & $\mathrm{x}$ \\
\hline Cambridge, MA & 127 & 528 & Oct 5 & Oct 20 & & & \\
\hline Chicago, IL & 88 & 390 & Oct 15 & Nov 2 & $\mathrm{x}$ & $x$ & $x$ \\
\hline Cincinnati, $\mathrm{OH}$ & 68 & 557 & Oct 6 & Nov 12 & $\mathrm{x}$ & $\mathrm{x}$ & $\mathrm{x}$ \\
\hline Cleveland, $\mathrm{OH}$ & 88 & 581 & Oct 15 & Nov 11 & $\mathrm{x}$ & $\mathrm{x}$ & $\mathrm{x}$ \\
\hline Columbus, $\mathrm{OH}$ & 50 & 406 & Oct 10 & Nov 10 & $\mathrm{x}$ & $\mathrm{x}$ & $\mathrm{x}$ \\
\hline Dayton, $\mathrm{OH}$ & 91 & 378 & Oct 9 & Nov 2 & & & \\
\hline Denver, CO & 77 & 703 & Oct 6 & Nov 11 & $\mathrm{x}$ & & $\mathrm{x}$ \\
\hline Detroit, MI & 53 & 308 & Oct 20 & Nov 6 & $\mathrm{x}$ & $\mathrm{x}$ & $\mathrm{x}$ \\
\hline Fall River, MA & 166 & 640 & Sep 27 & Oct 24 & & & $\mathrm{x}$ \\
\hline Grand Rapids, MI & 36 & 227 & Oct 20 & Nov 7 & & & $\mathrm{x}$ \\
\hline Indianapolis, IN & 41 & 335 & Oct 9 & Oct 30 & $\mathrm{x}$ & $\mathrm{x}$ & $\mathrm{x}$ \\
\hline Jersey City, NJ & 143 & 297 & \multicolumn{2}{|c|}{ none } & & & \\
\hline Kansas City, MO & 76 & 708 & Oct 8 & Nov 18 & $\mathrm{x}$ & $\mathrm{x}$ & $\mathrm{x}$ \\
\hline Los Angeles, CA & 69 & 535 & Oct 11 & Dec 1 & $x$ & $x$ & $\mathrm{x}$ \\
\hline Louisville, KY & 75 & 560 & Oct 7 & Nov 11 & $x$ & $x$ & $x$ \\
\hline Lowell, MA & 125 & 534 & n.a. & n.a. & & & \\
\hline Memphis, TN & 122 & 568 & Oct 6 & Nov 1 & $x$ & $x$ & $x$ \\
\hline Milwaukee, WI & 38 & 339 & Oct 12 & Nov 4 & $x$ & $\mathrm{x}$ & $\mathrm{x}$ \\
\hline Minneapolis, MN & 39 & 316 & Oct 13 & Nov 15 & $\mathrm{x}$ & $\mathrm{x}$ & $\mathrm{x}$ \\
\hline Nashville, TN & 163 & 690 & Oct 6 & Nov 1 & $\mathrm{x}$ & $\mathrm{x}$ & $\mathrm{x}$ \\
\hline Newark, NJ & 105 & 575 & Oct 10 & Oct 22 & & & \\
\hline New Haven, CT & 114 & 591 & \multicolumn{2}{|c|}{ none } & & & \\
\hline New Orleans, LA & 177 & 759 & Oct 10 & Nov 15 & $\mathrm{x}$ & $\mathrm{x}$ & $\mathrm{x}$ \\
\hline New York, NY & 93 & 506 & Oct 4 & Nov 2 & $\mathrm{x}$ & $\mathrm{x}$ & $\mathrm{x}$ \\
\hline Oakland, CA & 114 & 544 & Oct 18 & Nov 16 & & & $\mathrm{x}$ \\
\hline Omaha, NE & 85 & 580 & Oct 4 & Nov 1 & & & $x$ \\
\hline Philadelphia, PA & 257 & 804 & Oct 3 & Oct 26 & $x$ & $x$ & $x$ \\
\hline Pittsburgh, PA & 133 & 829 & Oct 4 & Nov 12 & $x$ & $x$ & $x$ \\
\hline Portland, OR & 61 & 544 & Oct 11 & Nov 16 & $x$ & $x$ & $\mathrm{x}$ \\
\hline Providence, RI & 107 & 599 & Oct 6 & Oct 25 & & & \\
\hline Richmond, VA & 116 & 514 & Oct 6 & Nov 4 & & & $x$ \\
\hline Rochester, NY & 75 & 401 & Oct 9 & Nov 5 & & & \\
\hline St. Louis, MO & 57 & 422 & Oct 7 & Nov 13 & $\mathrm{x}$ & $x$ & $x$ \\
\hline St. Paul, MN & 57 & 422 & Oct 13 & Nov 15 & $\mathrm{x}$ & $\mathrm{x}$ & $\mathrm{x}$ \\
\hline San Francisco, CA & 148 & 715 & Oct 18 & Nov 16 & $\mathrm{x}$ & $\mathrm{x}$ & $\mathrm{x}$ \\
\hline Seattle, WA & 52 & 461 & Oct 5 & Nov 12 & $\mathrm{x}$ & $\mathrm{x}$ & $\mathrm{x}$ \\
\hline Spokane, WA & 76 & 528 & Oct 9 & Nov 18 & $\mathrm{x}$ & $\mathrm{x}$ & $\mathrm{x}$ \\
\hline Syracuse, NY & 151 & 566 & Oct 7 & Oct 25 & & & \\
\hline Toledo, $\mathrm{OH}$ & 58 & 386 & Oct 15 & Nov 4 & $x$ & & $\mathrm{x}$ \\
\hline Washington, DC & 147 & 639 & Oct 4 & Nov 4 & $\mathrm{x}$ & & $\mathrm{x}$ \\
\hline Worcester, MA & 130 & 644 & Sep 26 & Oct 21 & $x$ & & \\
\hline median & 91 & 544 & Oct 9 & Nov 4 & & & \\
\hline $\mathrm{N}$ & \multicolumn{2}{|c|}{47} & \multicolumn{2}{|c|}{43} & 31 & 27 & 37 \\
\hline
\end{tabular}

Table 6: List of cities with mortality data in Collins et al. (1930) and available data on closings of places of amusement (sources cited in footnote 7), bank clearings, and business conditions. Mortality is excess P\&I in deaths per 100,000. New York City: dates of staggered business hours.

\section{Appendix 2 (with Gadi Barlevy): Dynamics inspired by the SIR model}

Economists are fast becoming familiar with the SIR (susceptible, infected, recovered) model of epidemic dynamics and adapting it into economic models (Atkeson 2020; Al- 
varez, Argente, and Lippi 2020; Eichenbaum, Rebelo, and Trabandt 2020). This appendix uses it to derive a simple regression equation.

Consider the following discrete time version of the SIR model. The population of 1 consists of three groups: The stock of susceptible, $S_{t}$, the stock of infected, $I_{t}$, and the stock of recovered, $R_{t}$. At each date, we have

$$
S_{t}+I_{t}+R_{t}=1
$$

The stocks evolve according to the following law of motion:

$$
\begin{aligned}
S_{t+1} & =\left(1-\beta_{t} I_{t}\right) S_{t} \\
I_{t+1} & =\left(1+\beta_{t} S_{t}-\gamma\right) I_{t} \\
R_{t+1} & =R_{t}+\gamma I_{t}
\end{aligned}
$$

Condition (3) implies that the fraction of susceptible who become infected is equal to $\beta_{t} I_{t}$, so proportional to the fraction of agents infected at date $t$. We allow $\beta$ to vary over time to leave room for interventions intended to curb the epidemic. Condition (4) implies that the stock of infected grows by those formerly susceptible who become infected, but that a constant fraction $\gamma$ of those previously infected recover, a euphemism which means they either die or become immune. Finally, condition (5) keeps tab on the total number of recovered agents. The initial condition is that $R_{t}=0$ at date $t=0$ and $I_{t}>0$ at date $t=0$.

Suppose that a fraction $\phi \in(0,1)$ of those who recover from infection die. We focus on deaths since death rates because that is the only data available in the historical record for the 1918 pandemic. Alvarez, Argente, and Lippi (2020) and Eichenbaum, Rebelo, and Trabandt (2020) make $\phi$ dependent on the number of infected to model the effect of an overwhelmed health care system, but lacking knowledge of the health care system's capacity and usefulness in 1918 we neglect this aspect here and assume that $\phi$ is constant.

The cumulative deaths at date $t$ satisfy $D_{t}=\phi R_{t}$. In addition, a fraction $\phi$ of all infected who transition to recovery die, meaning the change in deaths is given by

$$
\Delta D_{t} \equiv D_{t}-D_{t-1}=\phi \gamma I_{t-1}
$$

Since $S_{t}+I_{t}+R_{t}=1$, we have

$$
\begin{aligned}
S_{t} & =1-I_{t}-R_{t} \\
& =1-\frac{\Delta D_{t+1}}{\phi \gamma}-\frac{D_{t}}{\phi}
\end{aligned}
$$

We can substitute this into (4) to arrive at a law of motion for the number of new deaths each period using only data on deaths:

$$
\begin{aligned}
\Delta D_{t+2} & =\left(1+\beta_{t} S_{t}-\gamma\right) \Delta D_{t+1} \\
& =(1-\gamma) \Delta D_{t+1}+\beta_{t} S_{t} \Delta D_{t+1} \\
& =(1-\gamma) \Delta D_{t+1}+\beta_{t}\left(1-\frac{\Delta D_{t+1}}{\phi \gamma}-\frac{D_{t}}{\phi}\right) \Delta D_{t+1} \\
& =\left(1+\beta_{t}-\gamma\right) \Delta D_{t+1}-\frac{\beta_{t}}{\phi \gamma}\left(\Delta D_{t+1}\right)^{2}-\frac{\beta_{t}}{\phi} D_{t} \Delta D_{t+1}
\end{aligned}
$$


or, more compactly,

$$
\Delta D_{t}=f_{\Delta D}\left(\Delta D_{t-1},\left(\Delta D_{t-1}\right)^{2}, D_{t-2} \Delta D_{t-1}\right)
$$

Next, we consider economic activity, using the Alvarez, Argente, and Lippi (2020) framework. They assume that all living agents supply one unit of labor inelastically with productivity $w$ if they are susceptible or recovered and $w_{i} \leq w$ if they are infected. Total output is given by

$$
Y_{t}=w\left(1-I_{t}-D_{t}\right)+w_{i} I_{t}
$$

Replacing $D_{t}=D_{t-1}+\Delta D_{t}$ and using (6) to replace $\Delta D_{t}$ we can rewrite this as

$$
\begin{aligned}
Y_{t} & =w\left(1-I_{t}-D_{t}\right)+w_{i} I_{t} \\
& =w-\left(w-w_{i}\right) \frac{\Delta D_{t+1}}{\phi \gamma}-w D_{t}
\end{aligned}
$$

Following Alvarez, Argente, and Lippi (2020) we model NPIs such as social distancing as forcing a fraction $1-\theta$ of living agents to stay at home. The remaining fraction $\theta$ work and produce. The assumption is that only those who work can bump into each and meet, and so we must replace (3) with

$$
S_{t+1}=\left(1-\tilde{\beta} I_{t}\right) S_{t}
$$

where $\tilde{\beta}=\beta \theta^{2}$. For output, we must replace (7) with

$$
Y_{t}=\tilde{w}\left(1-I_{t}-D_{t}\right)+\tilde{w}_{i}
$$

where $\tilde{w}=w \theta$.

We find that $\Delta D_{t+1}$ is a linear function of $\left[\begin{array}{lll}\Delta D_{t} & \left(\Delta D_{t}\right)^{2} & D_{t-1} \Delta D_{t}\end{array}\right]$ with theoretical coefficients $b \equiv\left[1+\beta_{t}-\gamma,-\beta_{t} / \phi \gamma,-\beta_{t} / \phi\right]$, and $Y_{t}$ a linear function of $\left[\begin{array}{lll}1 & \Delta D_{t+1} & D_{t}\end{array}\right]$ with theoretical coefficients $\left[w_{t},-\left(w_{t}-w_{i t}\right) / \phi \gamma,-w_{t}\right]$. This suggests a regression of mortality on mortality lagged, lagged squared, and lagged and interacted with cumulated deaths. The ratio $b_{3} / b_{2}$ would yield an estimate of $\gamma$, while $\beta=b_{1}-1+\gamma$.

A regression of economic variables on future mortality (as proxy for current infected) and current cumulated deaths. To test whether the coefficients $\beta$ and $\left(w, w_{i}\right)$ change during NPIs, we add to the regression interactions of all regressors with a dummy equal to 1 during a NPI and 0 otherwise.

\section{Bibliography}

Acemoğlu, Daron, Victor Chernozhukov, Iván Werning, and Michael Whinston. 2020. Optimal Targeted Lockdowns in a Multi-Group SIR Model. Working paper 27102. NBER, May.

Aimone, Francesco. 2010. “The 1918 Influenza Epidemic in New York City: A Review of the Public Health Response." Public Health Reports (1974-) 125:71-79.

Alvarez, Fernando, David Argente, and Francesco Lippi. 2020. “A Simple Planning Problem for Covid-19 Lockdown." April 6. 
Atkeson, Andrew. 2020. What Will Be the Economic Impact of COVID-19 in the US? Rough Estimates of Disease Scenarios. Working paper 26867. NBER, March.

Balke, Nathan S., and Robert J. Gordon. 1989. "The Estimation of Prewar Gross National Product: Methodology and New Evidence." Journal of Political Economy 97, no. 1 (February): 38-92.

Barro, Robert J. 2020. Non-Pharmaceutical Interventions and Mortality in U.S. Cities during the Great Influenza Pandemic, 1918-1919. Working paper 27049. NNER, April.

Barro, Robert, José Ursúa, and Joanna Weng. 2020. The Coronavirus and the Great Influenza Pandemic: Lessons from the "Spanish Flu" for the Coronavirus's Potential Effects on Mortality and Economic Activity. Working paper 26866. NBER, March.

Beach, Brian, Karen Clay, and Martin Saavedra. 2020. "The 1918 Inuenza Pandemic and its Lessons for COVID-19." Journal of Ecnomic Literature forthcoming.

Bell, Clive, and Maureen Lewis. 2004. "The Economic Implicationsof Epidemics Old and New." World Economics 5 (4): 137-74.

Benjamin, Georges C., Elizabeth Fee, and Theodore M. Brown. 2010. “William Augustus Evans (1865-1948): Public Health Leader at a Critical Time." American Journal of Public Health 100, no. 11 (November): 2073-73.

Benmelech, Efraim, and Carola Frydman. 2020. The 1918 Influenza Did Not Kill the US Economy. VOX CEPR Policy Portal, April.

Bootsma, Martin C. J., and Neil M. Ferguson. 2007. "The effect of public health measures on the 1918 influenza pandemic in U.S. cities." Proceedings of the National Academy of Sciences 104, no. 18 (April): 7588-93.

Brainerd, Elizabeth, and Mark V. Siegler. 2002. "The Economic Effects of the 1918 Influenza Epidemic."

Brundage, John F., and G. Dennis Shanks. 2008. “Deaths from Bacterial Pneumonia during 1918-19 Influenza Pandemic." Emerging Infectious Diseases 14, no. 8 (August): 119399.

Bureau of Labor Statistics. 1923. Retail Prices, 1913 to December 1922. Bulletin 334. June.

_. 1929. Wholesale Prices, 1913 to 1927. Bulletin 473. January. 1932. Fluctuation in Employment in Ohio, 1914 to 1929. Bulletin 553. March.

Bureau of the Census. 1913-1922. Mortality Statistics. Government Printing Office.

Burns, Arthur F., and Wesley C. Mitchell. 1946. Measuring Business Cycles. New York: NBER.

Clay, Karen, Joshua Lewis, and Edson Severnini. 2018. "Pollution, Infectious Disease, and Mortality: Evidence from the 1918 Spanish Influenza Pandemic." The Journal of Economic History 78, no. 4 (October): 1179-1209. 
Collins, Selwyn D., W. H. Frost, Mary Gover, and Edgar Sydenstricker. 1930. "Mortality from Influenza and Pneumonia in 50 Large Cities of the United States, 1910-1929." Public Health Reports (1896-1970) 45 (39): 2277-2328.

Commonwealth of Massachusetts. 1913-1922. Annual Report on the Statistics of Manufactures. Wright \& Potter Printing Company.

Commonwealth of Massachusetts, Bureau of Statistics. 1917-1920. Annual Report on the Statistics of Manufactures. Wright \& Potter Printing Company.

Commonwealth of Massachusetts, Office of the Secretary. 1920. Annual Report on the Vital Statistics of Massachusetts for the Year 1918. Boston, MA: Wright \& Potter Printing Co.

Congressional Budget Office. 2006. A Potential Influenza Pandemic: Possible Macroeconomic Effects and Policy Issues. Washington, DC, July.

Copeland, Morris A. 1929. "An Index of the Dollar Volume of Retail Trade, 1914-1927." Harvard Business Review 7, no. 2 (January): 175-84.

Correia, Sergio, Stephan Luck, and Emil Verner. 2020. Pandemics Depress the Economy, Public Health Interventions Do Not: Evidence from the 1918 Flu. Technical report. SSRN.

Dahl, Christian Møller, Casper Worm Hansen, and Peter Sandholt Jensen. 2020. “The 1918 Epidemic and a V-shaped Recession: Evidence from Municipal Income Data." Covid Economics, no. 6 (April).

Department of Commerce, Bureau of the Census. 1917. Abstract of the Census of Manufactures, 1914. Washington, DC: Government Printing Office.

Domènech Feliu, Jordi, Juan Ramon Roses Vendoiro, and Sergi Basco Mascaro. 2020. The Redistributive Effects of Pandemics: Evidence on the Spanish Flu. Technical report 2020-05. Universidad Carlos III, Instituto Figuerola, May.

Eichel, Otto M. 1923. A Special Report on the Mortality from Influenza in New York State during the Epidemic of 1918-19. New York State Department of Health.

Eichenbaum, Martin, Sergio Rebelo, and Mathias Trabandt. 2020. “The Macroeconomics of Epidemics." April 9.

Eyler, John M. 2010. “The State of Science, Microbiology, and Vaccines Circa 1918.” Public Health Reports 125, no. 3_suppl (April): 27-36.

Federal Reserve Board. 1918. Federal Reserve Bulletin. Washington, DC: Government Printing Office.

_. 1919a. Federal Reserve Bulletin. Washington, DC: Government Printing Office.

1919b. Fifth Annual Report covering operations for the year 1918. Washington, DC: Government Printing Office.

1943. Banking and Monetry Statistics, 1914-41. Washington, DC: Government Printing Office. 
Friedman, Milton, and Anna Jacobson Schwartz. 1963. A Monetary History of the United States, 1867-1960. Princeton University Press.

Frost, W. H. 1920. "Statistics of Influenza Morbidity: With Special Reference to Certain Factors in Case Incidence and Case Fatality." Public Health Reports 35, no. 11 (March): 584-97.

Gao, Song, Jinmeng Rao, Yuhao Kang, Yunlei Liang, and Jake Kruse. 2020. "Mapping County-Level Mobility Pattern Changes in the United States in Response to COVID19." SSRN Electronic Journal.

Hale, Thomas, Noam Angrist, Beatriz Kira, Anna Petherick, Toby Phillips, and Samuel Webster. 2020. Variation in Government Responses to COVID-19. Working Paper 032. Version 5.0. Blavatnik School of Government, April.

Hatchett, Richard J., Carter E. Mecher, and Marc Lipsitch. 2007. "Public health interventions and epidemic intensity during the 1918 influenza pandemic." Proceedings of the National Academy of Sciences 104, no. 18 (April): 7582-87.

Hilt, Eric, and Wendy M. Rahn. 2018. Financial Asset Ownership and Political Partisanship: Liberty Bonds and Republican Electoral Success in the 1920s. Working Paper, Working Paper Series 24719. NBER, June.

Jordan, Edwin O. 1927. Epidemic Influenza: A Survey. Chicago: American Medical Association.

Karlsson, Martin, Therese Nilsson, and Stefan Pichler. 2013. The Impact of the 1918 Spanish Flu Epidemic on the Economic Performance in Sweden. Technical report.

Kilbourne, Edwin D. 2006. "Influenza Pandemics of the 20th Century." Emerging Infectious Diseases 12, no. 1 (January): 9-14.

Linder, Forrest E., and Robert D. Grove. 1947. Vital Statistics Rates in the United States, 19001940. Washington, DC: GPO.

Macaulay, Frederick R. 1938. Some Theoretical Problems Suggested by the Movements of Interest Rates, Bond Yields and Stock Prices in the United States since 1856. New York: NBER.

Markel, Howard, Harvey B. Lipman, J. Alexander Navarro, Alexandra Sloan, Joseph R. Michalsen, Alexandra Minna Stern, and Martin S. Cetron. 2007. “Nonpharmaceutical Interventions Implemented by US Cities During the 1918-1919 Influenza Pandemic." JAMA 298, no. 6 (August): 644 .

Meltzer, Allan H. 2010. A History of the Federal Reserve, Volume 1: 1913-1951. University of Chicago Press.

Mills, Christina E., James M. Robins, and Marc Lipsitch. 2004. “Transmissibility of 1918 pandemic influenza." Nature 432, no. 7019 (December): 904-06.

Minneapolis Department of Health. 1918. Annual Report. Minneapolis, MN: Syndicate Publishing Co. 
Miron, Jeffrey A., and Christina D. Romer. 1990. “A New Monthly Index of Industrial Production, 1884-1940." Journal of Economic History 50 (2).

Monthly Labor Review. 1926. "Trend of Employment." Monthly Labor Review 23 (6): 149_ 85.

Moore, Geoffrey H., and Victor Zarnowitz. 1986. "The Development and Role of the National Bureau of Economic Research's Business Cycle Chronologies." In The American Business Cycle, edited by Robert J. Gordon, 735-79. Chicago: NBER.

New York State Department of Health. 1920. Thirty Ninth Annual Report. Albany, NY: J. B. Lyon Company Printers.

New York State Department of Labor. 1940. Trend of Employment in New York State Factories from 1914 to 1939. Special Bulletin 206. June.

Norling, Johannes. 2020. "Household Expenditure in the United States During the 1918 Influenza Pandemic." April.

Olson, Donald R., Lone Simonsen, Paul J. Edelson, and Stephen S. Morse. 2005. "Epidemiological evidence of an early wave of the 1918 influenza pandemic in New York City." Proceedings of the National Academy of Sciences 102, no. 31 (July): 11059-63.

Patterson, K. David, and Gerald F. Pyle. 1991. "The Geography And Mortality of the 1918 Influenza Pandemic." Bulletin of the History of Medicine 65 (1): 4-21.

Persons, Warren M. 1919. “Indices of Business Conditions." Review of Economics and Statistics 1, no. 1 (January): 5-107.

Place, Edwin H. 1918. “The Contagious Diseases and the Child Conservation Movement." Commonhealth 5, no. 11 (November): 309-17.

Robertson, John D. 1918. A Report on an Epidemic of Influenza in the City of Chicago in the Fall of 1918. Educational Series 15. Chicago: City of Chicago Department of Health.

Romer, Christina D. 1988. "World War I and the postwar depression A reinterpretation based on alternative estimates of GNP." Journal of Monetary Economics 22, no. 1 (July): 91-115.

1989. “The Prewar Business Cycle Reconsidered: New Estimates of Gross National Product, 1869-1908." Journal of Political Economy 97, no. 1 (February): 1-37.

1994. “Remeasuring Business Cycles." The Journal of Economic History 54 (3): 573609.

Rorty, M. C. 1923. “The Statistical Control of Business Activities.” Harvard Business Review 1, no. 2 (January): 154-66.

Ruhland, George C. 1918. "Influenza in Milwaukee." Bulletin of the Milwaukee Health Department 8, nos. 10-11 (October): 3-4. 
Sydenstricker, Edgar. 1920. Difficulties in computing civil death rates for 1918 with especial reference to epidemic influenza. Public Health Report 583. Washington, DC: Government Printing Office.

United States Fuel Administration. 1919. The Report of the Distribution Division, 1918-19: Part III. Washington, DC: Government Printing Office.

Vaughn, Warren T. 1921. Influenza: An Epidemiological Study. Baltimore: American Journal of Hygiene. 